\title{
Paradoxical effects of shock: The role of shock intensity and interresponse times followed by shock
}

Jessica B. Long

West Virginia University

Follow this and additional works at: https://researchrepository.wvu.edu/etd

\section{Recommended Citation}

Long, Jessica B., "Paradoxical effects of shock: The role of shock intensity and interresponse times followed by shock" (2009). Graduate Theses, Dissertations, and Problem Reports. 2926.

https://researchrepository.wvu.edu/etd/2926

This Dissertation is protected by copyright and/or related rights. It has been brought to you by the The Research Repository @ WVU with permission from the rights-holder(s). You are free to use this Dissertation in any way that is permitted by the copyright and related rights legislation that applies to your use. For other uses you must obtain permission from the rights-holder(s) directly, unless additional rights are indicated by a Creative Commons license in the record and/ or on the work itself. This Dissertation has been accepted for inclusion in WVU Graduate Theses, Dissertations, and Problem Reports collection by an authorized administrator of The Research Repository @ WVU.

For more information, please contact researchrepository@mail.wvu.edu. 
Paradoxical Effects of Shock: The Role of Shock Intensity and Interresponse Times Followed by Shock

\author{
Jessica B. Long
}

\begin{abstract}
Dissertation Submitted to the
Eberly College of Arts and Sciences at West Virginia University in partial fulfillment of the requirements for the degree of

Doctor of Philosophy

in Psychology
\end{abstract}

Michael Perone, Ph.D., Chair

Karen G. Anderson, Ph.D.

Kennon A. Lattal, Ph.D.

Constance Toffle, Ph.D.

Oliver Wirth, Ph.D.

Department of Psychology

Morgantown, West Virginia

2009

Keywords: punishment, interresponse times, electric shock, shock intensity, rats 


\section{ABSTRACT \\ Paradoxical Effects of Shock: The Role of Shock Intensity and Interresponse TimesFollowed by Shock}

Jessica B. Long

In operant conditioning experiments concerned with punishment, when electric shock is contingent on an animal's response, response rates typically decrease. In some cases, however, response rates increase. Four experiments investigated these paradoxical effects of shock by manipulating shock intensity and the time between two consecutive responses (interresponse time) that produces shock. Lever pressing by rats was maintained by a variable-interval 40-s schedule of food reinforcement. Shock followed either relatively long (Experiments 1 and 2) or relatively short (Experiments 3 and 4) interresponse times. The range of interresponse times eligible for shock was raised by lowering or raising the interresponse times that produced shock. Shock intensity was raised from $0.05 \mathrm{~mA}$ to either $0.4 \mathrm{~mA}$ or $0.8 \mathrm{~mA}$. Shock contingent on long interresponse times punished long interresponse times, leading to increased response rates. Shock contingent on short interresponse times punished short interresponse times, leading to decreased response rates. In two experiments, raising the range of interresponse times that produced shock increased or decreased response rates depending on whether the interresponse times were long or short, respectively. In the other two experiments, there was an effect of shock intensity. When long interresponse times produced shock, low intensities punished long interresponse times and increased response rates. High intensities had the opposite effect. When short interresponse times produced shock, high shock intensities punished short interresponse times and decreased response rates more than low intensities. These results demonstrate that interresponse times may serve as functional units of behavior when the behavioral consequence is a punisher and may explain why punishment procedures occasionally increase responding. Moreover, they establish experimental parameters that may be useful for future studies of punishment. 


\section{Acknowledgements}

I thank the members of my committee, Drs. Michael Perone, Andy Lattal, Karen Anderson, Oliver Wirth, and Constance Toffle for their valuable feedback and suggestions on this project. I thank my advisor, Dr. Michael Perone, for what he has taught me about research, behavior analysis, and instruction over the years. I thank those who assisted me in running animals, namely Chuck Williamson, Nick Perone, and Nicole Bartow. I am grateful to my fellow lab members, Yusuke Hayashi, Leigh Schrimpf, and Anne Foreman, for their friendship and encouragement. Finally, I thank my family for their constant support. I am forever grateful to my husband, Jeff Everly, for his understanding, patience, and encouragement. Thank you for everything. 
Table of Contents

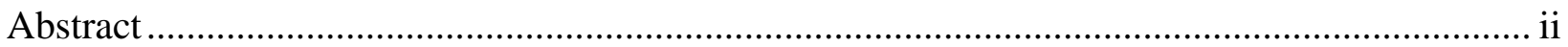

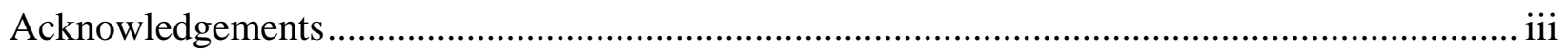

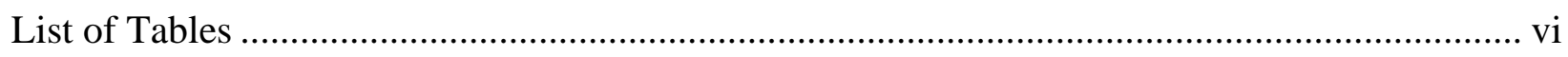

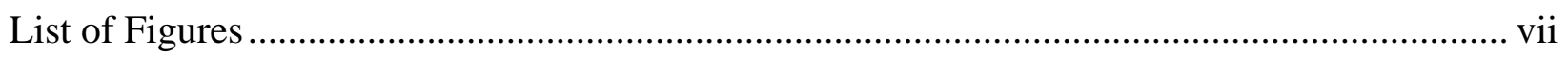

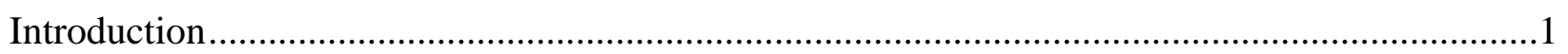

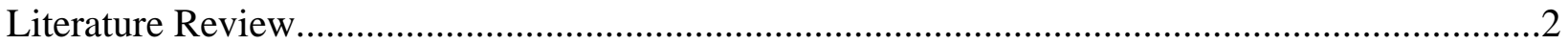

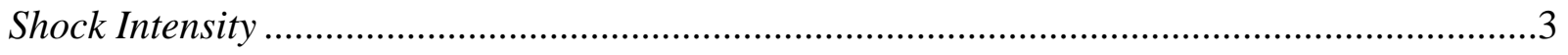

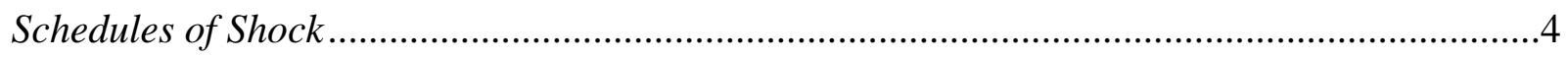

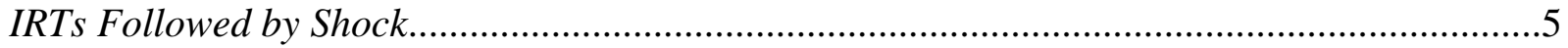

Interactive Effects of Shock Intensity and IRTs that Produce Shock ......................................8

Changes in the Temporal Reach of Behavioral Consequences ................................................8

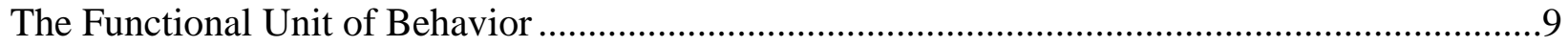

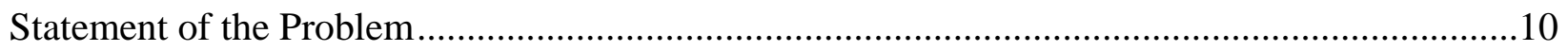

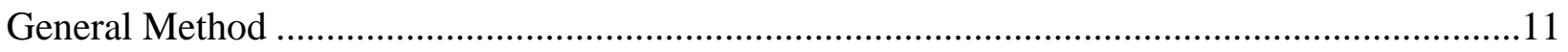

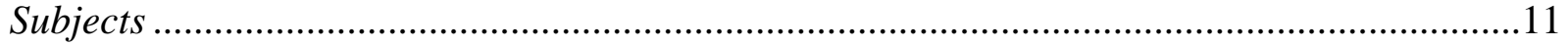

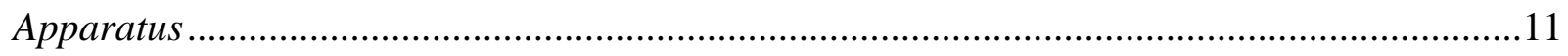

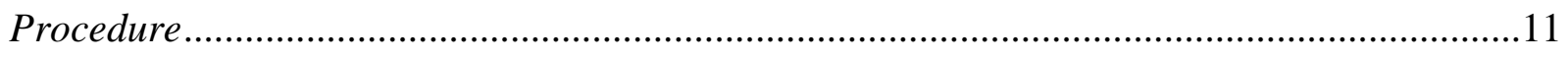

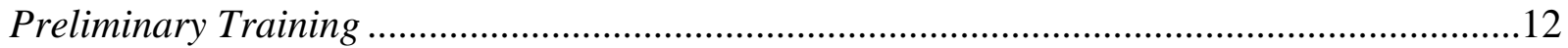

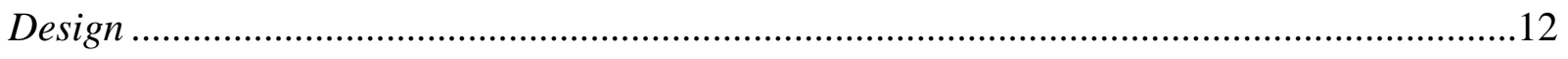

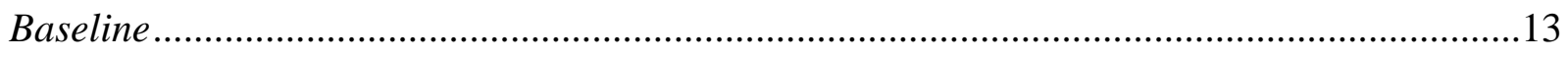

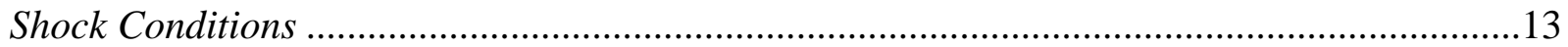

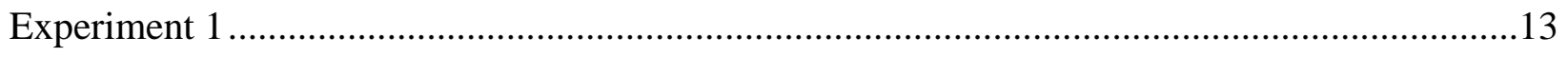

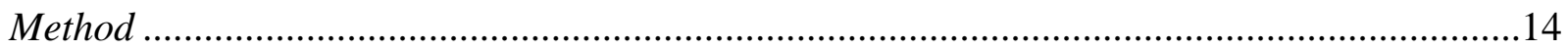

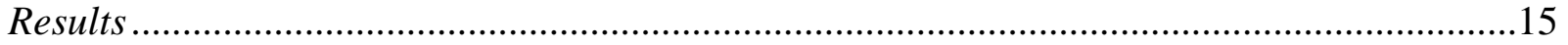

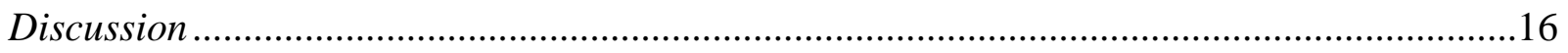

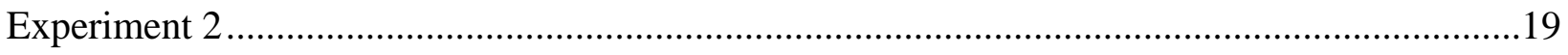

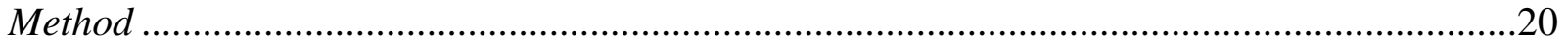

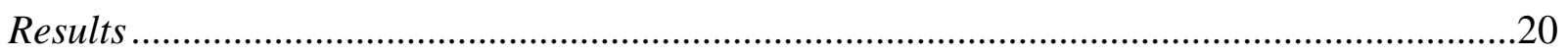

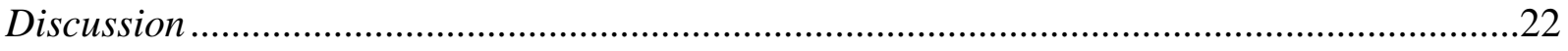

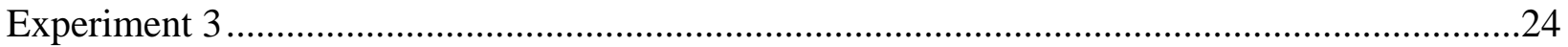




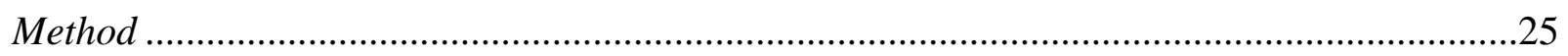

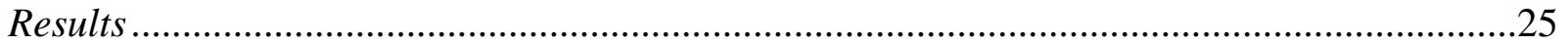

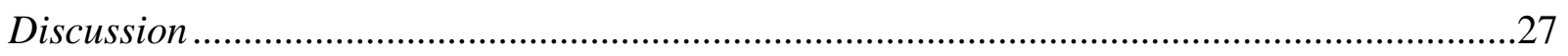

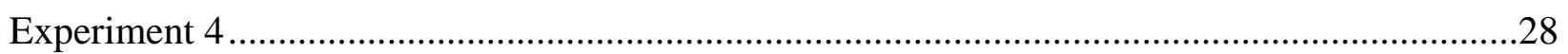

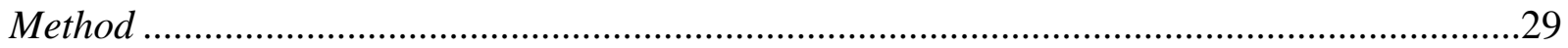

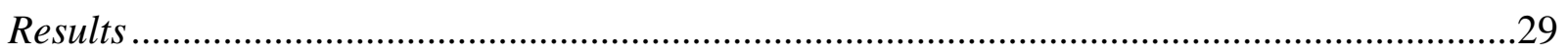

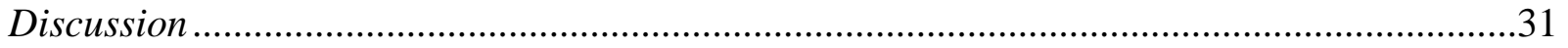

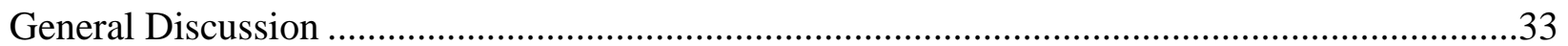

Summary and Comparison of Findings ..................................................................................33

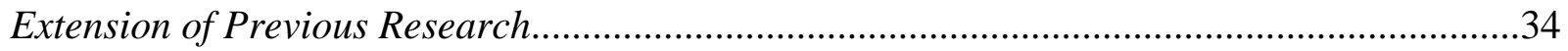

Interresponse times as functional units of behavior ...........................................................35

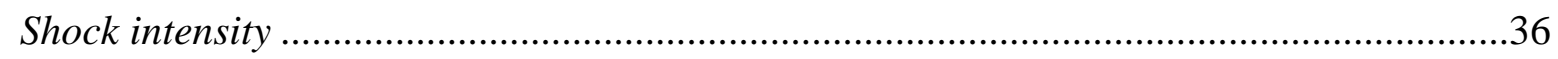

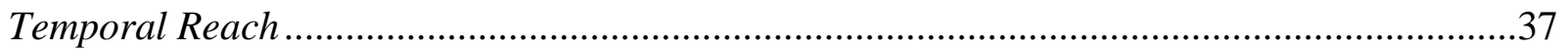

Implications for Generalized and Localized Effects of Shock ....................................................37

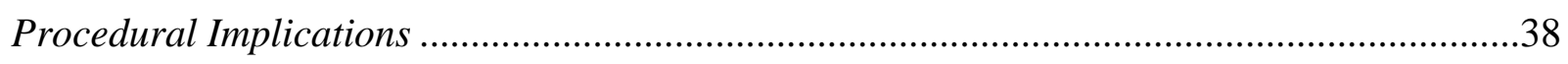

Conclusions .......................................................................................................................

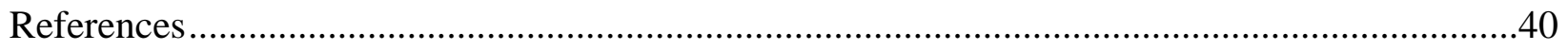

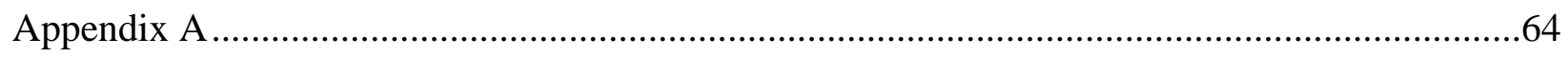

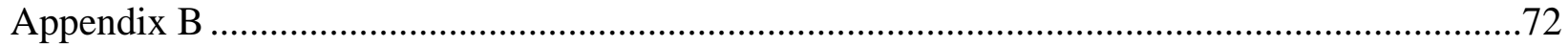

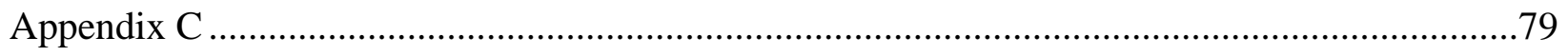

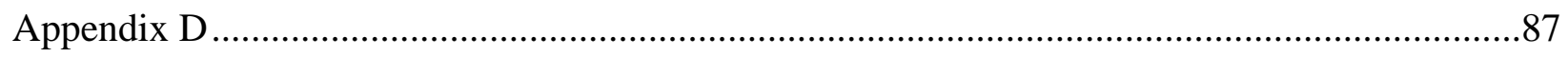




\section{List of Tables}

Table 1. Summary of procedural details from studies involving shock punishment. Details include the schedule of reinforcement, schedule of shock, shock intensity, shock duration, species, and effects on response rates

Table 2 (Experiment 1). Values of $t$ (s) for each shock condition. Shock intensity and percentiles used to establish $t$ are also shown

Table 3 (Experiment 1). Number of sessions, reinforcement rates and shock rates for each condition. Mean rates are given with standard deviations noted in parthentheses

Table 4 (Experiment 2). Values of $t$ (s) for each shock condition. Shock intensity and percentiles used to establish $\mathrm{t}$ are also shown

Table 5 (Experiment 2). Number of sessions, reinforcement rates and shock rates

for each condition. Mean rates are given with standard deviations noted in parthentheses

Table 6 (Experiment 3). Values of $t$ (s) for each shock condition. Shock intensity and percentiles used to establish $\mathrm{t}$ are also shown.

Table 7 (Experiment 3). Number of sessions, reinforcement rates and shock rates for each condition. Mean rates are given with standard deviations noted in parthentheses

Table 8 (Experiment 4). Values of $t$ (s) for each shock condition. Shock intensity and percentiles used to establish t are also shown.

Table 9. (Experiment 4). Number of sessions, reinforcement rates and shock rates for each condition. Mean rates are given with standard deviations noted in parthentheses 


\section{List of Figures}

Figure 1 (Experiment 1). Percent of responses followed by shock. Error bars extend one standard deviation above and one standard deviation below the mean of each shock condition. The reference line indicates the percent of baseline responses that satisfied the shock contingency...55

Figure 2 (Experiment 1). Proportion of baseline response rates across all shock conditions. Error bars extend one standard deviation above and one standard deviation below the mean .56

Figure 3 (Experiment 2). Percent of responses followed by shock. Error bars extend one standard deviation above and one standard deviation below the mean .57

Figure 4 (Experiment 2). Proportion of baseline response rates across all shock conditions. Error bars extend one standard deviation above and one standard deviation below the mean. .58

Figure 5 (Experiment 3). Percent of responses followed by shock. Error bars extend one standard deviation above and one standard deviation below the mean.

Figure 6 (Experiment 3). Proportion of baseline response rates across all shock conditions. Error bars extend one standard deviation above and one standard deviation below the mean.

Figure 7 (Experiment 4). Percent of responses followed by shock. Error bars extend one standard deviation above and one standard deviation below the mean.

Figure 8 (Experiment 4). Proportion of baseline response rates across all shock conditions. Error bars extend one standard deviation above and one standard deviation below the mean

Figure 9 (Experiments 1, 2, 3, 4). Proportion of baseline response rates for all rats in the four experiments......

Figure A1 (Experiment 1). Mean shocks per session across shock conditions. Error bars extend one standard deviation above and below the mean.

Figure A2 (Experiment 1). Summaries of the IRT distributions from the stable baseline sessions and all shock sessions displayed in the form of box and whisker plots.

Figure A3 (Experiment 1). Mean response rates across the baseline and shock conditions for each phase. Error bars extend one standard deviation above and one standard deviation below the mean

Figure B1 (Experiment 2). Mean shocks per session across each shock conditions. Error bars extend one standard deviation above and one standard deviation below the mean. Rat JL2 was not exposed to the fifth shock condition 


\section{List of Figures (continued)}

Figure B2 (Experiment 2). Summaries of the IRT distributions from the stable baseline sessions and all shock sessions displayed in the form of box and whisker plots. All other details are the same as those in Figure A2.

Figure B3 (Experiment 2). Mean response rates across the baseline and shock conditions for each phase. Error bars extend one standard deviation above and one standard deviation below the

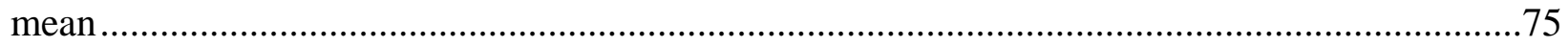

Figure C1 (Experiment 3). Mean shocks per session across shock conditions. Error bars extend one standard deviation above and one standard deviation below the mean

Figure C2 (Experiment 3). Summaries of the IRT distributions from the stable baseline sessions and all shock sessions displayed in the form of box and whisker plots. All other details are the same as those in Figure A2 .

Figure C3 (Experiment 3). Mean response rates across the baseline and shock conditions for each phase. Error bars extend one standard deviation above and one standard deviation below the mean

Figure D1 (Experiment 4). Mean shocks per session across shock conditions. Error bars extend one standard deviation above and one standard deviation below the mean

Figure D2 (Experiment 4). Summaries of the IRT distributions from the stable baseline sessions and all shock sessions displayed in the form of box and whisker plots. All other details are the same as those in Figure A2 .

Figure D3 (Experiment 4). Mean response rates across the baseline and shock conditions for each phase. Error bars extend one standard deviation above and one standard deviation below the mean 
Azrin and Holz (1966) defined punishment as the process by which a response-dependent stimulus reduces the future probability of the response. The stimulus is called a punishing stimulus or a punisher. In the typical procedure for studying punishment, food occasionally is delivered contingent on a rat's lever presses. Once responding stabilizes, a punishment contingency is added by delivering response-dependent electric shock through a grid floor. By comparing responding before and after the addition of the shock contingency, punishment can be assessed.

Although adding a shock contingency often decreases response rates, in some cases it increases response rates. This paradoxical effect may depend on several factors. One factor is the schedule of shock, or the rule stating under which conditions shock will be delivered. Other factors include the schedule of reinforcement, the manner of introducing the shock, shock duration, shock frequency, shock intensity, and the time between successive responses that produces shock (Arbuckle \& Lattal, 1992; Azrin \& Holz, 1966; Baron, 1991; Boe, 1966; Church, 1963; Sizemore \& Maxwell, 1985). Of present interest are two of these factors: shock intensity and the time between two successive responses, or interresponse times (IRTs), that produce shock. An IRT is calculated by subtracting the time at which the first response occurred from the time at which the second response occurred. For example, if a rat presses a lever $10 \mathrm{~s}$ after the session starts, and the next lever press occurs $12 \mathrm{~s}$ after the session starts, then the IRT is $2 \mathrm{~s}$. Previous research suggests that response rates are increased when long IRTs are followed by low-intensity shock (Arbuckle \& Lattal, 1992; Filby \& Appel, 1966; Galbicka \& Branch, 1981; Sizemore \& Maxwell, 1985) but are decreased when long IRTs are followed by high-intensity shock (Filby \& Appel, 1966; Sizemore \& Maxwell, 1985).

The reasons for this effect of shock intensity on long IRTs are unclear. One explanation is that shock punishes not responses but IRTs, and the type of IRTs punished by shock changes with shock intensity. When shock intensity is low, the IRT contiguous with shock may be punished. As shock intensity is raised, the temporal reach of shock may become greater. Hence, when shock intensity is high, the punishing effects of shock may spread to a sequence of IRTs (Arbuckle \& Lattal, 1992, Galbicka \& Branch, 1981; Sizemore \& Maxwell, 1985).

In addition to the shock intensity, the type of IRTs that produce shock may determine whether shock increases or decreases response rates. When long IRTs produce low-intensity shock, long IRTs decrease in frequency and response rates are increased (Arbuckle \& Lattal, 1992; Sizemore \& Maxwell, 1985). By contrast, when short IRTs produce low-intensity shock, short IRTs decrease in frequency and response rates are decreased. (Arbuckle \& Lattal, 1987; 1992). Note that low-intensity shock tends to influence the class of IRTs contiguous with shock, but when high shock intensities are used, the punishing effects may extend beyond the class of IRTs contiguous with shock to other classes of IRT. When the frequency of both short and long IRTs are decreased, response rates drop to low levels (Galbicka \& Branch, 1981). Therefore, whether shock increases or decreases response rates may depend on the range of the IRTs punished by shock which, in turn, may depend on shock intensity. 
Some experiments have manipulated shock intensity or the IRTs that produce shock, but relatively few studies have examined both variables simultaneously. Experiments that have studied both variables usually have included a limited range of shock intensities or have arranged shock following long, but not short, IRTs (cf. Arbuckle \& Lattal, 1992). A thorough understanding of the paradoxical effects of shock requires that the effects of shock be studied across a wider range of parameters. The present experiments examined the conditions under which shock increases or decreases response rates by manipulating shock intensity and the IRTs that produce shock. A wide range of shock intensities was used, and shock was contingent on long or short IRTs.

Four experiments were conducted. Rats' lever presses were reinforced with food on a variable interval (VI) 40-s schedule. On this schedule, the first response after an average of $40 \mathrm{~s}$ elapsed produced food. In the punishment conditions, lever presses also produced shock. The experimental variables were shock intensity and the schedule relating shock and IRTs. In the first two experiments, relatively long IRTs produced shock. In the second two, relatively short IRTs produced shock. Shock intensity was varied from $0.05 \mathrm{~mA}$ to either $0.4 \mathrm{~mA}$ or $0.8 \mathrm{~mA}$. Effects of shock on both IRT distributions and response rates were assessed.

\section{Literature Review}

Table 1 summarizes experiments that investigated the effects of shock on response rates. Peer-reviewed articles were obtained from key-word searches of the PSYCInfo psychological research database and the reference lists of articles previously obtained (if the articles were cited repeatedly or if they included manipulations of shock intensity or IRTs that produce shock). Key words included shock AND punishment, shock AND punishment AND behavior, and responsedependent shock AND punishment AND behavior. Articles were excluded if they omitted response rate or IRT frequency distributions as a primary measure, if their purpose was to examine shock-maintained or shock-elicited responding, or if their primary manipulation did not involve at least one of the following: the schedule of reinforcement, the schedule of shock, shock intensity, shock duration, or shock frequency.

A total of 26 articles met the search criteria. For each article, the following information is presented: the authors, the year of publication, the schedule of reinforcement, the schedule of shock, shock intensity, shock duration, the subject species, whether increases in response rates were observed, and whether decreases in responses were observed. Studies that reported increased response rates are presented first (in order of publication date).

Overall, the majority of articles summarized in Table 1 reported decreased response rates: punishment. Seven articles, however, reported increased response rates. Because the proposed research is concerned with understanding these paradoxical effects of shock, the following review will focus on studies that reported increased response rates.

In discussing the results of Filby and Appel (1966), Appel (1968), Lande (1981), Galbicka and Branch (1981), Arbuckle and Lattal (1987, 1992), and Sizemore and 
Maxwell (1985), particular attention will be given to the shock intensity and the IRTs that produce shock. For ease of communication, shock intensities falling near the lower or upper limits of the intensity range for a particular species will be described as "low" or "high", respectively. For example, for rats "low intensities" will include those ranging from $0.05 \mathrm{~mA}$ to $0.2 \mathrm{~mA}$ whereas "high intensities" will include those $0.6 \mathrm{~mA}$ or greater.

The distinction between low and high shock intensities is admittedly vague. For example, with rats it was unclear whether $0.4 \mathrm{~mA}$ should be considered a low intensity or a high one. Even when the programmed intensity is the same across studies, the experienced intensity may depend on additional variables such as the shock duration, the position of the animal when shocked, the amount of moisture on the animal's skin, the exact placement of electrodes, the quality of the shock scrambler, the animal's history with shock, the manner of introducing shock, and the cleanliness of the shock grid (Azrin \& Holz, 1966; Baron, 1991; Dinsmoor, 1998). For example, moisture on a rat's foot enhances the intensity experienced just as standing on two instead of four feet reduces it. Although the variables listed above probably do not explain differences between the effects of low shock intensities and those of high shock intensities, they may help to explain why an intermediate intensity, such as $0.4 \mathrm{~mA}$, increases responding in some cases and decreases it in others.

When considering the role of shock intensity, what matters most is not the specific intensities that increased or decreased responding but the general pattern regarding shock intensity and response rates. For studies in which shock increases responding, there seems to be an intensity that serves as a turning point such that intensities less than this value increase responding and intensities greater than this value decrease responding. The intensity that serves as the turning point may vary across studies or individual subjects for the reasons noted previously. Regardless, the general pattern is the same.

Interresponse times will be described as "short", "intermediate”, or "long”. Those IRTs in the lower portion of the distribution will be considered "short" IRTs, those in the middle of the IRT distribution will be considered "intermediate" IRTs, and those in the upper portion of the IRT distribution will be considered "long” IRTs. Note that IRT distributions vary according to the species, the response topography, and the baseline levels of responding. When possible, the descriptors "short", "intermediate" and "long" will be based on those given by the authors of the individual experiments because these descriptors already take into account the IRT distributions typical for that particular species and response topography.

\section{Shock Intensity}

Typically, when shock increases response rates, the shocks delivered are low in intensity (Appel, 1968; Arbuckle \& Lattal, 1992; Filby \& Appel, 1966; Lande, 1981; Sizemore \& Maxwell, 1985). For example, Filby and Appel (1966) reported that $0.2 \mathrm{~mA}$ and $0.4 \mathrm{~mA}$ shock increased response rates, but shock intensities of $0.6 \mathrm{~mA}$ and higher decreased response rates. 
Appel (1968), Arbuckle and Lattal (1992), Lande (1981) and Sizemore and Maxwell (1985) also reported increases in response rates when shock intensity was low.

Although increases in response rates may occur when shock intensity is low, this is not to say that low-intensity shock necessarily increases response rates. Several experimenters found that low-intensity shock either decreased responding or had no effect (Appel \& Peterson, 1965; Azrin, 1960; Azrin, Holz, \& Hake, 1963; Boroczi, Storms, \& Broen, 1964; Brethower \& Reynolds, 1962; Church, 1963; Church, Raymond, \& Beauchamp, 1967; Dinsmoor, 1952; Estes, 1944; Hake, Azrin, \& Oxford, 1967, Seligman \& Campbell, 1965). For example, Hake, Azrin, and Oxford (1967) reinforced squirrel monkeys' lever presses with food on a VI 30-s, VI 60-s, or VI 120-s schedule. Once responding stabilized, each response produced shock. Shock intensity was raised across sessions until response rates neared zero. The step size and sequence of shock intensity varied across the eight monkeys. For example, the shock intensity for one monkey was raised in the following order: $80 \mathrm{~V}, 140 \mathrm{~V}, 160 \mathrm{~V}, 180 \mathrm{~V}, 200 \mathrm{~V}, 220 \mathrm{~V}$. For another monkey, shock intensity was raised as follows: $40 \mathrm{~V}, 65 \mathrm{~V}, 80 \mathrm{~V}, 90 \mathrm{~V}, 100 \mathrm{~V}, 120 \mathrm{~V}$. Overall, shock decreased response rates even when the shock intensity was low.

\section{Schedules of Shock}

In addition to shock intensity, increases in response rates most likely depend on other variables. One variable may be the schedule of shock. For example, as seen in Table 1, the studies that reported increases in response rates often involved different schedules of shock than those that reported decreases. In most of the experiments that reported increases, shock was delivered on a VI schedule or a differential schedule in which only IRTs exceeding a preset value produced shock. By contrast, in the experiments that reported decreases, shock was delivered on a fixed-ratio (FR) schedule in which shock was delivered after a fixed number of responses. Therefore, in this section, the studies that reported increases in response rates will be reviewed, and particular attention will be paid to the schedule of shock.

Filby and Appel (1966) examined the effects of shock delivered on a VI schedule in which the first response after a varying amount of time produced shock. Food and shock were delivered on independent VI schedules with identical means. Across groups, the VI means were 30-s, 60-s, and 180-s. Within groups, shock intensity was raised from $0.2 \mathrm{~mA}$ to $1.3 \mathrm{~mA}$ across conditions. At $0.2 \mathrm{~mA}$, response rates in the VI 30-s and VI 60-s groups increased, and response rates in the VI 180-s group decreased. At $0.4 \mathrm{~mA}$, response rates in the VI 30-s group increased, and response rates in the VI 60-s and VI 180-s groups decreased. At $0.6 \mathrm{~mA}$ and higher, response rates in all three groups decreased.

Appel (1968) also reported increases in response rates. He examined the effects of shock intensity when shock was delivered on an FR-1 schedule or a fixed-interval (FI) schedule. On the FR-1 schedule, every response produced shock. On the FI schedule, the first response after a fixed period of time produced shock. Rats' lever presses were reinforced with milk on a VI 60-s schedule. Rats were randomly assigned to one of five groups. Across groups, the schedules of 
shock delivery were: FR-1, FI 10-s, FI 30-s, FI 60-s, and FI 120-s. Within groups, shock intensity was raised across conditions in this order: $0.05 \mathrm{~mA}, 0.1 \mathrm{~mA}, 0.2 \mathrm{~mA}, 0.3 \mathrm{~mA}, 0.4 \mathrm{~mA}$, $0.5 \mathrm{~mA}, 0.6 \mathrm{~mA}$, and $0.8 \mathrm{~mA}$. Each shock condition was preceded and followed by several baseline sessions with only the VI food schedule operative. At $0.05 \mathrm{~mA}$, response rates in the FR-1, FR 10-s, FI 30-s, and FI 60-s groups increased, and response rates in the FI 120-s group decreased. At $0.1 \mathrm{~mA}$, response rates in the FI 30-s and FI 60-s groups increased, and response rates in the other groups decreased. At $0.2 \mathrm{~mA}$ and higher, shock decreased response rates in all five groups.

Lande (1981) studied the effects of shock delivered on a variable-ratio (VR) schedule whereby shocks were delivered after a varying number of responses. Pigeons' key pecks produced food on a VI 60-s schedule. In the first shock condition, shock was delivered on a VR-10 schedule. Shock intensity was raised across sessions in this order: $4 \mathrm{~mA}, 5 \mathrm{~mA}, 6 \mathrm{~mA}$, $8 \mathrm{~mA}, 10 \mathrm{~mA}, 13 \mathrm{~mA}, 16 \mathrm{~mA}$. One pigeon was also exposed to $2.5 \mathrm{~mA}$ shock. Shock intensity was raised until the highest intensity was reached or until responding ceased or became erratic. Once the final shock intensity had been determined experimentally, the mean ratio of the VR schedule was manipulated across conditions as follows: 100, 400, 800, 400, 100, and 10. Response rates increased for 7 of 12 pigeons when shock was delivered on a VR 10. However, the shock intensity at which these increases occurred varied across subjects. For the only pigeon exposed to it, 2.5-mA shock increased response rates. For 3 pigeons, 4-mA shock increased response rates. For 2 pigeons, 5-mA shock increased response rates. For 4 pigeons, 6-mA shock increased response rates. For 1 pigeon, 8-mA shock increased response rates. For all pigeons, shocks of $10 \mathrm{~mA}$ or more decreased response rates. When shock was delivered on a VR-100, VR-400, or VR-800 schedule, response rates decreased. Overall, while the intensity that increased responding varied across pigeons, the general pattern remained the same. Specifically, low intensities increased responding whereas high intensities decreased it.

Taken together, the experiments of Filby and Appel (1966), Appel (1968), and Lande (1981) indicate that shock delivered on VI, FI, or VR schedules can increase responding. Although Appel (1966) reported that an FR schedule increased responding, the only FR schedule used was an FR-1, making conclusions about FR schedules difficult. Other schedules of shock have increased responding as well. One such schedule is a differential schedule in which shock is more likely to follow IRTs of a particular duration.

\section{IRTs Followed by Shock}

In the remaining studies in Table 1, response rates were increased when shock followed long IRTs. These experiments differ in how the punishment of long IRTs was arranged. In some (e.g., Arbuckle \& Lattal, 1987; 1992, Experiment 2; Galbicka \& Branch, 1981; Sizemore \& Maxwell, 1985), shock was contingent on IRTs exceeding a specific value. In others (Arbuckle \& Lattal, 1992, Experiment 1), shock followed long IRTs differentially but was not contingent on long IRTs per se. 
In Galbicka and Branch’s (1981) research, shock was either contingent on, or independent of, particular IRTs. Squirrel monkeys' lever presses produced food on a VI 60-s schedule. In the shock conditions, lever presses also produced 1.0-mA tail shock according to a differential IRT schedule or a random-ratio (RR) schedule. On the differential IRT schedule, shock was contingent on long IRTs such that approximately one-third of the IRTs longer than the criterion value, $t$, were followed by shock. To determine the value of $t$, the $90^{\text {th }}$ percentile of the IRT distribution was calculated for each of the last three sessions of the preceding condition, regardless of whether the preceding condition was a baseline or a shock condition. The median of these three values was used as initial value of $t$. Across conditions, the value of $t$ was reduced. In the conditions with the RR shock schedule, every 30th response on average produced shock. Thus, in the differential IRT condition, shock depended on long IRTs whereas in the RR-30 condition, shock was independent of IRTs. Response rates increased when long IRTs produced shock and decreased when shock was independent of IRTs. As the value of $t$ was lowered and the portion of the IRT distribution susceptible to shock was raised, response rates increased. Shock contingent on long IRTs selectively punished long IRTs, and increased the relative frequency of shorter IRTs. By contrast, shock delivered independently of IRTs decreased the relative frequency of shorter IRTs while increasing the frequency of longer ones. The punishment of short IRTs on schedules that deliver shock independently of IRTs may stem from the fact that the majority of IRTs generated by most schedules of reinforcement are short, making it more likely that shock will follow short IRTs differentially and decreases response rates (Anger, 1956; Arbuckle \& Lattal, 1992; Blough, 1963; Blough \& Blough, 1968; Doughty \& Richards, 2002; Galbicka \& Branch, 1981; Holz \& Azrin, 1963; Peele, Casey, \& Silberberg, 1984; Shimp, 1968; Shimp, 1969; Shull, Gaynor \& Grimes, 2001; Sizemore \& Maxwell, 1985).

In addition to the IRTs followed by shock, the portion of the IRT distribution susceptible to the shock contingency may determine responding. In Galbicka and Branch's (1981) research, when long IRTs produced shock, raising the portion of the IRT distribution susceptible to the shock contingency increased responding further. Arbuckle and Lattal (1987) also demonstrated that raising the portion of the IRT distribution susceptible to shock exaggerates the effects of shock when shock is delivered on a differential schedule.

In Arbuckle and Lattal's (1987) experiment, short IRTs produced shock and long IRTs cancelled shock. Pigeons' key pecks produced food on a VI 180-s schedule. In the shock conditions, pecks also produced shock on a VI 30-s schedule. Shock intensity varied across subjects and was either $35 \mathrm{~V}$ or $55 \mathrm{~V}$. In some conditions, a shock-avoidance contingency was added: once the VI 30-s schedule had set up a shock, a response terminating an IRT longer than or equal to some specified duration cancelled the shock. A response terminating an IRT shorter than the specified duration produced the shock. Because longer IRTs could cancel shock in the shock-avoidance conditions, these conditions arranged the differential reinforcement of longer IRTs whereas the other shock conditions did not. The shock-avoidance conditions also arranged the differential punishment of shorter IRTs. Across the shock-avoidance conditions, the specified IRT durations were $30 \mathrm{~s}, 10 \mathrm{~s}$, and $5 \mathrm{~s}$. Lowering the specified IRT durations raised the 
portion of the IRT distribution that cancelled shock and reduced the portion that produced shock. In the shock conditions without the shock-avoidance contingency, the effects of shock were inconsistent across pigeons and exposures. In two cases, responding decreased. In one case, responding increased, and in the other, there was no change. In the shock-avoidance conditions, response rates consistently decreased. As more IRTs cancelled shock and fewer produced shock, responding increased albeit not above baseline levels. Overall, Arbuckle and Lattal's work demonstrates that the portion, or range, of IRTs that produce shock as well as the duration of IRTs that produce shock determine response rates.

In another study by Arbuckle and Lattal (1992, Experiment 1) pigeons’ key pecks produced food on a VI 180-s schedule, and shock was delivered on either a VI 30-s schedule or a VI-like nondifferential schedule. The VI-like nondifferential schedule, hereafter referred to as a nondifferential schedule, is similar to a VI schedule because both schedules are time-based schedules in which the first response after a varying amount of time produces shock. Nondifferential schedules differ from VI schedules in terms of the probability of shock. On VI schedules, the probability that a response will produce shock increases with the passage of time. Therefore, shock is more likely to follow long IRTs than short IRTs, and long IRTs are likely to be punished differentially. By contrast, on a nondifferential schedule, the probability that a response will produce shock is fixed independently of IRT duration. Hence, although both VI schedules and nondifferential schedules deliver shock after a varying period of time, VI schedules differentially punish long IRTs whereas nondifferential schedules are equally likely to punish long and short IRTs. Across conditions, shock intensity was raised in 10-V steps. The maximum intensity varied across subjects and was either $40 \mathrm{~V}$ or $50 \mathrm{~V}$. Response rates in both the VI shock condition and the nondifferential shock condition were higher than those in the conditions without shock. On both shock schedules, the frequency of long IRTs decreased relative to those from the conditions without shock. Raising the intensity increased response rates for some subjects, but this effect was not consistent across subjects.

As expected, the IRTs followed by shock on the VI schedule were slightly longer than those followed by shock on the nondifferential schedule, however, contrary to the predictions made by Arbuckle and Lattal (1992), the IRT distributions and response rates on the two shock schedules were similar. According to Arbuckle and Lattal, the VI and nondifferential schedules produced similar effects because the first shock condition, in which shock was delivered on a VI schedule, produced long-lasting shifts in the IRT distributions which remained after the shock contingency was removed and the baseline was reinstated.

In a second experiment, Arbuckle and Lattal (1992, Experiment 2) studied the punishment of short and long IRTs. Pigeons' key pecks produced food on a VI 180-s schedule. In some conditions, pecks also produced $30-\mathrm{V}, 45-\mathrm{V}$, or $50-\mathrm{V}$ shock, depending on the subject. Shock was delivered on either a nondifferential schedule similar to that in the previous experiment or a differential schedule. Two types of differential schedules were used: On one, shock was contingent on short IRTs; On the other, shock was contingent on long IRTs. In the differential shock conditions, the IRTs that produced shock decreased in frequency compared to 
conditions with the nondifferential shock schedule or no shock schedule. The effects on overall response rates, however, were inconsistent across subjects.

Combined, the experiments of Galbicka and Branch (1981) and Arbuckle and Lattal $(1987,1992)$ demonstrate that the IRTs can be punished and in some cases may determine response rates. Punishing long IRTs increases responding. This occurs regardless of whether shock is delivered on a VI schedule or is contingent on IRTs greater than a specific value. Punishing short IRTs decreases responding, although this effect seems less robust compared to when long IRTs are punished. Moreover, raising the portion of the IRT distribution susceptible to the shock contingency appears to intensify these effects (Galbicka \& Branch, 1981; Arbuckle \& Lattal, 1987).

Thus far, the effects of shock intensity and the shock schedule, especially as it pertains to the IRTs followed by shock, have been examined independently. Whether and how these variables interact must also be considered.

\section{Interactive Effects of Shock Intensity and IRTs that Produce Shock}

Sizemore and Maxwell (1985) investigated the effects of shock intensity and the IRTs that produce shock. Rats' lever pressing was reinforced with food on a VI 40-s schedule. Once responding stabilized, a shock contingency was added. Across conditions, shock intensity was raised from $0.1 \mathrm{~mA}$ to $0.4 \mathrm{~mA}$ in $0.1-\mathrm{mA}$ steps. Two experiments differed in terms of the IRTs specified by the shock contingency. In the first experiment, all IRTs greater than $8 \mathrm{~s}$ ("long” IRTs) produced shock. At $0.1 \mathrm{~mA}$ and $0.2 \mathrm{~mA}$, response rates increased, but at $0.3 \mathrm{~mA}$ and $0.4 \mathrm{~mA}$, responding was eliminated. In the second experiment, all IRTs greater than $8 \mathrm{~s}$ but less than $12 \mathrm{~s}$ ("intermediate” IRTs) produced shock. At $0.1 \mathrm{~mA}$, response rates increased. At higher shock intensities, response rates decreased but responding was not eliminated. The IRTs that produced shock decreased differentially in almost all cases. The exception was when long IRTs produced $0.3-\mathrm{mA}$ or $0.4-\mathrm{mA}$ shock. In these conditions, responding was eliminated and all IRTs, regardless of their duration, decreased in frequency.

In Sizemore and Maxwell's (1985) research, analyses of overall IRTs showed that long IRTs were punished at low shock intensities, but that shock punished other classes of IRTs when high shock intensities were used. Here, shock intensity and the IRTs that produce shock interact with low shock intensities increasing or decreasing responding depending on the shock schedule and high shock intensities decreasing responding regardless of the shock schedule.

\section{Changes in the Temporal Reach of Behavioral Consequences}

The reasons for the interactive effects of shock intensity and the IRTs that produce shock have not yet been identified. As noted previously, it is possible that by raising the shock intensity, the temporal reach of shock is also raised and the number of IRTs that are captured by the punishment contingency increases. There is no reason, however, to assume that changes in 
the temporal reach of a behavioral consequence are limited to cases where that consequence is a punisher. Raising the intensity, or magnitude, of any behavioral consequence may increase its temporal reach regardless of whether the consequence is a punisher or a reinforcer.

Doughty and Richards (2002) demonstrated how the magnitude of a consequence affects the temporal reach of its behavioral effect. They examined the effects of reinforcer magnitude on responding under differential-reinforcement-of-low-rate (DRL) schedules. On a DRL schedule, an IRT longer than a specified criterion produces a reinforcer. In the first experiment, rats' lever presses produced either $30 \mathrm{ml}$ or $300 \mathrm{ml}$ of water on a DRL schedule. The experiment was divided into three phases. In the first phase, IRTs longer than $72 \mathrm{~s}$ produced $30 \mathrm{ml}$ or 300 $\mathrm{ml}$ of water, depending on the rat. After responding stabilized, the amount of water was reversed such that rats that were previously given $30 \mathrm{ml}$ were given $300 \mathrm{ml}$ and vice versa. In the second phase, the reinforcement schedule was changed to a DRL18-s schedule. In the third phase, the DRL schedule from the second phase was used and the water amounts alternated each session. Across phases, $300 \mathrm{ml}$ of water produced higher response rates than $30 \mathrm{ml}$, indicating that $30 \mathrm{ml}$ was more effective in the differential reinforcement of long IRTs. Analyses of the IRT distributions revealed that as the size of the reinforcer increased, the distributions became more positively skewed, and intermediate and short IRTs increased in frequency. In other words, when the reinforcer was large, the differential reinforcement of long IRTs became less differential and generalized to other classes of IRTs. Similar results also were obtained by Kirshenbaum, Brown, Hughes, and Doughty (2008).

The experiments of Doughty and Richards (2002) and Kirshenbaum, Brown, Hughes, and Doughty (2008) support the idea that the temporal reach of a behavioral consequence increases as the magnitude of a consequence is raised. Arbuckle and Lattal (1992) suggested that a similar outcome may occur with punishment. Results from Sizemore and Maxwell's (1985) first experiment, in which high shock intensities punished all classes of IRTs, are consistent with but do not directly establish the idea that more IRTs are affected by shock as shock intensity is raised. More direct evidence of the changes in the temporal reach of shock as it applies to punishment is needed.

\section{The Functional Unit of Behavior}

By focusing on IRTs as the functional units of behavior, it becomes clear that the paradoxical effects of shock may not be paradoxical at all. Rather, these effects may simply reflect changes in the IRTs punished by shock. When shock decreases response rates, it may be because shock punishes short IRTs. By contrast, when shock increases response rates, it may be because shock punishes long IRTs. The notion that shock may punish IRTs rather than responses per se will hereafter be referred to as the IRT model. Similarly, the idea that shock punishes responses, not IRTs, will hereafter be referred to as the response model. The response model emphasizes a structural approach to behavior. While structural approaches are not given much credence in behavior analysis, the response model is included here because it is sometimes 
adopted by individuals who criticize punishment as being ineffective (Axelrod, 1990; Azrin \& Holz, 1966; Hutchinson, 1977; Newsome, Favell, \& Rincover, 1983; Pazulinec, Meyerrose, \& Sajwaj, 1983; Robinson, Funk, Beth, \& Bush, 2005).

\section{Statement of the Problem}

The common procedure for studying punishment, response-dependent shock, produces paradoxical effects. In some cases, shock increases rather than decreases responding. Increases in response rates are most likely when long IRTs are punished differentially, and this is most likely when shock intensity is low (Appel, 1968, Filby \& Appel, 1966, Galbicka \& Branch, 1981; Sizemore \& Maxwell, 1985).

The exact nature of the interaction between shock intensity and IRTs followed by shock remains unclear. One explanation is that shock increases or decreases responding because of localized or generalized effects on classes of IRTs. At low intensities, the effect of shock is localized to the IRTs most close in time to the shock. If long IRTs produce shock, long IRTs decrease in frequency, and response rates increase (Arbuckle \& Lattal, 1992; Sizemore \& Maxwell, 1985). If short IRTs produce shock, short IRTs decrease in frequency and response rates decrease (Arbuckle \& Lattal, 1992). At high shock intensities, the temporal reach of shock extends to a longer sequence of IRTs, which most likely includes a variety of IRT durations. Under these circumstances, various IRT classes would decrease in frequency, and response rates would decrease.

Although some experiments with reinforcement suggest that temporal reach of a behavioral consequence increases as the magnitude of the consequence increases (Doughty \& Richards, 2002; Kirshenbaum, Brown, Hughes, \& Doughty, 2008; Shull, Gaynor, \& Grimes, 2002), evidence supporting this idea as it pertains to punishment is lacking. Results obtained by Sizemore and Maxwell (1985) are consistent with the idea, but they do not directly establish that the temporal reach of shock varies as a function of shock intensity.

The purpose of the present research was to investigate how shock intensity and the IRTs that produce shock interact to determine levels of responding. In four experiments, rats' lever presses were reinforced with food on a VI 40-s schedule. Once responding stabilized, responsedependent shock was added. Shock intensity was manipulated from $0.05 \mathrm{~mA}$ to $0.4 \mathrm{~mA}$ or $0.8 \mathrm{~mA}$. In the first two experiments, shock delivery was contingent on long IRTs. In the second two experiments, shock delivery was contingent on short IRTs. The experiments also differed in their arrangements of the experimental manipulations. In two experiments, shock intensity was raised before the portion of the IRT distribution susceptible to shock was raised. In the other two, the portion of the IRT distribution susceptible to shock was raised prior to raising the shock intensity. 
General Method

Subjects

Experimentally naive male Sprague-Dawley rats served as subjects, 4 in each experiment. They were maintained at $80 \%$ ( $\pm 2 \%$ ) of their free-feeding weights by food obtained during the experimental sessions and, if necessary, by supplemental feedings at least 30 min after the sessions. Weights were adjusted on a monthly basis according to growth charts provided by the supplier. The rats were housed individually in a room with a 12:12 hr reversed light/dark cycle.

\section{Apparatus}

Sessions were conducted in four identical operant chambers enclosed in ventilated soundattenuating chests (Med Associates Inc., St. Albans, VT). Each chamber was $29 \mathrm{~cm}$ long, $22 \mathrm{~cm}$ high and $24 \mathrm{~cm}$ deep. The ceiling and side walls were constructed of Plexiglas, and the end walls were made of stainless steel. The floor consisted of 19 stainless-steel rods $0.5 \mathrm{~cm}$ in diameter spaced approximately $1.3 \mathrm{~cm}$ apart. On the front wall were two retractable levers. Each lever was $4.4 \mathrm{~cm}$ wide, $1.3 \mathrm{~cm}$ thick, and protruded $1.9 \mathrm{~cm}$ into the chamber when inserted. The inside edges of the levers were spaced $11.4 \mathrm{~cm}$ apart $(5.7 \mathrm{~cm}$ from the middle of the wall). The tops of the levers were positioned $8 \mathrm{~cm}$ from the floor. Approximately $5 \mathrm{~cm}$ above each lever was a white cue light (No. 1820 bulb). During all experimental sessions, only the left lever was inserted. The right lever remained retracted and inoperative. Responses on the left lever were reinforced occasionally with 45-mg food pellets dispensed into a magazine centered on the front wall. The rat's head entries into the magazine were detected with a photocell. Punishing stimuli consisted of scrambled foot shock controlled by a constant-current shock generator (Med Associates ENV-413). General illumination was provided by a houselight (No. 1820 bulb) located on the back wall. White noise $(85 \mathrm{~dB})$ masked extraneous sounds. Experimental events were controlled and recorded using a computer with Med Associates interfacing hardware and MED-PC IV@ software.

\section{Procedure}

Sessions usually were conducted seven days per week at approximately the same time each day. Sessions lasted until 60 reinforcers were delivered or 60 min had elapsed. A 3-min presession delay allowed the rats to recover from any disruptive effects of handling. During the presession delay, the chamber was darkened and the levers were retracted. The start of the session was signaled by onset of the houselight and insertion of the left lever. During delivery of a reinforcer, the houselight was turned off and remained off until 2 s elapsed after the rat's head entered the food magazine. 


\section{Preliminary Training}

Magazine training was conducted to establish the reinforcing efficacy of pellet delivery. Then lever presses were reinforced according to an FR-1 schedule. Once the lever press was acquired, rats were exposed to a VI schedule of reinforcement (Fleshler \& Hoffman, 1962) consisting of 15 intervals presented randomly without replacement (whereupon the schedule was repeated). Over the course of 8 to 10 sessions, the mean interval was raised from VI 5-s to VI 40-s, at which point preliminary training ended. The use of a VI 40-s schedule follows Sizemore and Maxwell's (1985) procedure.

\section{Design}

The independent variables were shock intensity and the IRTs eligible for shock. Two experiments targeted relatively long IRTs by presenting shock contingent on IRTs greater than the criterion $t$ (an IRT $>t$ schedule). Two experiments targeted relatively short IRTs by presenting shock contingent on IRTs less than the criterion $t$ (an IRT $<t$ schedule).

All experiments were organized into four phases. Each phase consisted of a baseline condition followed by five shock conditions. The baseline consisted simply of a VI 40-s schedule of pellet delivery. Phases were defined in terms of the shock intensity or the percentile used to establish $t$ during the five shock conditions that followed the baseline. In Experiments 1 and 3, shock intensity was held constant within a phase and raised across phases, beginning with an intensity of $0.05 \mathrm{~mA}$. The conditions within each phase differed in terms of the percentile used to establish $t$. In Experiments 2 and 4, $t$ was manipulated across phases, either by raising the percentile used to establish $t$ or by lowering it - as described below for the individual experiments. In these experiments, $t$ was held constant within each phase, and the conditions within the phase differed in terms of shock intensity.

Although previous research suggests that shock intensity and shock contingencies involving IRTs have interactive effects, it is unclear whether these depend on how manipulations in shock intensity and shock contingencies are arranged. The present experiments provided an additional test of the generality of these effects by varying how manipulations of shock intensity and the IRTs that produced shock were arranged. If different experimental arrangements produced similar results, then the interactive effects of shock and IRT contingencies are independent of the sequencing of these manipulations.

It is possible that response rates during the shock conditions could reflect pre-existing differences in the response rates from the initial baseline rather than an effect of the shock contingency. To control for this, matching was used to assign rats to the experiments. Rats were ranked from highest to lowest on the basis of their stabilized response rates in the initial baseline. Rats with ranks 1 through 4 were then assigned to the four experiments using random assignment without replacement. This process was repeated until all 16 rats were assigned to an experiment. 


\section{Baseline}

In each baseline, lever pressing was reinforced on a VI 40-s schedule, and no shock was administered. This condition remained in effect for a minimum of 20 sessions and until responding was judged stable. Stability judgments considered response rates over the last six sessions. Responding was judged stable when the difference between the mean of the first block of three sessions and the mean of the second block was within $10 \%$ of the overall mean, and there was an absence of trend as judged visually.

\section{Shock Conditions}

Following each baseline, rats were exposed to five experimental conditions in which food was presented on a VI 40-s schedule and shock was presented on either an IRT $>t$ schedule or an IRT $<t$ schedule. If food and shock were scheduled to be presented after the same response, shock was delivered immediately and food delivery was postponed until after the next response. The first response within a new interval was ineligible for shock. On the IRT $>t$ schedule, each IRT that exceeded the temporal criterion $t$ was followed by shock. On the IRT $<t$ schedule, each IRT less than $t$ was followed by shock. The value of $t$ was determined by cumulating the IRTs from the stable baseline sessions, calculating the deciles of the cumulative IRT distribution, and setting $t$ to one of these deciles (details below). All shocks lasted $100 \mathrm{~ms}$. The following shock intensities were used: $0.05 \mathrm{~mA}, 0.1 \mathrm{~mA}, 0.2 \mathrm{~mA}, 0.4 \mathrm{~mA}$, and $0.8 \mathrm{~mA}$.

Each shock condition was designed to last five sessions but was terminated early (a) if responding was suppressed below $10 \%$ of the baseline rate for two consecutive sessions, or (b) if the IRT distributions of the most recent two sessions shifted outside the range of the IRTs that produce shock. The first situation occurred in some of the experiments (details to be presented in reports of the individual experiments). The second situation never occurred. When a shock condition was terminated early, the entire phase was also terminated (i.e., the remaining shock conditions within the phase were cancelled), and the baseline condition for the next phase was started.

\section{Experiment 1}

Experiment 1 examined the effects of shock intensity on responding when long IRTs produced shock. Shock intensity was raised across phases. Within each phase, the percentile used to establish $t$ was lowered across the five shock conditions.

According to the IRT model described previously, IRTs rather than responses serve as the functional units of behavior. At low shock intensities, the temporal reach of shock is presumably short, and the effects of shock should be confined to the IRT contiguous with shock. At higher intensities, the temporal reach of shock is presumably greater, and the effects of shock should extend to a sequence of IRTs preceding shock. Because this model emphasizes IRTs rather than 
responses as the functional units of behavior, it predicts that shock will not punish responses but the class of IRTs that produce shock. In Experiment 1, shock was contingent on long IRTs. Under this arrangement, low-intensity shock was expected to punish long IRTs and increase responding whereas high-intensity shock is expected to punish other classes of IRTs and decrease responding. There should also be an effect of the range of IRTs eligible for shock. By raising the range of IRTs that produce shock, shock should punish a variety of IRTs and decrease response rates. According to the IRT model, there should be an interaction between shock intensity and the range of IRTs followed by shock. Low intensities may punish more classes of IRTs if the range of IRTs followed by shock is raised. Likewise, high intensities may punish fewer classes of IRTs if the range of IRTs followed by shock is limited, as when $t$ is set to the $90^{\text {th }}$ percentile.

On the other hand, if the IRT model is incorrect and responses serve as the functional units, then shock should decrease responding regardless of the IRTs that produce shock. According to this response model, no predictions can be made regarding the class of IRTs punished by shock. There should be an effect of shock intensity, with high shock intensities expected to decrease responding more than low shock intensities. Additionally, the range of IRTs eligible for shock should have an effect on responding but only because this manipulation also signifies an increase in the rate of, or number of responses followed by, shock. Raising the range of IRTs eligible for shock should decrease responding further. No interaction between shock intensity and the range of IRTs eligible for shock is expected.

Overall, the two sets of predictions differ in the direction of the expected effects. Predictions based on the IRT model indicate that shock will increase or decrease responding depending on whether the intensity is low or high, respectively. By contrast, predictions based on the response model indicate that shock will only decrease responding. According to the response model, high intensities will decrease responding more than low intensities. In other words, raising the shock intensity should change the size of the effect but not its direction. According to both the IRT model and the response model, raising the range of IRTs eligible for shock should produce greater effects, although the models differ in their explanations of this. Finally, only the first set of predictions includes an interaction between shock intensity and the range of IRTs eligible for shock.

\section{Method}

Table 2 shows the number of baseline sessions, shock intensities, and values of $t$ for the four phases. (Results for Rat JL14 are limited to the first phase because this rat was injured during the second baseline condition and was eliminated from the study.) Shock was administered according to an IRT $>t$ schedule. Across phases, shock intensity was raised from $0.05 \mathrm{~mA}$ to $0.4 \mathrm{~mA}$ as shown in the table. Within phases, the percentiles used to establish $t$ were based on the baseline condition at the outset of each phase and were lowered across the shock 
conditions. Under this arrangement, the portion of the IRT distribution that was susceptible to the shock contingency was raised gradually at each shock intensity.

Results

Analyses for all experiments are based on the six stable baseline sessions and all shock sessions (five per condition unless noted otherwise). Table 3 lists the mean reinforcement rates. Across phases, reinforcement rates were similar. Within a phase, reinforcement rates in the baseline and shock conditions were similar, with rates in the shock conditions within 0.09 reinforcers per minute of the baseline rate. Reinforcement rates were stable from session to session, as shown standard deviations of 0.03 reinforcers per minute or less. The obtained reinforcement rates were close to the programmed rates of 1.5 reinforcers per minute, meaning that any changes in the IRT distributions or response rates cannot be attributed to changes in reinforcement rates. Rather, these effects reflect effects of the shock contingency.

Appendix A includes a series of figures for Experiment 1. Figure A1 shows the number of shocks per session. Table 3 lists the mean shock rates. Across phases, raising the shock intensity had no systematic effect on the shock rates. The exception was Rat JL16, who had lower shock rates at the two highest intensities. Similar shock rates across phases indicate that the IRT distributions and response rates were also similar across phases. Within a phase, as the range of IRTs susceptible to shock was raised (i.e., the percentile was lowered) shock rates increased, with rates 3 to 5 times faster at the $50^{\text {th }}$ percentile than at the $90^{\text {th }}$ percentile. This suggests that while raising the range of IRTs susceptible to shock may have caused the IRT distributions to shift away from long IRTs, these shifts were not severe enough to avoid shock. Similar results are shown in Figure A1 in Appendix A with the number of shocks.

Figure 1 shows an assessment of changes in the IRT distributions in terms of the percentage of responses followed by shock. Recall that each phase began with a baseline condition without shock, and the IRT distribution from the stable sessions defined the percentiles to be followed by shock in the subsequent conditions. If the IRT distribution in the shock conditions matched the baseline distributions, the percentage of responses followed by shock would be those indicated by the dashed reference line in each panel. Deviations from the dashed reference line indicate shifts in the IRT distributions relative to the baseline. Functions above the dashed reference line indicate the IRT distributions shifted toward the IRTs that produced shock. Functions below the dashed reference line indicate the IRT distributions shifted away from the IRTs that produced shock.

All of the functions in Figure 1 fall below the dashed reference line, meaning that shock contingent on long IRTs punished long IRTs, and the IRT distributions shifted toward shorter IRTs. This shift reduced the portion of the IRT distribution susceptible to shock. Across phases, raising the shock intensity had no apparent effect on the percentage of responses followed by shock (i.e., the IRT distributions). Within each phase, raising the range of IRTs susceptible to shock (i.e., lowering the percentile used to define $t$ ) produced greater deviations of the functions 
from the dashed reference lines. These effects did not depend on the shock intensity, indicating there was no interaction between shock intensity and the portion of the IRT distribution susceptible to shock.

A two-way (Shock Intensity $\times$ Percentile), repeated-measures ANOVA was conducted on the differences between the percentage of responses followed by shock and those indicated by the reference line to assess changes in the IRT distributions. Rat JL14 was dropped from the analysis. This analysis corroborated that the there was a main effect of the range of IRTs eligible for shock, i.e., the percentile, on the IRT distributions $(F(4,8)=102.82, p<.01)$. Post-hoc comparisons were evaluated with the Least Significance Difference test. Alpha was set to .05 and all of the differences were statistically significant. There was not a main effect of intensity $(F(3,6)=3.12, p>.05)$ or an interaction between intensity and range of IRTs eligible for shock $(F(12,24)=1.69, p>.05)$.

Absolute response rates are presented in Figure A3 in Appendix A. Figure 2 shows proportional response rates calculated by dividing the response rate from each shock session by the mean baseline response rate. These session-by-session proportions were then averaged to create a mean over the five sessions of each shock condition. Hereafter, mean proportions at least one standard deviation above the reference line will be considered instances of facilitation. Mean proportions at least one standard deviation below the reference line will be considered instances of suppression.

As shown in Figure 2, shock contingent on long IRTs usually facilitated responding. One way of demonstrating this is by counting the number of proportions that are at least one standard deviation above baseline. Doing so reveals that in approximately $57 \%$ of the cases, shock facilitated responding. Across phases, shock intensity did not appear to have an effect on responding, given that proportional response rates were similar when 0.1-mA, 0.2-mA, and 0.4-mA shock was delivered. Within a phase, shock facilitated responding most when a large portion of the IRT distribution was susceptible to shock, i.e., at the $60^{\text {th }}$ and $50^{\text {th }}$ percentiles.

A two-way (Shock Intensity $\times$ Percentile), repeated-measures ANOVA was conducted with Rat JL14 omitted from the analysis. This corroborated that there was a main effect of the range of IRTs eligible for shock on proportional response rates $(F(4,8)=15.26, p<.01)$. Posthoc comparisons were evaluated with the Least Significance Difference test and alpha was set to .05. The following differences were statistically significant: response rates at the $90^{\text {th }}$ and $80^{\text {th }}$ percentile, the $90^{\text {th }}$ and the $60^{\text {th }}$ percentile, and the $80^{\text {th }}$ and the $60^{\text {th }}$ percentile. There was not a main effect of intensity $(F(3,6)=2.82, p>.05)$ or an interaction between intensity and the range of IRTs eligible for shock $(F(12,24)=1.25, p>.05)$.

\section{Discussion}

Overall, shock delivered contingent on long IRTs punished long IRTs and increased response rates. There was no effect of shock intensity. There was an effect of the range of IRTs susceptible to shock. Raising the range of IRTs susceptible to shock caused the punishing effects 
of shock to extend beyond long IRTs to shorter classes of IRTs. As the range of IRTs susceptible to shock was raised, response rates increased. There was no interaction between shock intensity and the percentile, or range of IRTs susceptible to shock. The effects were fairly consistent within and across rats.

Across phases raises in shock intensity were confounded with raises in the cumulative exposures to shock. Cumulative exposure to shock can affect responding (Azrin \& Holz, 1966), in two ways. One way is through habituation in which the rats' responsiveness to shock decreases with repeated administrations and shock becomes less effective over time. The second way is through sensitization. With sensitization, rats' responsiveness to the shock increases with repeated administrations and shock becomes more effective over time. Habituation and sensitization are opposing processes. In the present experiment, it seems more likely that habituation occurred rather than sensitization. Note that by reducing the effectiveness of shock over time, habituation would make IRT distributions and response rates more similar across phases whereas sensitization would have the opposite effect. This may explain the absence of an effect of shock intensity across phases.

Within-phase changes in IRT distributions and response rates, or the lack thereof, may have been influenced by habituation as well. Two points on this are worth mentioning. First, comparisons made across phases involve greater differences in the cumulative number of shocks than those made within a phase. This means that the effects of habituation are less likely to be confounded with raising the range of IRTs susceptible to shock than with raises in shock intensity. Second, even if habituation influenced responding within phases, habituation would minimize differences in IRT distributions and response, not exaggerate them. Therefore, one can still conclude that there was an effect of the range of IRTs susceptible to shock.

Any study involving electric shock risks habituation or sensitization (Azrin \& Holz, 1966). The possibility of habituation or sensitization cannot be eliminated, but they can be assessed by varying the order in which subjects are exposed to the different conditions. In the present experiment, habituation or sensitization could have been assessed and disentangled from any effects of the shock intensity by varying the order in which the shock intensity was manipulated. Doing so, however, would have involved exposing the rats to higher shock intensities sooner which can lead to complete and irreversible suppression (Azrin \& Holz, 1966). For the repeated-measures design employed here, complete and irreversible suppression would have prevented completion of the experiment. For this reason, the convention of raising the shock intensity across phases was followed. To minimize the effects of the cumulative number of shocks on responding, the number of shock sessions per condition was limited to five.

As the range of IRTs eligible for shock was raised within phases, shock rates and the number of responses followed by shock increased. This may lead others to argue that changes in shock rate, and not the portion of IRTs susceptible to shock, were responsible for within-phase changes in the IRT distributions and response rates, indicating that responses and not IRTs were the functional units of behavior. Recall however, that if responses were the functional units, shock would be expected to punish responses and decrease responding. Raising the number of 
responses followed by shock by raising the range of IRTs eligible for shock would decrease responding further. By contrast, if IRTs were the functional units, then shock would be expected to increase, not decrease responding. Raising the range of IRTs eligible for shock would increase responding further. As noted previously, in the present experiment, the latter was observed, indicating that IRTs and not responses served as the functional units.

The results of Experiment 1 are consistent with the literature in a few ways. First, shock contingent on long IRTs punished long IRTs but not short IRTs. This finding is consistent with the results of Arbuckle and Lattal (1992) and Sizemore and Maxwell (1985). Second, raising the range of IRTs eligible for shock (i.e., lowering the percentile used for $t$ ) punished long IRTs. Galbicka and Branch (1981) reported a similar effect when shock was contingent on long IRTs.In their experiment, rather than flattening the IRT distributions and punishing a variety of IRTs, shock contingent on long IRTs punished long IRTs. Raising the portion of the IRT distribution to shock by lowering the value of $t$ punished shorter IRTs, causing the distributions to become more positively skewed. Third, as was reported by Filby and Appel (1966), Arbuckle and Lattal (1987, 1992), Galbicka and Branch (1981), and Sizemore and Maxwell (1985), shock contingent on long IRTs increased response rates. Raising the range of IRTs eligible for shock increased response rates further. Similar findings were reported by Galbicka and Branch (1981).

Results from the present experiment are inconsistent with previous findings in that there was not an effect of shock intensity on the IRT distributions or response rates, nor was there an interaction between shock intensity and the range of IRTs eligible for shock. As noted previously, several experiments reported an effect of shock intensity in which low shock intensities punished long IRTs and increased responding but high intensities punished a wide range of IRTs and decreased responding (Filby \& Appel, 1966; Appel, 1968; Galbicka \& Branch, 1981; Lande, 1981; Sizemore \& Maxwell; 1985). The lack of an effect of shock intensity may be due to habituation across phases as previously discussed. Another explanation is that the return to a no-shock baseline between phases strengthened responding, particularly long IRTs, in such a way that it became resistant to shock in the subsequent shock conditions. Previous research involving shock punishment has shown that responding can become resistant to punishment when punishment periods are repeatedly separated by periods of no punishment, sometimes referred to as vacations from punishment (Orme-Johnson, 1967). There also may have been too few intensities to create a reliable difference in IRT distributions or response rates. Including additional intensities in the future should address this issue.

Alternatively, shock duration may have been so brief that low and high shock intensities were functionally equivalent. Of the three studies cited in Table 1 that reported increased response rates with rats, all of them used shock durations greater than $100 \mathrm{~ms}$. In Filby and Appel's (1966) and Appel's (1968) research, shock lasted 500 ms. In Sizemore and Maxwell's work, shock lasted $400 \mathrm{~ms}$. If the brief shock duration was responsible for the lack of an effect of shock intensity, then shock intensity should not have had an effect in the remaining experiments, given that the these experiments also used 100-ms shock. If, however, habituation or too few shock intensities was responsible for the lack of an effect of shock intensity, then the 
different arrangement of experimental manipulations used in Experiment 2 should address this issue.

Lastly, the lack of an effect of shock intensity may be due to the fact that intensity was raised across phases rather than within phases. Shock intensity is another way of conceptualizing the punisher. Some research on reinforcement magnitude have shown no effect of reinforcement magnitude when manipulations are made across phases or on a simple schedule but have shown an effect of reinforcement magnitude when made within phases or on concurrent schedules, in which two independent schedules operate simultaneously (Bonem \& Crossman, 1988; Catania, 1963). The same may be true when punishment magnitude is manipulated across phases by raising the shock intensity. It should be noted, however, that a cursory glance at the punishment literature reveals a few cases in which raising the shock intensity across phases affected responding (e.g., Azrin \& Holz, 1961; Hake, Azrin, \& Oxford, 1967; Sizemore \& Maxwell, 1985).

\section{Experiment 2}

Like Experiment 1, Experiment 2 examined the effects of shock intensity on responding when long IRTs produced shock. Experiments 1 and 2 differed, however, in their arrangements of the experimental manipulations. In Experiment 2, the percentile used to establish $t$ was lowered across phases, and shock intensity was raised across the five shock conditions within each phase. Experiment 2 also examined a broader range of intensities than Experiment 1 by including an intensity of $0.8 \mathrm{~mA}$.

As with Experiment 1, the IRT model predicts that shock contingent on long IRTs will punish long IRTs and increase responding. Moreover, this theory predicts an effect of the range of IRTs eligible for shock. Raising the range of IRTs eligible for shock should punish more classes of IRTs and decrease responding. It is unclear whether there will be an effect of shock intensity given that there was no effect of shock intensity in Experiment 1. If the absence of an effect of shock intensity in Experiment 1 was due to too few intensities being used, then there should be an effect of intensity in the present experiment. Lower intensities should punish long IRTs and increase responding. Higher intensities are expected to punish long IRTs as well as other classes of IRTs and decrease responding. Given that there was no interaction between the range of IRTs susceptible to shock and shock intensity in Experiment 1 despite the predictions of the IRT model for that experiment, it is unclear whether an interaction is predicted for Experiment 2.

If the IRT model is incorrect and responses rather than IRTs serve as the functional units of behavior, then shock contingent on long IRTs should decrease, not increase, responding. This response model makes no predictions on the type of IRTs that are punished when shock is contingent on long IRTs. Therefore, there is no reason to expect that long IRTs will be punished more than shorter IRTs. Instead, the IRT distributions should become flatter, rather than more positively skewed. The response model also predicts an effect of the range of IRTs susceptible to 
shock. Specifically, raising the range of IRTs eligible for shock is expected to decrease responding because doing so raises the rate of, or number of responses followed by, shock. An effect of shock intensity is also predicted. Although all shock intensities are expected to decrease responding, high intensities should decrease responding more than low intensities.

As with Experiment 1, in Experiment 2, the two sets of predictions differ in the direction of the effects. According to the IRT model, shock should increase responding, at least at the low intensities. By contrast, according to the response model, shock should decrease responding. According to both accounts, raising the range of IRTs susceptible to shock should exaggerate the effects of shock. If the lack of an effect of shock intensity in Experiment 1 was due to too few intensities being used or habituation, then according to the IRT model, there should be an effect of shock intensity with low intensities increasing responding and high intensities decreasing it. According to the response model, raising the shock intensity should decrease responding further.

\section{Method}

Table 4 shows the number of baseline sessions, the percentiles used to establish $t$, and the values of $t$. Baseline conditions lasted until responding stabilized (13 to 42 sessions), and shock conditions lasted five sessions unless noted otherwise. Shock was administered on an IRT $>t$ schedule. Across phases, the percentile of the baseline IRT distribution used to establish $t$ was lowered from the $80^{\text {th }}$ to the $50^{\text {th }}$ percentile. Within a phase, shock intensity was raised across the shock conditions from $0.05 \mathrm{~mA}$ to $0.8 \mathrm{~mA}$ as shown in the table.

\section{Results}

For Rat JL2, results at the $70^{\text {th }}$ percentile exclude the last shock condition because 0.4-mA shocks suppressed responding below $10 \%$ of the baseline rate, and the $0.8 \mathrm{~mA}$ condition was not conducted. For all other conditions, analyses are based on the 6 stable baseline sessions and all 5 shock sessions.

Table 5 lists the mean reinforcement rates. Across phases, reinforcement rates were similar. Within a phase, at $0.05 \mathrm{~mA}, 0.1 \mathrm{~mA}$, and $0.2 \mathrm{~mA}$, reinforcement rates were within 0.1 reinforcers per minute of the baseline rates and were stable with standard deviations of 0.05 reinforcers per minute or less. When 0.4-mA shock was delivered, reinforcement rates were usually similar to the baseline rates, but in a few cases dropped by nearly $80 \%$. When $0.8-\mathrm{mA}$ shock was delivered, reinforcement rates were often low. In some cases, reinforcement rates fell to near zero. In other cases, rates were nearly $30 \%$ to $60 \%$ below the baseline rates.

Reinforcement rates in the $0.4-\mathrm{mA}$ and $0.8-\mathrm{mA}$ conditions were unstable with standard deviations as high as 0.65 reinforcers per minute. The obtained reinforcement rates were close to the programmed rates of 1.5 reinforcers per minute when shock intensity ranged from $0.05 \mathrm{~mA}$ to $0.4 \mathrm{~mA}$, but were less than half of the programmed rates when $0.8-\mathrm{mA}$ shock was delivered. Given these findings, a loss of reinforcement cannot explain changes in IRT distributions or 
response rates when shock intensity ranged from $0.05 \mathrm{~mA}$ to $0.2 \mathrm{~mA}$ but may explain low response rates in the $0.4-\mathrm{mA}$ and $0.8-\mathrm{mA}$ shock conditions.

The number of shocks are shown in Figure B1 in Appendix B. Table 5 also lists the mean shock rates. Across phases, raising the range of IRTs eligible for shock increased shock rates making it difficult to disentangle the effects of these two variables. Higher shock rates in the later phases indicate that while the IRT distributions may have shifted away from long IRTs, this shift was not great enough to avoid shock. Some long IRTs were still emitted. Within a phase, raising the shock intensity from $0.05 \mathrm{~mA}$ to $0.4 \mathrm{~mA}$ did not affect shock rates. At $0.8 \mathrm{~mA}$, shock rates for all rats except Rat JL13 dropped by approximately 50\%, indicating that responding decreased dramatically at this intensity. Similar findings are shown with the number of shocks in Figure B1 in Appendix B.

In Figure 3, the functions fall below the reference line in all conditions except those involving 0.8-mA shock, indicating that shock contingent on long IRTs punished these IRTs except when shock intensity was $0.8 \mathrm{~mA}$. At this intensity, long IRTs increased in frequency and responding decreased dramatically. Across phases, raising the range of IRTs susceptible to shock had no effect on the IRT distributions. This is indicated by similar deviations between the obtained functions and the reference line across phases. Within a phase, shock ranging from $0.05 \mathrm{~mA}$ to $0.4 \mathrm{~mA}$ punished long IRTs, causing the IRT distributions to shift toward short IRTs. For all rats except JL13, 0.8-mA shock produced the opposite effect. This intensity decreased responding so severely that the few responses that were emitted terminated long IRTs, thereby increased the frequency of long IRTs relative to baseline.

A two-way (Shock Intensity $\times$ Percentile), repeated-measures ANOVA was conducted on the differences between the percentage of responses followed by shock and those indicated by the reference line. Rat JL2 was omitted from the analysis. This analysis showed no effect of the range of IRTs susceptible for shock $(F(4,8)=3.60, p>.05)$ or shock intensity $(F(3,6)=2.47$, $p>$.05). There was not an interaction between shock intensity and the range of IRTs susceptible to shock $(F(12,24)=0.19, p>.05)$. This analysis most likely reports different results than those presented in Figure 3 because the former excludes data for Rat JL2 whereas the latter does not.

Absolute response rates are presented in Figure B3 in Appendix B. Figure 4 shows proportional response rates calculated as described for Figure 2. In general, shock contingent on long IRTs usually facilitated responding except at $0.8 \mathrm{~mA}$. Counting the number of proportions at least one standard deviation above or below the baseline reveals that shock facilitated responding in approximately $58 \%$ of the conditions, had no effect in approximately $25 \%$ of the conditions, and suppressed responding in almost $16 \%$ of the conditions. Across phases, raising the range of IRTs eligible for shock did not affect responding. Within a phase, intensities of $0.4 \mathrm{~mA}$ or less usually facilitated responding whereas $0.8-\mathrm{mA}$ shock suppressed responding in approximately $93 \%$ of the conditions. In many cases, 0.8-mA shock suppressed responding to near zero. Rat JL13 was the exception. For this rat, 0.8-mA shock facilitated responding half of the time. 
A two-way (Percentile $\times$ Shock Intensity), repeated-measures ANOVA was conducted. As noted previously, there were no data for Rat JL2 at the $70^{\text {th }}$ percentile phase during the 0.8-mA condition. Zeroes were entered for this rat in this condition because it was response rates in the previous conditions suggested that low rates such as these would likely have been obtained had the rat been exposed to the condition. Support for this comes from the very low response rates in the preceding shock condition, and early termination of the 0.4-mA condition. The analysis corroborated that there was a main effect of shock intensity on proportional response rates $(F(4,12)=12.02, p<.01)$. Post-hoc comparisons were evaluated with the Least Significance Difference test and alpha was set to .05. The following differences were statistically significant: response rates at $0.8 \mathrm{~mA}$ and $0.05 \mathrm{~mA}, 0.8 \mathrm{~mA}$ and $0.1 \mathrm{~mA}, 0.8 \mathrm{~mA}$ and $0.2 \mathrm{~mA}, 0.8 \mathrm{~mA}$ and $0.4 \mathrm{~mA}$. There was no main effect of the range of IRTs eligible for shock, i.e., the percentile, $(F(3,9)=1.07, p>.05)$. There also was no interaction between the range of IRTs eligible for shock and shock intensity $(F(12,36)=1.78, p>.05)$.

\section{Discussion}

Overall, shock contingent on long IRTs punished long IRTs and increased response rates except when 0.8-mA shock was used. Changes in the IRT distributions were not significant most likely because data from one rat was omitted. Raising the range of IRTs eligible for shock had no effect on the IRT distributions or response rates. There was an effect of shock intensity on response rates. There also appeared to be an effect of shock intensity on IRT distributions, but the statistical analysis showed no significant effect. Shock intensities of $0.4 \mathrm{~mA}$ or less increased response rates. By contrast, 0.8-mA shock decreased response rates dramatically for all rats except one. There was no interaction between the range of IRTs eligible for shock (i.e. the percentile) and shock intensity.

The results are consistent with previous findings in several ways. First, according to the graphical display of the data, there was an effect of the shock schedule on IRT distributions. Shock contingent on long IRTs punished long IRTs except when the shock intensity was high. Similar results were obtained by Arbuckle and Lattal (1992; Experiments 1 and 2) and Sizemore and Maxwell (1985). This finding supports the IRT model because only this model predicted the punishment of long IRTs. Long IRTs were also punished in Experiment 1. Note, however, that Experiment 1 did not include an intensity of $0.8 \mathrm{~mA}$, which may explain why there was an effect of intensity in the present experiment but not in Experiment 1.

Second, there was an effect of the shock schedule on response rates. Shock following long IRTs increased response rates. Similar results were reported by Galbicka and Branch (1981), Arbuckle and Lattal (1992; Experiment 2), and Sizemore and Maxwell (1985) and in Experiment 1. The increased response rates support the IRT model because only this model predicted increased response rates. If the response model was correct, and responses served as the functional units, then shock should have decreased responding. 
Third, according to the graphical displays of the data and assuming the statistical results were influenced by the omission of data for Rat JL2, there was an effect of shock intensities on IRT distributions. Low shock intensities punished long IRTs whereas high intensities punished other IRTs. Similar results were reported by Sizemore and Maxwell (1985) when shock followed long IRTs. This finding supports the idea that raising the shock intensity extended the temporal reach of shock, and punished classes of IRTs shorter than the long IRTs that produced shock.

Fourth, there was an effect of shock intensities on response rates. Low shock intensities increased responding. High intensities decreased responding. In research by Filby (1968), Filby and Appel (1966), Lande (1981), and Sizemore and Maxwell (1985), low shock intensities increased responding. Numerous studies have shown that high shock intensities suppress responding (e.g. Azrin, 1956; 1959; 1960; Azrin \& Holz, 1961; Karsh, 1962; Azrin, Holz, \& Hake, 1963; Holz, Azrin, \& Ulrich, 1963; Boroczi, Storms, \& Broen, 1964; Seligman \& Cambell, 1965; Boe, 1966) even when shock follows long IRTs differentially (e.g., Appel, 1968; Arbuckle \& Lattal, 1992; Filby \& Appel, 1966; Sizemore \& Maxwell, 1985).

It is possible that the effect of shock intensity on response rates is due to shock-elicited behavior. Previous research has shown that shock elicits behavior that can increase or decrease response rates (Azrin, 1959; Galbicka \& Platt, 1984; Sizemore \& Maxwell, 1985). When shock intensity is low, shock may elicit aggression directed toward the operandum which is measured as an increase in response rates. By contrast, when shock intensity is high, shock may elicit freezing, escape attempts, or other behavior that is incompatible with the operant response (Azrin, 1959; Galbicka \& Platt, 1984).

Fifth, for most rats, high intensities decreased responding to near zero. Severe suppression at high intensities is common. For example, in Appel's (1968) research, 0.8-mA shock administered to rats eliminated responding for all groups of rats except those exposed to an FI-120s schedule of shock. In Filby and Appel's (1966) work, 0.8-mA shock decreased responding below 0.2 responses per minute for all rats, regardless of the schedule of reinforcement or shock.

Sixth, there was no interaction between the range of IRTs susceptible to shock (i.e. the percentile) and shock intensity. Similar findings were reported in Experiment 1.

The results of the present experiment are inconsistent with previous findings in that there was no effect of the range of IRTs susceptible to shock. This is inconsistent with the results of Experiment 1, as well as those of Galbicka and Branch (1981). The lack of an effect for the range of IRTs susceptible shock may be due to habituation to the shock across phases. As noted previously, with habituation, an animal's responsiveness to shock decreases as exposure to the shock increases. Shock then loses its effectiveness over time. A similar possibility was discussed in Experiment 1 regarding shock intensity. Because each phase consisted of 25 shock sessions, the cumulative number of shocks increased dramatically across phases. (Rat JL2 was the exception, with less than 20 shock sessions in the $70^{\text {th }}$ percentile phase.) Therefore, habituation was confounded with raises in the range of IRTs susceptible to shock. Habituation is 
less of a concern within phases because the cumulative number of shocks did not increase as dramatically within phases as it did across phases.

Different results from Experiments 1 and 2 with regard to effects of the range of IRTs susceptible to shock also may stem from differences in the number of times the range of IRTs susceptible to shock was raised or the initial percentiles used for $t$. In Experiment 2, the range of IRTs susceptible to shock was raised four times, as opposed to five in Experiment 1. Moreover, in Experiment 2, the $80^{\text {th }}$ percentile, as opposed to the $90^{\text {th }}$, was used as the initial value of $t$. In Experiment 1, the greatest changes in IRT distributions and response rates occurred when the range of IRTs eligible for shock was raised (i.e. the percentile used for $t$ was lowered from the 90th to the 80th). Subsequent manipulations may produce less dramatic differences. By excluding the $90^{\text {th }}$ percentile as a value of $t$, Experiment 2 may have missed dramatic changes in IRT distributions and response rates, resulting in no effect of the range of IRTs susceptible to shock.

Finally, the lack of an effect of the range of IRTs susceptible to shock may be due to the fact that this variable was manipulated across phases and no-shock baselines separated each shock phase. As was noted in the discussion of Experiment 1, these baselines serve as vacations from punishment, which make responding resistant to punishment when they occur repeatedly (Orme-Johnson, 1967).

\section{Experiment 3}

Experiment 3 examined the effects of shock intensity on responding when short IRTs produced shock. As in Experiment 1, shock intensity was raised across phases. Within each phase, the percentile used to establish $t$ was raised across the five shock conditions, increasing the portion of the IRT distribution that was susceptible to the shock contingency.

According to both the IRT model, which emphasizes IRTs as the functional units of behavior, and the response model, which emphasizes responses as the functional units of behavior, shock delivered contingent on short IRTs should decrease responding. The models differ in their explanations of these decreases. According to the IRT model, responding will decrease because short IRTs will be punished. The IRT distributions should shift toward long IRTs, becoming more negatively skewed. According to the response model, responding will decrease because responses per se will be punished.

According to both models, there should be an effect of shock intensity in which high shock intensities decrease responding more than low shock intensities. Furthermore, raising the portion of the IRT distribution susceptible to shock should decrease responding further. According to the IRT model, raising the portion of the IRT distribution susceptible to shock should punish shorter classes of IRTs, shifting the IRT distributions toward long IRTs and decreasing responding. According to the response model, raising the portion of the IRT distribution susceptible to shock will decrease responding further by increasing the number of responses that are punished (i.e., increasing the rate of shock). 


\section{Method}

Table 6 lists the number of baseline sessions, shock intensities, and values of $t$ for the four phases. Baseline conditions lasted until responding stabilized (13 to 44 sessions), and shock conditions lasted five sessions. Shock was administered according to an IRT $<t$ schedule. Across phases, shock intensity was raised from $0.05 \mathrm{~mA}$ to $0.4 \mathrm{~mA}$. Within a phase, the percentiles used to establish $t$ were raised across conditions, increasing the range of IRTs eligible for shock.

Results

Table 7 lists the mean reinforcement rates. Across phases, reinforcement rates were similar. Within a phase, reinforcement rates in the baseline and shock conditions were similar, with rates in the shock conditions no more than $15 \%$ below the baseline rates. Reinforcement rates were stable within a phase, with standard deviations of 0.06 reinforcers per minute or less in all conditions except one. In most cases, the obtained reinforcement rates were close to the programmed rates. The exception was Rat JL17, for whom the obtained reinforcement rates in the last two phases were $70 \%$ to $85 \%$ less than the programmed rate. Interestingly, this effect aemerged in the baseline condition from the third phase and was not a carryover from the last shock condition in the second phase. The similarity of the obtained and programmed reinforcement rates in the shock conditions indicates that changes in the IRT distributions and response rates cannot be attributed to a loss of reinforcement in these conditions. Rather, such changes must be attributed to the shock contingency.

The number of shocks is shown in Figure C1 in Appendix C. Table 7 lists the mean shock rates. Across phases, raising the shock intensity had no effect on shock rates. This indicates that IRT distributions were similar across phases. Within a phase, raising the range of IRTs susceptible to shock increased shock rates. Shock rates were three to four times higher at the $50^{\text {th }}$ percentile than at the $10^{\text {th }}$ percentile. Similar findings are shown with the number of shocks in Figure C1 in Appendix C. It is possible that any within-phase changes in the IRT distributions or response rates were due, not to raising the range of IRTs susceptible to shock, but to higher shock rates. This seems unlikely however, given in Experiment 1, shock rates also increased within phases but with an opposite effect on rates: an increase. The findings of Experiments 1 and 3 combined suggest that high shock rates alone do not increase or decrease responding. Rather, the schedule of shock largely determine whether shock increases or decreases response rates.

Figure 5 indicates shifts in the IRT distributions by showing the percentage of responses followed by shock. (Box-and-whisker plots of the IRT distributions are presented in Figure C2 in Appendix C.) The reference line in each panel indicates the percentage of responses that would have been followed by shock if the IRT distribution in the shock conditions matched the baseline distributions. Functions above the reference line indicate that shock punished long IRTs, and the IRT distributions shifted toward short IRTs. Functions below the reference line 
indicate shock punished short IRTs, and the IRT distributions shifted toward long IRTs. The greater the deviation between the functions and the reference line, the greater the shift in the IRT distributions.

In Figure 5, for most rats, the functions usually fell below the reference line indicating that shock contingent on short IRTs punished short IRTs. Across phases, raising the shock intensity had no effect on the IRT distributions. Within a phase, in about half of the cases, raising the range of IRTs susceptible to shock caused the IRT distributions to shift further toward long IRTs, indicating that shock punished IRTs longer than those followed by shock. This effect is best seen in the results of JL17. Here, in all of the phases, the differences between the obtained functions and the reference line are greater at the $40^{\text {th }}$ and $50^{\text {th }}$ percentiles, when large portions of the IRT distributions were susceptible to shock, than at the $10^{\text {th }}$ and $20^{\text {th }}$ percentiles, when smaller portions of the IRT distributions were susceptible to shock.

A two-way (Shock Intensity $\times$ Percentile), repeated-measures ANOVA corroborated that there was a main effect of range of IRTs susceptible to shock, i.e., the percentile, on IRT distributions $(F(4,12)=17.48, p<.01)$. Post-hoc comparisons were evaluated with the Least Significance Difference test and alpha was set to .05. The following differences were statistically significant: IRT distributions at the $40^{\text {th }}$ and $10^{\text {th }}$ percentile, the $40^{\text {th }}$ and $20^{\text {th }}$ percentile, the $50^{\text {th }}$ and $10^{\text {th }}$ percentile, the $50^{\text {th }}$ and $20^{\text {th }}$ percentile, the $50^{\text {th }}$ and $30^{\text {th }}$ percentile, and the $50^{\text {th }}$ and $40^{\text {th }}$ percentile. There was not a significant main effect of shock intensity $(F(3,9)=0.87, p>.05)$, or an interaction between shock intensity and the range of IRTs susceptible to shock $(F(12,36)=0.62, p>.05)$.

Absolute response rates are presented in Figure C3 in Appendix C. Figure 6 shows proportional response rates calculated as described for Figure 2. In general, shock contingent on short IRTs did not always have an effect on responding, but when it did, it usually decreased responding. Counting the number of proportions at least one standard deviation above or below baseline levels reveals that shock had no effect in $45 \%$ of the conditions, decreased responding in $36 \%$ of the conditions, and increased responding in 19\% of the conditions. Across phases, raising the shock intensity had no effect on responding. It should be noted, however, that in the few conditions where shock increased responding, shock intensity was low. Within a phase, raising the portion of the IRT distribution susceptible to shock decreased responding. This is evidenced by lower response rates at the $40^{\text {th }}$ and $50^{\text {th }}$ percentiles than at the $10^{\text {th }}$ and $20^{\text {th }}$ percentiles. There was no interaction between the shock intensity and the range of IRTs susceptible to shock (i.e., the percentile).

A two-way (Shock Intensity $\times$ Percentile), repeated-measures ANOVA corroborated that there was a main effect of the range of IRTs susceptible to shock, i.e., percentile $(F(4,12)=6.19$, $p<.01)$. Post-hoc comparisons were evaluated with the Least Significance Difference test and alpha was set to .05. The following differences were statistically significant: response rates at the $50^{\text {th }}$ and $10^{\text {th }}$ percentile, the $50^{\text {th }}$ and $20^{\text {th }}$ percentile, and the $50^{\text {th }}$ and $40^{\text {th }}$ percentile. There was not a main effect of shock intensity $(F(3,9)=1.01, p>.05)$, or an interaction between shock intensity and range of IRTs susceptible to shock $(F(12,36)=1.29, p>.05)$. 


\section{Discussion}

Shock contingent on short IRTs tended to punish short IRTs. In half of the conditions, the punishment of short IRTs resulted in decreased response rates. There was no effect of shock intensity on IRT distributions or response rates. There was an effect of the range of IRTs susceptible to shock. Raising the range of IRTs susceptible to shock punished short IRTs further and decreased response rates. There was no interaction between shock intensity and the range of IRTs susceptible to shock.

The fact that raising the range of IRTs susceptible to shock punished short IRTs further supports the IRT model. Recall that predictions based on this model included shifts in the IRT distributions away from short IRTs. By contrast, predictions based on the response model made no clear predictions regarding the IRT distributions. One might argue that shifts away from short IRTs and toward long IRTs are consistent with the decreased response rates predicted, however, previous research indicates that when shock is delivered independently of IRT durations, the IRT distributions do not shift toward long IRTs but become flattened (Galbicka \& Branch, 1981).

Results from Experiment 3 are consistent with previous research in a few ways. First, shock contingent on short IRTs punished these IRTs. Although very few studies have investigated the effects of shock following short IRTs, the few that have also reported punishment of short IRTs (Arbuckle \& Lattal, 1987; 1992, Experiment 2).

Second, in some conditions, shock decreased response rates. Decreased response rates is the most commonly reported effect of response-dependent shock (e.g. Azrin, 1956; 1959; 1960; Azrin \& Holz, 1961; Azrin, Holz, \& Hake,1963; Azrin \& Oxford, 1967; Boe, 1966; 1971; Boroczi, Storms, \& Broen, 1964; Camp, Raymond \& Church, 1966; 1967; Church, Raymond, \& Beauchamp, 1967; Hake, Azrin, \& Oxford, 1967; Holz, 1968; Holz, Azrin, \& Ulrich, 1963; Karsh, 1962; Seligman \& Cambell, 1965).

Third, in Experiment 3, as the portion of the IRT distribution susceptible to shock was raised, shock punished IRTs other than those followed by shock. A similar effect was reported in Experiment 1 and by Galbicka and Branch (1981), although in both of these studies, shock was contingent on long IRTs. Therefore, the current findings extend previous research by demonstrating that the portion of the IRT distribution susceptible to shock is an important determinant of IRT distributions regardless of whether shock is contingent on short or long IRTs.

Finally, there was an effect of the portion of the IRT distribution susceptible to shock on response rates. Experiment 1 and Galbicka and Branch (1981) also reported an effect of this variable, although in these experiments, response rates increased instead of decreased, most likely because shock was contingent on long as opposed to short IRTs.

The present findings differed from previous findings in that shock sometimes had no effect or increased responding, and there was no effect of shock intensity on IRT distributions or response rates. It seems odd that shock continent on short IRTs occasionally increased responding. Although it should be noted comparisons of Figure 6 and Figure C3 reveals that in almost $50 \%$ of the conditions where shock increased responding, the baseline response rates 
were fairly low, i.e., below 30 responses per minutes and did not recover to their pre-shock levels. This can be seen in the $0.1 \mathrm{~mA}$ phase for Rat JL1 and Rat JL15. When absolute response rates are low, small increases or decreases translate into large differences in relative rates. This phenomenon may help to explain why shock contingent on short IRTs occasionally increased responding. Increased responding at low intensities may also be attributed to shock-elicited behavior, as described previously for Experiment 2.

The absence of an effect of shock intensity on IRT distributions or response rates is inconsistent with previous findings. In previous research, the effects of shock intensity are robust with high shock intensities suppressing responding greatly regardless of whether low shock intensities increased responding, as in the experiment of Filby and Appel (1968), or decreased responding, as was reported by Hake, Azrin, and Oxford (1967) among others (e.g., Appel \& Peterson, 1965; Azrin 1959; Azrin \& Holz, 1961; Azrin, Holz, \& Hake, 1963; Boroczi, Storms, \& Broen, 1964; Hake, Azrin, \& Oxford, 1967; Sizemore \& Maxwell, 1985). The lack of an effect of shock on responding may stem from low baseline response rates. When baseline response rates are high, there is more room for these rates to drop without decreasing the rate of reinforcement. By contrast, when baseline response rates are low, there is limited room for response rates to drop without facing the countervailing factors of reinforcement.

The lack of an effect of shock intensity may also reflect habituation to shock across phases. Recall that there was not an effect of shock intensity in Experiment 1, where intensity was manipulated across phases, but there was an effect of intensity in Experiment 2, when intensity was manipulated within phases. Another explanation is that too few shock intensities were used to produce reliable differences in IRT distributions or response rates.

\section{Experiment 4}

Like Experiment 3, Experiment 4 examined the effects of shock intensity when short IRTs produce shock. Experiments 3 and 4 differed in their arrangements of the experimental manipulations. In Experiment 4, the percentile used to establish $t$ was raised across phases. Shock intensity was raised across the five shock conditions within each phase. Experiment 4 also expanded on the range of shock intensities used by including 0.8-mA shock.

As in Experiment 3, according to both the IRT model and the response model, shock contingent on short IRTs should decrease responding. The IRT model explains this decrease through the punishment of short IRTs whereas the response model explains it through the punishment of responses. If the IRT model is correct, raising the range of IRTs susceptible to shock should shift IRT distributions toward long IRTs and decrease responding. If the response model is correct, raising the range of IRTs susceptible to shock should decrease responding further by raising the number of responses followed by shock. The response model makes no specific predictions about changes in the IRT distributions. Assuming that the lack of an effect of shock intensity in Experiment 3 was due to too few intensities used, then according to the IRT 
model, high shock intensities should decrease responding more than low intensities. The same prediction can be made based on the response model.

\section{Method}

Table 8 shows the number of baseline sessions, percentiles, and values of $t$. During the second baseline, Rat JL7 became injured with a pulled muscle and response rates dropped. Remedial training was conducted by changing the schedule of food delivery to an FR-1. Once responding recovered, food was delivered on a VI 5-s schedule, and the mean interval was raised gradually until the standard VI 40-s schedule was reached. For all rats, baseline conditions lasted until responding stabilized (13 to 56 sessions) and shock conditions lasted 5 sessions (unless otherwise noted). Shock was administered on an IRT $<t$ schedule. Across phases, the percentile used to establish $t$ was raised as shown in the table. Within a phase, shock intensity was raised across conditions as shown in the table.

\section{Results}

Table 9 lists the mean reinforcement rates. Across phases, reinforcement rates were similar, meaning any changes in IRT distributions or responding across phases cannot be attributed to differences in reinforcement. Within a phase, reinforcement rates in the baseline and first four shock conditions were also similar, differing by less than 0.05 reinforcers per minute. In several cases, reinforcement rates were lowest in the fifth shock condition when 0.8-mA shock was used. Reinforcement rates in this condition were almost $10 \%$ less than in previous conditions. Given that reinforcement rates in the $0.8-\mathrm{mA}$ conditions were only $10 \%$ less than those in previous conditions, it is unlikely that a loss of reinforcement alone caused any changes in the IRT distributions or response rates in these conditions. Within a phase, reinforcement rates were stable with standard deviations of 0.07 reinforcers per minute or less in all cases except one. The obtained reinforcement rates were close to the programmed rates. Again, the similarity of obtained and programmed reinforcement rates suggests that any changes in IRT distributions or responses rates are most likely due to the shock contingency and not a loss of reinforcement.

The number of shocks per session is shown in Figure D1 in Appendix D. Table 9 also shows mean shock rates. Across phases, raising the range of IRTs susceptible to shock had no effect on shock rates. Recall that the portion of the IRTs susceptible to shock was based on the IRT distributions from the baseline condition of each phase. If the baseline IRT distributions were similar across phases, the shock rates would have increased across phases as the portion of the IRT distribution susceptible to shock was raised. Therefore, the similarity in shock rates across phases indicates that the baseline IRT distributions differed across phases. Specifically, across phases, the baseline IRT distributions away from short IRTs and response rates decreased. Within phases, shock rates decreased as the intensity was raised, indicating that short IRTs were 
punished. These shifts in the IRT distributions within phases were dramatic enough to reduce the shock rate and suggest that response rates also decreased within phases. Similar findings are shown with the number of shocks per session in Figure D1 in Appendix D.

Figure 7 indicates shifts in the IRT distributions by showing the percentage of responses followed by shock. (Box-and-whisker plots of the IRT distributions are presented in Figure D2 in Appendix D.) The reference line in each panel indicates the percentage of responses that would have been followed by shock if the IRT distribution in the shock conditions matched the baseline distributions. Functions above the reference line indicate that shock punished long IRTs, and the IRT distributions shifted toward short IRTs. Functions below the reference line indicate shock punished short IRTs, and the IRT distributions shifted toward long IRTs. The greater the deviation between the functions and the reference line, the greater the shift in the IRT distributions. As with Figure 3, the reference lines increased across phases because the range of IRTs eligible for shock was raised across phases. The relevant feature, therefore, is not the raising of the obtained functions across phases but the deviations between these functions and the reference lines.

In Figure 7, the functions usually fell below the reference line indicating that shock contingent on short IRTs punished these IRTs. Across phases, raising the range of IRTs susceptible to shock shifted the IRT distributions away from short IRTs and toward long ones. This is indicated by slightly greater deviations of the functions from the reference line across phases, and is especially clear in the results of JL18. Within phases, raising the shock intensity punished IRTs other than those short IRTs followed by shock. This is evident by the greater differences between the functions and the reference line at high intensities than at low ones. At $0.8 \mathrm{~mA}$, for all rats except JL12, very few responses were followed by shock. This indicates that the IRT distributions shifted away from short IRTs so much that the rats were able to avoid shock by responding slowly.

A two-way (Percentile $\times$ Shock Intensity), repeated-measures ANOVA corroborated that there was a main effect of the range of IRTs susceptible to shock, i.e., the percentile, on IRT distributions $(F(3,9)=31.20, p<.01)$. Post-hoc comparisons were evaluated with the Least Significance Difference test, alpha was set to .05, and all differences were statistically significant. There was a main effect of intensity $(F(4,12)=48.34, p<.01)$. Post-hoc comparisons revealed that all of the differences involving $0.2 \mathrm{~mA}, 0.4 \mathrm{~mA}$, or $0.8 \mathrm{~mA}$ were statistically significant. There was a significant interaction between the range of IRTs susceptible to shock and shock intensity $(F(12,36)=4.03, p<.01)$. The effects of shock intensity became greater as the range of IRTs susceptible to shock increased.

Absolute response rates are presented in Figure D3 in Appendix D. Figure 8 shows proportional response rates calculated as described for Figure 2. In general, shock contingent on short IRTs usually suppressed responding. The exception was Rat JL12, for whom response rates in the shock conditions were often similar to baseline response rates. Counting the number of proportions at least one standard deviation above or below the baseline reveals that shock suppressed responding in 59\% of the conditions, had no effect in $40 \%$ of the conditions, and 
facilitated responding in only $1 \%$ of the conditions. Across phases, response rates were similar indicating there was no effect of the range of IRTs susceptible to shock. Within a phase, high shock intensities suppressed responding more than low shock intensities. At $0.05 \mathrm{~mA}$, response rates were usually $10 \%$ to $20 \%$ lower than baseline levels whereas at $0.8 \mathrm{~mA}$, response rates were often $40 \%$ to $60 \%$ lower than baseline levels.

A two-way (Percentile $\times$ Shock Intensity), repeated-measures ANOVA corroborated that there was a main effect of shock intensity on response rates $(F(4,12)=60.83, p<.01)$. Post-hoc comparisons were evaluated with the Least Significance Difference test and alpha was set to 05 . All of the differences involving $0.4 \mathrm{~mA}$ or $0.8 \mathrm{~mA}$ were statistically significant as was the difference between $0.1 \mathrm{~mA}$ and $0.2 \mathrm{~mA}$. There was not a main effect of the range of IRTs susceptible to shock $(F(3,9)=0.65, p>.05)$ nor an interaction between shock intensity and the range of IRTs susceptible to shock $(F(12,36)=1.83, p>.05)$.

\section{Discussion}

Overall, in most cases, shock contingent on short IRTs punished short IRTs and decreased responding. The range of IRTs susceptible to shock had an effect on the IRT distributions but not on response rates. Raising the range of IRTs susceptible to shock punished IRTs short IRTs further. There was an effect of shock intensity on both IRT distributions and response rates. In general, high shock intensities punished short IRTs more than low intensities. High shock intensities also decreased response rates more than low shock intensities. These effects were consistent within and across rats.

These findings are consistent with previous research in several respects. First, shock contingent on short IRTs punished these IRTs. These findings are consistent with those of Experiment 3, as well as those reported by Arbuckle and Lattal (1987; 1992, Experiment 2). Second, shock contingent on short IRTs often decreased responding. As noted previously, the ability of shock to decrease responding is a common finding in the literature. This is true when shock is delivered independently of IRTs (e.g., Azrin, 1956; 1959; 1960; Azrin \& Holz, 1961; Azrin, Holz, \& Hake,1963; Azrin \& Oxford, 1967; Boe, 1966; 1971; Boroczi, Storms, \& Broen, 1964; Camp, Raymond \& Church, 1966; 1967; Church, Raymond, \& Beauchamp, 1967; Hake, Azrin, \& Oxford, 1967; Holz, 1968; Holz, Azrin, \& Ulrich, 1963; Karsh, 1962; Seligman \& Cambell, 1965) and when shock is contingent on short IRTs (Arbuckle \& Lattal, 1987; 1992, Experiment 2). Third, there was an effect of shock intensity on response rates. High shock intensities decreased response rates more than low shock intensities. Similar findings have been reported by Filby and Appel (1968) and Hake, Azrin, and Oxford (1967) among others (e.g., Appel \& Peterson, 1965; Azrin 1959; Azrin \& Holz, 1961; Azrin, Holz, \& Hake, 1963; Boroczi, Storms, \& Broen, 1964; Hake, Azrin, \& Oxford, 1967; Sizemore \& Maxwell, 1985). Finally, consistent with the findings of Experiments 1, 2, and 3, there was no interaction between the shock intensity and the range of IRTs susceptible to shock on response rates. 
The findings of the present study are inconsistent with previous research in two ways: the range of IRTs susceptible to shock affected the IRT distributions but not response rates and high intensities did not eliminate responding. In Arbuckle and Lattal's (1992) research, shock contingent on short IRTs affected IRT distributions without producing consistent concomitant changes in response rates. In their study, however, the range of IRTs susceptible to shock was not raised. In the present experiment, the lack of an effect of the range of IRTs susceptible to shock is inconsistent with previous research by Galbicka and Branch (1981) and Sizemore and Maxwell (1985) in which these manipulations produced graded effects in response rates. The lack of an effect of the range of IRTs susceptible to shock is also inconsistent with the results of Experiments 1 and 3 and may be due to habituation across phases or an insufficient number of raises in the range of IRTs susceptible to shock. Regardless, it is interesting that in all four experiments, there was no effect for the variable manipulated across phases. However, when the same variable was manipulated within phases, there was an effect. This probably reflects a complication of the design in which within-phase manipulations included 5 levels of the independent variable whereas across-phase manipulations included only 4 levels of the independent variable.

In the present experiment, responding was maintained when 0.8-mA shock was delivered. This finding is inconsistent with the previous findings of Appel (1968), Filby and Appel (1966), Boroczi, Storms, and Broen (1964) and Dworkin, Bimle, and Miyauchi (1989), as well as those reported for Experiment 2. These differences may be due to differences in the shock schedule as it relates to elicited behavior. For example, in Experiment 2 and Filby and Appel (1966), shock followed long IRTs differentially whereas in the present experiment shock followed short IRTs. High-intensity shock has been reported to elicit responses incompatible with lever pressing (or key pecking), such as freezing (e.g. Azrin 1956; Galbicka \& Platt, 1954). Suppose such responses were elicited by the 0.8-mA shock in Experiments 2 and 4. In Experiment 2, if 0.8-mA shock elicited freezing, the freezing increased the duration of the next IRT, which in turn increased the probability that the IRT will be eligible for shock under the IRT $>t$ shock schedule. Hence, in Experiment 2, once a long IRT was followed by 0.8-mA shock, the shock may have elicited freezing, which increased the probability that another shock would be delivered. The cycle then continues, making it likely that responding will produce shock. This might explain the near zero levels of responding produced by 0.8-mA shock in Experiment 2.

By contrast, in Experiment 4, if 0.8-mA shock elicited freezing, the freezing would increase the probability that the next IRT would be long. However, unlike in Experiment 2, in Experiment 4, shock was delivered on an IRT $<t$ schedule. Long IRTs were not eligible for shock. If 0.8-mA shock elicited freezing, thereby resulting in a long IRT, then this long IRT would not produce another shock, i.e., would not be punished. Low rates of responding were not punished, moreover, they still produced food reinforcement. (Ceasing to respond altogether would forfeit the food reinforcement.) Experiment 4, high response rates were punished by shock but low response rates were not punished. Therefore, although responding in both experiments may be influenced by incompatible responses elicited by $0.8-\mathrm{mA}$ shock, in Experiment 2, the 
elicited responses produce additional shocks whereas in Experiment 4, they produced fewer shocks.

\section{General Discussion}

\section{Summary and Comparison of Findings}

The current study examined the paradoxical effects of shock by manipulating two variables: shock intensity and the IRTs that produce shock. In all experiments, there was an effect of the shock schedule, or type of IRT that produced shock, on IRT distributions and response rates. Shock contingent on long IRTs punished long IRTs and increased response rates. Shock contingent on short IRTs punished short IRTs and decreased response rates, although the effects on response rates were less robust in one of the experiments (Experiment 3).

In Experiments 2 and 4, there was an effect of shock intensity on IRT distributions and response rates. In Experiment 2, in which shock was contingent on long IRTs, low intensities punished long IRTs and increased responding whereas very high intensities punished a variety of IRTs and decreased responding. In Experiment 4, in which shock was contingent on short IRTs, shock punished short IRTs and decreased responding, with high intensities producing greater effects than low ones. Whether shock intensity had an effect depended on the arrangement of the experimental manipulations. There was an effect of shock intensity in Experiments 2 and 4 which involved raising the shock intensity within phases from $0.05 \mathrm{~mA}$ to $0.8 \mathrm{~mA}$. Shock intensity did not have an effect, however, in Experiments 1 and 3 which involved raising the intensity across phases from $0.05 \mathrm{~mA}$ to $0.4 \mathrm{~mA}$.

A similar pattern occurred with the range of IRTs susceptible to shock. In Experiments 1 and 3, there was an effect of the range of IRTs that susceptible to shock on IRT distributions and response rates. In Experiment 4, raising the range of IRTs susceptible to shock affected the IRT distributions but not response rates. In Experiment 3, there was no effect of the range of IRTs susceptible to shock on either IRT distributions or response rates. Experiments 1 and 3, which involved raising the range within phases from $10 \%$ to $50 \%$ (i.e., lowering the percentile from 90 to 50 or raising it from 10 to 50) reported an effect. Experiments 2 and 4 that involved raising the range of IRTs susceptible to shock across phases from $20 \%$ to $50 \%$ (i.e. lowering the percentile from 80 to 50 or raising it from 20 to 50) did not report an effect or reported an effect on IRT distributions but not response rates.

In each experiment except Experiment 4, there was no interaction between the shock intensity and the range of IRTs susceptible to shock on IRT distributions or response rates. The exception was Experiment 4, in which there was an interaction between these two variables on IRT distributions. Comparison of the results of Experiments 2 and 4, indicates that when the shock intensity is very high, i.e., $0.8 \mathrm{~mA}$, whether shock simply decreases or completely eliminates shock may depend on the shock schedule. When long IRTs produced 0.8-mA shock, responding was eliminated. By contrast, when short IRTs produced 0.8-mA shock, responding 
decreased but was not eliminated. This suggests that there is an interaction between shock intensity and the shock schedule. Other evidence for an interaction between shock intensity and the schedule of shock comes from the fact that shock increased responding in Experiments 1 and 2, in which shock was contingent on long IRTs, but not in Experiments 3 and 4, in which shock was contingent on short IRTs.

Because the shock schedule was manipulated across experiments rather than within experiments, the effects of the shock schedule and any interactions involving the shock schedule cannot be seen in the figures of the individual experiments. Figure 9 allows comparisons between the effects of the two shock schedules by displaying proportional response rates from all four experiments according to each experimental arrangement. Details regarding the calculation of the proportional response rates are as described previously for Figure 2. The first and third sets of panels show data from Experiments 1 and 2, in which shock was contingent on long IRTs. Closed data points represent data from Experiment 1. Open data points represent data from Experiment 2. The second and fourth sets of panels show data from Experiments 3 and 4 in which shock contingent on short IRTs. Closed data points represent data from Experiment 3. Open data points represent data from Experiment 4. The sets of panels differ in their construction. The construction of first two sets of panels represents the experimental arrangements of Experiments 1 and 3. In these experiments, shock intensity was raised across phases and the range of IRTs susceptible to shock was raised within a phase. The construction of the second two sets of panels represents the experimental arrangements of Experiments 2 and 4 in which the range of IRTs susceptible to shock was raised across phases and shock intensity was raised within a phase. Only rats in Experiment 1 were exposed to the $90^{\text {th }}$ percentile condition, and only rats in Experiment 3 were exposed to the $10^{\text {th }}$ percentile condition. Only rats in Experiments 2 and 4 were exposed to the $0.8-\mathrm{mA}$ shock condition.

Comparing the first two sets of panels with each other, and the second two panel sets with each other reveals that there was an effect of the shock schedule. As shown in the first and third panel sets, shock contingent on long IRTs tended to facilitate responding, except when the intensity was $0.8 \mathrm{~mA}$. By contrast, the second and fourth panel sets show that shock contingent on short IRTs usually suppressed responding. (Data from Rat JL15 seem to be the exceptions.) The effects of the shock schedule were dependent on shock intensity. Low intensities increased or decreased responding, depending on whether shock followed long or short IRTs, respectively. High intensities decreased responding. Even at the high intensities, however, the amount of suppression depended on the schedule, with 0.8-mA eliminating responding when shock was contingent on long IRTs but not when it was contingent on short IRTs.

\section{Extension of Previous Research}

The present results extend previous findings by helping to establish that IRTs can serve as functional units of behavior when the behavioral consequence is a punisher and clarifying the role of shock intensity in punishment procedures. 
Interresponse times as functional units of behavior. The current study supports the idea that IRTs can serve as functional units of behavior when the behavioral consequence is a punisher. The greatest evidence of this comes from the effects of the shock schedule on response rates. Recall that according to the IRT model, which emphasized IRTs as functional units, shock contingent on long IRTs should increase responding whereas shock contingent on short IRTs should decrease it. By contrast, according to the response model, shock should decrease responding regardless of the type of IRTs that produced shock. Results from the present experiments support the IRT model. Additional support for the IRT model comes from the effects of the shock schedule on IRT distributions. According to the IRT model, shock contingent on IRTs should shift the IRT distributions away from the IRTs followed by shock. By contrast, according to the response model, no predictions about IRTs can be made. Although it may seem that anytime responding decreases, the IRT distributions necessarily shift toward long IRTs, when shock is delivered independently of IRT duration, the IRT distributions do not shift toward long IRTs. Rather, the distributions become flatter with lower peaks and broader ranges (Galbicka \& Branch, 1981; Lande, 1981) The results of the present experiments indicated shifts in the IRT distributions away from the IRTs that produced shock, thereby supporting the IRT model.

It may not be surprising that IRTs serve as functional units of behavior when IRT durations are specified by the punishment contingency. The issue that remains is whether IRTs serve as functional units under other punishment contingencies. Some evidence suggests that they might. For example, consider the typical study involving response-dependent shock. First, a baseline is established using a schedule of reinforcement. On most schedules of reinforcement, the majority of IRTs are short (Anger, 1956; Arbuckle \& Lattal, 1992, Experiment 1; Blough, 1963; Blough \& Blough, 1968; Doughty \& Richards, 2002; Galbicka \& Branch, 1981, Holz \& Azrin, 1963; Peele, Casey, \& Silberberg, 1984; Shimp, 1968; Shimp, 1969; Shull, Gaynor \& Grimes, 2001; Sizemore \& Maxwell, 1985). Given that the majority of IRTs generated by a schedule of reinforcement are short, it is most likely that punishers delivered without respect to IRTs will follow short IRTs. For this reason, shock delivered independently of IRTs may decrease response rates because it punishes short IRTs.

Galbicka and Branch (1981) compared the effects of shock contingent on long IRTs with those of shock delivered independently. In their experiment, shock delivered independently of IRTs punished short IRTs, causing the IRT distributions to become more dispersed and shift toward longer IRTs. In Arbuckle and Lattal's (1992; Experiment 2) research, shock was also delivered independently of IRTs in some conditions. Their analysis, however, does not provide comparisons between the IRT distributions in the baseline conditions and shock conditions. Therefore, in their experiment, it is unclear whether shock delivered independently of IRTs punished short IRTs.

By demonstrating that IRTs and not responses serve as functional units of behavior, some of the criticisms of punishment are shown to be false. Among these criticisms are the following: punishment sometimes increases behavior (Axelrod, 1990; Azrin \& Holz, 1966; Hutchinson, 
1977; Newsome, Favell, \& Rincover, 1983; Pazulinec, Meyerrose, \& Sajwaj, 1983) and punishment sometimes has no effect (Axelrod, 1990; Azrin \& Holz, 1966; Robinson, Funk, Beth, $\&$ Bush, 2005). Each of these claims shall be addressed in turn.

The claim that punishment sometimes increases behavior is problematic for two reasons. First, punishment by its mere definition cannot increase the behavior it is contingent on. This claim confuses punishment with the procedures typically used to study it. However, to say that response-dependent shock increases behavior is another matter. This leads to the second point. If response-dependent shock increases response rates, it most likely does so because it is punishing long IRTs. Therefore, the seemingly paradoxical effects of shock are not really paradoxical at all because the functional units of behavior are IRTs not responses. The mathematical relation between IRT distributions and response rates demands that the punishment of long IRTs is represented by an increase in response rates.

Another criticism of punishment is that it is sometimes has no effect (Axelrod, 1990; Azrin \& Holz, 1966; Robinson, Funk, Beth, \& Bush, 2005). Again, given the functional definition of punishment, this claim is illogical. Nevertheless, even if we interpret this claim as meaning the procedures that sometimes punish behavior occasionally fail to do so, the statement is still problematic because shock may punish IRTs without producing corresponding changes in responses rates, particularly when short IRTs are punished, as they are on most schedules. Evidence for this comes from Experiment 4 in which there were significant differences in the IRT distributions across phases but not significant differences in response rates.

Shock intensity. Previous research indicates that shock intensity is one of the most powerful determinants of responding with high shock intensities decreasing, if not eliminating, responding regardless of other variables, such as the shock schedule (Azrin, 1959; Azrin, 1960; Azrin \& Holz, 1961; Azrin, Holz, \& Hake, 1963; Boe; 1971; Church, Raymond, \& Beauchamp, 1963; Camp, Raymond \& Church, 1967; Holz, 1968; Holz, Azrin \& Ulrich, 1963; Karsh; 1962). The results of Experiment 4 show that responding can still be maintained when the shock intensity is high, like $0.8 \mathrm{~mA}$. What seems to be important is how the behavior elicited by high shock intensities affects contact with the shock and food schedules. Schedules that deliver shock contingent on short IRTs often arrange avoidance of the shock through low response rates. Responding slowly is better than not responding because the former still produces food reinforcement whereas the latter does not. Hence, it appears that shock intensity does not always trump other factors of responding. Rather, it interacts with them. High shock intensities may eliminate responding when shock is contingent on long IRTs but not when shock is contingent on short IRTs. Given that most IRTs generated by schedules of reinforcement are short (Anger, 1956; Arbuckle \& Lattal, 1992, Experiment 1; Blough, 1963; Blough \& Blough, 1968; Doughty \& Richards, 2002; Galbicka \& Branch, 1981, Holz \& Azrin, 1963; Peele, Casey, \& Silberberg, 1984; Shimp, 1968; Shimp, 1969; Shull, Gaynor \& Grimes, 2001; Sizemore \& Maxwell, 1985), this may explain why punishment sometimes decreases but does not eliminate responding. 


\section{Temporal Reach}

As noted previously, the paradoxical effects of shock may be attributable to changes in the temporal reach of shock at different shock intensities. When shock intensity is low, the temporal reach of shock may extend only to the IRT contiguous with shock. When shock intensity is high, the temporal reach of shock may be larger and affect a longer sequence of IRTs. Experiments 2 and 4 supported this idea by showing greater, and more general effects on IRT distributions, when the shock intensity was raised within phases.

The concept of temporal reach is very similar to that of contiguity, in which consequences delivered immediately are more effective than those delivered after some delay. Contiguity influences the acquisition and maintenance of responding as well as its suppression and elimination (Azrin,1956). In fact, punishment studies involving electric shock provide a unique way of studying contiguity and temporal reach because of the psychophysics of the punisher. Studies on reinforcement magnitude typically involve raising the number of pellets delivered, the duration of access to grain, or the concentration of sucrose. In these cases, the reinforcer delivery is inevitably delayed by virtue of the psychophysical properties of the stimuli used. By contrast, in studies on punishment magnitude, shock intensity is usually manipulated. Here the psychophysical properties of electric shock are such that these stimuli are experienced almost immediately, perhaps making the latter paradigm a more appropriate one for examining contiguity and temporal reach. Of future interest is whether shock intensity affects response rates and IRT distributions when shock delivery is delayed, and whether punisher intensity has an effect under these two arrangements.

\section{Implications for Generalized and Localized Effects of Shock}

Raising the shock intensity may cause the temporal reach of shock to increase and affect various classes of IRTs. In this sense, even when the punishment contingency specifies IRTs of a particular duration, raising the shock intensity may cause the effects of shock become less differential. Rather than being localized to the class of IRTs continuous with shock, shock may affect other classes of IRTs, creating what seems like a more widespread, or generalize, effect of shock.

Although the current study was not designed to assess generalized or localized effects of shock, support for generalized or localized effects of shock could be demonstrated empirically if three conditions are met. First, it must be shown that IRTs could serve as functional units of behavior when shock was the behavioral consequence. Second, it must be shown that delayed shock affects IRTs. If delayed shock cannot affect IRTs, then a sequence of IRTs preceding shock cannot serve as the functional units of behavior. Third, it must be demonstrated that the effects of delayed shock vary according to shock intensity.

Results from the current study, along with those from Arbuckle and Lattal (1992), Galbicka and Branch (1981), and Sizemore and Maxwell (1985) demonstrate that IRTs can serve 
as functional units of behavior when the behavioral consequence is shock. Furthermore, research by Galbicka and Branch (1981) has demonstrated that delayed 1.0 mA shock can still suppress IRTs. In their experiment, shock delivery was postponed from the contingent IRT. Under this arrangement, an IRT that met the shock criterion set up the shock, however, shock was delivered after five additional IRTs. Although suppression of criterion IRTs was greatest when shock delivery was immediate, delayed shock also suppressed criterion IRTs.

What has yet to be demonstrated is whether the effects of delayed shock on IRTs vary as a function of shock intensity. If delayed shock is more effective at suppressing criterion IRTs at high intensities than at low intensities, this would help to establish that the generalized and localized effects of shock may depend on shock intensity, with high intensities producing general effects and low intensities producing localized effects.

\section{Procedural Implications}

A notable feature of the obtained results is the degree to which responding quickly recovered during the no-shock baselines, particularly when high intensities were used. Some of the previous studies on response-dependent shock have cited complete or irreversible suppression, and these effects are sometimes considered disadvantages of studying punishment in a steady-state design. (Appel, 1961; Axelrod, 1990; Azrin, 1959; Azrin, 1960; Azrin \& Holz, 1966; Boe \& Church, 1967; Hake, Azrin, \& Oxford, 1967). Yet, in the current study, response recovery was not a problem.

Several procedural details may be responsible for the response recovery observed. First, while shock intensity was high at times, shock duration was only $100 \mathrm{~ms}$, which is relatively brief when rats are used as subjects. Other commonly used durations include $400 \mathrm{~ms}, 500 \mathrm{~ms}$, or and 1000 ms (Boe, 1966; Boroczi, Storms \& Broen, 1964; Church, Raymond, \& Beauchamp, 1967; Camp, Raymond, \& Church, 1966, 1967; Seligman \& Cambell, 1965). Second, although the shock schedule may have seemed dense, it was relatively lean when compared with many of the previous studies which included shock delivered on an FR-1 schedule (Azrin, 1959; Azrin, 1960; Azrin \& Holz, 1961; Boe, 1966; Holz, Azrin \& Ulrich, 1963; Boroczi, Storms \& Broen, 1964; Karsh, 1962; Seligman \& Cambell, 1965). In the present study, in most cases, less than $50 \%$ of responses were followed by shock, except when $0.8-\mathrm{mA}$ shock was used. Third, extended exposure to shock was limited. In previous research, animals were sometimes exposed to high-intensity shock for several sessions or for several hours within a session (e.g., Azrin, 1956; Azrin \& Holz, 1966). The current study limited session time to $60 \mathrm{~min}$. Imposing a 60 min time limit reduced the likelihood that decreases in responding were due to satiation to food reinforcement rather than to the shock itself. Additionally, condition were terminated early in the few cases where responding was suppressed severely, and the number of sessions at a given shock intensity was limited to five. These procedural details may be worth considering when designing future studies on punishment, particularly those employing a steady-state design. 


\section{Conclusions}

Whether shock increased or decreased response rates depended on the schedule of shock. Shock contingent on long IRTs often increased response rates whereas shock contingent on short IRTs often decreased response rates, with a few exceptions. Whether the shock intensity or the range of IRTs susceptible to shock had an effect depended on the experimental arrangements. The present study demonstrated that IRTs can serve as functional units of behavior when the behavioral consequence is a punisher. This finding indicates that the seemingly paradoxical effects of shock are in fact not paradoxical. The notion that IRTs serve as functional units of behavior also demonstrates that many of the criticisms against punishment are misleading. While the current study was not designed to assess the generalized or localized effects of shock, the results provide an important first step by demonstrating that IRTs can serve as functional units when the behavioral consequence is a punisher such as shock. Moreover, the parameters used in the current study may prove useful in future experiments on punishment and responsedependent shock delivery. 


\section{References}

Anger, D. (1956). The dependence on interresponse times upon the relative reinforcement of different interresponse times. Journal of Experimental Psychology, 52, 145-161.

Appel, J. B. (1961). Punishment in the squirrel monkey: Saimiri sciurea. Science, 133, 36.

Appel, J. B. (1968). Fixed-interval punishment. Journal of the Experimental Analysis of Behavior, 11, 803-808.

Appel, J. B. \& Peterson, N. J. (1965). Punishment: Effects of shock intensity on response suppression. Psychological Reports, 16, 721-730.

Arbuckle, J. L., \& Lattal, K. A. (1987). A role for negative reinforcement of response omission in punishment? Journal of the Experimental Analysis of Behavior, 48, 407-416.

Arbuckle, J. L., \& Lattal, K. A. (1992). Molecular contingencies in schedules of intermittent punishment. Journal of the Experimental Analysis of Behavior, 58, 361-375.

Axelrod, S. A. (1990). Myths that (mis)guide our profession. In A. C. Repp \& N. N. Singh (Eds.), Perspectives on the use of nonaversive and aversive interventions for persons with developmental disabilities (pp. 59-72). Sycamore, IL; Sycamore.

Azrin, N. H. (1956). Effects of two intermittent schedules of immediate and nonimmediate punishment. Journal of Psychology, 42, 3-21.

Azrin, N. H. (1959). Punishment and recovery during fixed-ratio performance. Journal of the Experimental Analysis of Behavior, 2, 161-163.

Azrin, N. H. (1960). Effects of punishment intensity during variable-interval reinforcement. Journal of the Experimental Analysis of Behavior, 3, 123-142.

Azrin, N. H., \& Holz, W. C. (1966). Punishment. In W. K. Honig (Ed.), Operant behavior: Areas of research and application (pp. 380-447). New York: Appleton-Century-Crofts.

Azrin, N. H., Holz, W. C., \& Hake, D. F. (1963). Fixed-ratio punishment. Journal of the Experimental Analysis of Behavior, 6, 141-148.

Baron, A. (1991). Avoidance and Punishment. In I.H. Iverson \& K.A. Lattal (Eds), Experimental analysis of behavior, parts 1 and 2 (pp. 173-217). New York: Elsevier Science.

Barrett, J. E. (1977). Effects of $d$-amphetamine on responding simultaneously maintained and punished by presentation of electric shock. Psychopharmacology, 54, 119-124

Barrett, J. E., \& Glowa, J. R. (1977). Reinforcement and punishment of behavior by the same consequent event. Psychological Reports, 40, 1015-1021.

Blough, D. S. (1963). Interresponse time as a function of continuous variables: A new method and some data. Journal of the Experimental Analysis of Behavior, 6, 237-246.

Blough, P. M. \& Blough, D. S. (1968). The distribution of interresponse times in the pigeon during variable-interval reinforcement. Journal of the Experimental Analysis of Behavior, 11, 23-27.

Boe, E. E. (1966). Effect of punishment duration and intensity on the extinction of an instrumental response. Journal of Experimental Psychology, 72, 125-131. 
Boe, E. E. (1971). Variable punishment. Journal of Comparative and Physiological Psychology, 75, 73-76.

Boe, E. E., \& Church, R. M. (1967). Permanent effects of punishment during extinction. Journal of Comparative and Physiological Psychology, 63, 486-492.

Boroczi, G., Storms, L. H., \& Broen, W. E. (1964). Response suppression and recovery of responding at different deprivation levels as functions of intensity and duration of punishment. Journal of Comparative and Physiological Psychology, 58, 456-459.

Branch, M. N. \& Dworkin, S. I. (1981). Effects of ratio contingencies on responding maintained by schedules of electric-shock presentation (response-produced shock). Journal of the Experimental Analysis of Behavior, 36, 191-205.

Brethower, D. M. \& Reynolds, G. S. (1962). A facilitative effect of punishment on nonpunished behavior. Journal of the Experimental Analysis of Behavior, 5, 191-199

Church, R. M. (1963). The varied effects of punishment on behavior. Psychological Review, 70, 369-402.

Church, R. M., Raymond, G. A., \& Beauchamp, R. D. (1967). Response suppression as a function of intensity and duration of a punishment. Journal of Comparative and Physiological Psychology, 52, 39-44.

Dinsmoor, J. A. (1952). A discrimination based on punishment. Quarterly Journal of Experimental Psychology, 4, 27-45.

Dinsmoor, J. A. (1998). Punishment. In W. T. O’Donohue (Ed.), Learning and behavior therapy (pp. 188-204). Needham Heights: Allyn \& Bacon.

Doughty, A. H. \& Richards, J. B. (2002). Effects of reinforcer magnitude on responding under differential-reinforcement-of-low-rate schedules of rats and pigeons. Journal of the Experimental Analysis of Behavior, 78, 17-30.

Dworkin, S. I., Bimle, C., \& Miyauchi, T. (1989). Differential effect of pentobaritand cocaine on punished and nonpunished responding. Journal of the Experimental Analysis of Behavior, 51, 173-184.

Estes, W. K. (1944). An experimental study of punishment. Psychological Monographs, 57, Whole No. 263.

Filby, Y. \& Appel, J. B. (1966). Variable-interval punishment during variable-interval reinforcement. Journal of the Experimental Analysis of Behavior, 9, 521-527.

Fleshler, M. \& Hoffman, H. S. (1962). A progression for generating variable-interval schedules. Journal of the Experimental Analysis of Behavior, 5, 529-530.

Galbicka, G., \& Branch, M. N. (1981). Selective punishment of interresponse times. Journal of the Experimental Analysis of Behavior, 35, 311-322.

Galbicka, G. \& Platt, J. R. (1984). Interresponse-time punishment: A basis for shock-maintained behavior. Journal of the Experimental Analysis of Behavior, 41, 291-308.

Hake, D. F., Azrin, N. H., \& Oxford, R. (1967). The effects of punishment intensity on squirrel monkeys. Journal of the Experimental Analysis of Behavior, 10, 95-107. 
Hawkes, L., \& Shimp, C. P. (1974). Choice between response rates. Journal of the Experimental Analysis of Behavior, 21, 109-115.

Holz, W. C. (1968). Punishment and rate of positive reinforcement. Journal of the Experimental Analysis of Behavior, 11, 285-292.

Holz, W. C. \& Azrin, N. H. (1963). A comparison of several procedures for eliminating behavior. Journal of the Experimental Analysis of Behavior, 6, 309-406.

Holz, W.C., Azrin, N.H., \& Unrich, R.E. (1963). Punishment of temporally spaced responding. Journal of the Experimental Analysis of Behavior, 6, 115-122.

Hutchinson, R.R. (1977). By-products of aversive control. In W. K. Honig \& J.E.R. Staddon (Eds.), Handbook of operant behavior (pp. 415-431). Englewood Cliffs, NJ; Prentice Hall.

Kirshenbaum, A., Brown, S., Hughes, D., \& Doughty, A. (2008). Differentialreinforcement-of-low-rate-schedule performance and nicotine administration: A systematic investigation of dose, dose-regimen, and schedule requirement. Behavioural Pharmacology, 19(7), 683-697.

Lande, S. D. (1981). An interresponse time analysis of variable-ratio punishment. Journal of the Experimental Analysis of Behavior, 35, 55-67.

Miyauchi, T., Dworkin, S. I., Co, C., \& Smith, J. E. (1988). Specific effects of punishment on biogenetic monoamine turnover in discrete rat brain regions. Brain Research, 454, 40-50.

Morse, W. H., \& Kelleher, R. T. (1977). Determinants of reinforcement and punishment. In W. K. Honig \& J. E. R. Staddon (Eds.) Handbook of operant behavior. Englewood Cliffs, NJ.: Prentice Hall.

Muenzinger, K. F. (1934). Motivation in learning: I. Electric shock for correct response in the visual discrimination habit. Journal of Comparative Psychology, 17, 267-277.

Newsome, C., Favell, J. E., \& Rincover, A. (1983). The side effects of punishment. In S. Axelrod $\&$ J. Apsche (Eds). The effects of punishment on human behavior. (pp. 285-316). New York: Academic Press.

Orme-Johnson, D. (1967). Response suppression as a function of vacation from punishment. Psychonomic Science, 8(7), 277-278.

Pazulinec, R., Meyerrose, M. \& Sajwaj, T. (1983). Punishment via response cost. In S. Axelrod \& J. Apsche (Eds). The effects of punishment on human behavior. (pp. 71-86). New York: Academic Press.

Peele, D. B., Casey, J., \& Silberberg, A. (1984). Primacy of interresponse-time reinforcement in accounting for rate differences under variable-ratio and variable-interval schedules. Journal of Experimental Psychology: Animal Behavior Processes, 10(2), 149-167.

Pitts, R. C., Lewis, M. J., \& Dworkin, S. I. (1992). Effects of ethanol on punished and nonpunished responding under conditions of equated reinforcement rates and similar response rates. Life Sciences, 52, 1-6. 
Reed, P. (1989). Influence of interresponse time reinforcement on signaled-reward effect. Journal of Experimental Psychology: Animal Behavior Processes, 15(3), 224-231.

Reed, P. (2007). Response rate and sensitivity to the molar feedback function relating response and reinforcement rate on VI+ schedules of reinforcement. Journal of Experimental Psychology: Animal Behavior Processes, 33(4), 428-439

Reed, P., Hildebrandt, T., DeJongh, J., \& Soh, M. (2003). Rats performance on variable-interval schedules with a linear feedback loop between response rate and reinforcement rate. Journal of the Experimental Analysis of Behavior, 79(2), 157-173.

Reed, P., Soh, M., Hildebrandt, T., DeJongh, J., \& Shek, W. Y. (2000). Free-operant performance on variable interval schedules with a linear feedback loop: No evidence for molar sensitivities in rats. Journal of Experimental Psychology: Animal Behavior Processes, 26(4), 416-427.

Robinson, D. H., Funk, D. C., Beth, A., \& Bush, A. M. (2005). Changing beliefs about corporal punishment: Increasing knowledge about ineffectiveness to build more consistent moral and informational beliefs. Journal of Behavioral Education, 14, 117-139.

Seligman, M. E. P. \& Campbell, B. A. (1965). Effect of intensity and duration of punishment on extinction of an avoidance response. Journal of Comparative and Physiological Psychology, 59, 295-297.

Shimp, C. P. (1968). Magnitude and frequency of reinforcement and frequencies of interresponse times. Journal of the Experimental Analysis of Behavior, 11, 525-535.

Shimp, C. P. (1969). The concurrent reinforcement of two interesponse times; The relative frequency of an interresponse time equals its relative harmonic length. Journal of the Experimental Analysis of Behavior, 12, 403-411.

Shimp, C. P. (1973). Synthetic variable-interval schedules of reinforcement. Journal of the Experimental Analysis of Behavior, 19, 311-330.

Shimp, C. P. (1974). Time allocation and response rate. Journal of the Experimental Analysis of Behavior, 21, 491-499.

Shimp, C. P., \& Hawkes, L. (1974). Time-allocation, matching, and contrast. Journal of the Experimental Analysis of Behavior, 22, 1-10.

Shull, R.L., Gaynor, S.T., \& Grimes, J.A. (2001). Response rate viewed as engagement bouts: Effects of relative reinforcement and schedule type. Journal of the Experimental Analysis of Behavior, 75, 247-274.

Sizemore, O. J. \& Maxwell, F. R. (1985). Selective punishment of interresponse times: The roles of shock intensity and scheduling. Journal of the Experimental Analysis of Behavior, 44, 355-366. 
Table 1. Summary of procedural details from punishment studies using shock, including the schedule of food presentation, the schedule of shock delivery, shock intensity, shock duration, experimental subjects and effects on response rates. The schedules listed include fixed-ratio (FR), fixed-interval (FI), variable-ratio (VR), variable-interval (VI), random-ratio (RR), random-interval (RI), and extinction (EXT). When no schedule parameter is reported, the parameter was adjusted across subjects. Shock intensity is reported in milliamps $(\mathrm{mA})$ or volts $(\mathrm{V})$.

\begin{tabular}{|c|c|c|c|c|c|c|c|c|}
\hline Authors & $\begin{array}{l}\text { Year of } \\
\text { Publication }\end{array}$ & $\begin{array}{l}\text { Reinforcement } \\
\text { Schedule }\end{array}$ & Shock Schedule & Shock Intensity & Shock Duration & Species & $\begin{array}{l}\text { Increased } \\
\text { Response } \\
\text { Rates } \\
\end{array}$ & $\begin{array}{l}\text { Decreased } \\
\text { Response Rates } \\
\end{array}$ \\
\hline Filby \& Appel & 1966 & $\begin{array}{l}\text { VI 30s, VI 60s, or } \\
\text { VI 180s }\end{array}$ & $\begin{array}{l}\text { VI 30s, VI 60s, } \\
\text { VI 180s }\end{array}$ & $\begin{array}{l}0.2 \mathrm{~mA}, 0.4 \mathrm{~mA} \text {, } \\
0.6 \mathrm{~mA}, 0.8 \mathrm{~mA}, \\
1.3 \mathrm{~mA}\end{array}$ & $500 \mathrm{~ms}$ & Rats & Yes & Yes \\
\hline Appel & 1968 & VI 60-s & $\begin{array}{l}\text { FR 1, FI 10-s, } \\
\text { FI 30-s, FI 60-s, } \\
\text { FI 120-s }\end{array}$ & $\begin{array}{l}0.1 \mathrm{~mA}, 0.2 \mathrm{~mA} \text {, } \\
0.3 \mathrm{~mA}, 0.4 \mathrm{~mA}, \\
0.5 \mathrm{~mA}, 0.6 \mathrm{~mA}, \\
0.8 \mathrm{~mA}\end{array}$ & $500 \mathrm{~ms}$ & Rats & Yes & Yes \\
\hline Galbicka \& Branch & 1981 & VI 60-s & $\begin{array}{l}\text { VI 30-s, } \\
\text { nondifferential } \\
\text { schedule }\end{array}$ & $1.0 \mathrm{~mA}$ & $200 \mathrm{~ms}$ & Monkeys & Yes & Yes \\
\hline Lande & 1981 & VI 60-s & $\begin{array}{l}\text { VR 10, VR 100, } \\
\text { VR 400, VR } 800\end{array}$ & $\begin{array}{l}2.5 \mathrm{~mA}, 4.0 \mathrm{~mA}, \\
5.0 \mathrm{~mA}, \\
6.0 \mathrm{~mA}, 8.0 \mathrm{~mA}, \\
10.0 \mathrm{~mA}, 13.0 \mathrm{~mA} \text {, } \\
16.0 \mathrm{~mA}\end{array}$ & $100 \mathrm{~ms}$ & Pigeons & Yes & Yes \\
\hline $\begin{array}{l}\text { Sizemore \& } \\
\text { Maxwell }\end{array}$ & 1985 & VI $40-\mathrm{s}$ & $\begin{array}{l}\text { Exp. } 1 \text { - differential } \\
\text { punish. long IRTs } \\
\text { Exp. } 2 \text { - differential } \\
\text { punish. intermediate } \\
\text { IRTs }\end{array}$ & $\begin{array}{l}0.1 \mathrm{~mA}, 0.2 \mathrm{~mA} \\
0.3 \mathrm{~mA}, 0.4 \mathrm{~mA}\end{array}$ & $400 \mathrm{~ms}$ & Rats & Yes & Yes \\
\hline Arbuckle \& Lattal & 1987 & VI 180-s & VI 30-s & $\begin{array}{l}10 \mathrm{~V}, 30 \mathrm{~V}, 55 \mathrm{~V}- \\
105 \mathrm{~V}\end{array}$ & $76 \mathrm{~ms}$ & Pigeons & Yes & Yes \\
\hline Arbuckle \& Lattal & 1992 & VI 180-s & $\begin{array}{l}\text { Exp. } 1 \text { - VI 30-s, } \\
\text { nondifferential } \\
\text { schedule } \\
\text { Exp. } 2 \text { - differential } \\
\text { schedule, } \\
\text { nondifferential } \\
\text { schedule }\end{array}$ & $\begin{array}{l}10 \mathrm{~V}, 20 \mathrm{~V}, 30 \mathrm{~V}, \\
40 \mathrm{~V}\end{array}$ & $70 \mathrm{~ms}$ & Pigeons & Yes & Yes \\
\hline
\end{tabular}


Table 1. (continued)

\begin{tabular}{|c|c|c|c|c|c|c|c|c|}
\hline Authors & $\begin{array}{l}\text { Year of } \\
\text { Publication } \\
\end{array}$ & $\begin{array}{l}\text { Reinforcement } \\
\text { Schedule } \\
\end{array}$ & Shock Schedule & Shock Intensity & Shock Duration & Species & $\begin{array}{l}\text { Increased } \\
\text { Response } \\
\text { Rates } \\
\end{array}$ & $\begin{array}{l}\text { Decreased } \\
\text { Response Rates } \\
\end{array}$ \\
\hline Azrin & 1956 & VI 180-s & FI, VI & $110 \mathrm{~V}$ & $500 \mathrm{~ms}$ & Pigeons & No & Yes \\
\hline Azrin & 1959 & FR 25 & FR 1 & $\begin{array}{l}1 \mathrm{~V}, 3 \mathrm{~V}, 7 \mathrm{~V}, \\
10 \mathrm{~V}, 20 \mathrm{~V}, 40 \mathrm{~V}, \\
60 \mathrm{~V}, 80 \mathrm{~V}, 100 \mathrm{~V}, \\
120 \mathrm{~V}\end{array}$ & $50 \mathrm{~ms}$ & Pigeons & No & Yes \\
\hline Azrin & 1960 & VI 30-s, VI 60-s & FR 1 & $\begin{array}{l}10 \mathrm{~V}, 20 \mathrm{~V}, 30 \mathrm{~V} \\
40 \mathrm{~V}, 50 \mathrm{~V}\end{array}$ & $100 \pm 5 \mathrm{~ms}$ & Pigeons & No & Yes \\
\hline Azrin \& Holz & 1961 & FI 300-s & FR 1 & $\begin{array}{l}30 \mathrm{~V}, 50 \mathrm{~V}, 60 \mathrm{~V}, \\
75 \mathrm{~V}, 90 \mathrm{~V}, 120 \\
\mathrm{~V}, 150 \mathrm{~V}, 180 \mathrm{~V}\end{array}$ & $100 \mathrm{~ms} \pm 4 \mathrm{~ms}$ & Pigeons & No & Yes \\
\hline Karsh & 1962 & FR 1 & FR 1 & $\begin{array}{l}75 \mathrm{~V}, 150 \mathrm{~V} \\
300 \mathrm{~V}, 600 \mathrm{~V}\end{array}$ & $100 \mathrm{~ms} \pm 4 \mathrm{~ms}$ & Rats & No & Yes \\
\hline $\begin{array}{l}\text { Azrin, Holz, \& } \\
\text { Hake }\end{array}$ & 1963 & $\begin{array}{l}\text { VI 60-s, VI 120-s, } \\
\text { VI 240-s }\end{array}$ & $\begin{array}{l}\text { FR 50, FR 100, } \\
\text { FR 200, FR 300, } \\
\text { FR 500, FR } 1000\end{array}$ & $\begin{array}{l}80 \mathrm{~V}, 160 \mathrm{~V} \\
240 \mathrm{~V}\end{array}$ & $100 \mathrm{~ms}$ & Pigeons & No & Yes \\
\hline $\begin{array}{l}\text { Holz, Azrin, \& } \\
\text { Ulrich }\end{array}$ & 1963 & DRL & FR 1 & $\begin{array}{l}30 \mathrm{~V}, 60 \mathrm{~V}, 90 \mathrm{~V}, \\
120 \mathrm{~V}, 150 \mathrm{~V}, \\
180 \mathrm{~V}\end{array}$ & $70 \mathrm{~ms}$ & Pigeons & No & Yes \\
\hline $\begin{array}{l}\text { Boroczi, Storms, \& } \\
\text { Broen }\end{array}$ & 1964 & FI 240-s & FR 1 & $\begin{array}{l}0.4 \mathrm{~mA}, 0.6 \mathrm{~mA}, \\
0.8 \mathrm{~mA}, 1.0 \mathrm{~mA}\end{array}$ & $\begin{array}{l}200 \mathrm{~ms}, 500 \mathrm{~ms}, \\
800 \mathrm{~ms}, 1,100 \mathrm{~ms}\end{array}$ & Rats & No & Yes \\
\hline $\begin{array}{l}\text { Seligman \& } \\
\text { Campbell }\end{array}$ & 1965 & EXT & FR 1 & $\begin{array}{l}45 \mathrm{~V}, 72 \mathrm{~V}, 115 \mathrm{~V} \\
185 \mathrm{~V}, 300 \mathrm{~V}\end{array}$ & $\begin{array}{l}150 \mathrm{~ms}, 500 \mathrm{~ms}, \\
2000 \mathrm{~ms}\end{array}$ & Rats & No & Yes \\
\hline Boe & 1966 & EXT & FR 1 & $0.25 \mathrm{~mA}, 2.00 \mathrm{~mA}$ & $\begin{array}{l}50 \mathrm{~ms}, 100 \mathrm{~ms}, \\
30 \mathrm{~ms}, 1000 \mathrm{~ms} \text {, } \\
3000 \mathrm{~ms}\end{array}$ & Rats & No & Yes \\
\hline
\end{tabular}


Table 1. (continued)

\begin{tabular}{|c|c|c|c|c|c|c|c|c|}
\hline Authors & $\begin{array}{l}\text { Year of } \\
\text { Publication } \\
\end{array}$ & $\begin{array}{l}\text { Reinforcement } \\
\text { Schedule } \\
\end{array}$ & Shock Schedule & Shock Intensity & Shock Duration & Species & $\begin{array}{l}\text { Increased } \\
\text { Response } \\
\text { Rates } \\
\end{array}$ & $\begin{array}{l}\text { Decreased } \\
\text { Response Rates } \\
\end{array}$ \\
\hline $\begin{array}{l}\text { Camp, Raymond, \& } \\
\text { Church }\end{array}$ & 1966 & VI 60-s & VI 120-s, FR & $25.0 \mathrm{~mA}$ & $1000 \mathrm{~ms}$ & Rats & No & Yes \\
\hline $\begin{array}{l}\text { Church, Raymond, } \\
\text { \& Beauchamp }\end{array}$ & 1967 & VI 60-s & VI 120-s & $\begin{array}{l}\text { Exp. } 1 \text { - } 0.16 \mathrm{~mA} \\
\text { Exp. } 2 \text { - } 0.05 \mathrm{~mA} \text {, } \\
0.15 \mathrm{~mA}, 0.25 \mathrm{~mA}\end{array}$ & $\begin{array}{l}\text { Exp. } 1 \text { - } 150 \mathrm{~ms} \text {, } \\
300 \mathrm{~ms}, 500 \mathrm{~ms} \text {, } \\
1000 \mathrm{~ms} \text {, } \\
3000 \mathrm{~ms} \\
\text { Exp. } 2 \text { - } 250 \mathrm{~ms} \text {, } \\
500 \mathrm{~ms}, 1000 \mathrm{~ms} \text {, } \\
2000 \mathrm{~ms}\end{array}$ & Rats & No & Yes \\
\hline $\begin{array}{l}\text { Hake, Azrin, \& } \\
\text { Oxford }\end{array}$ & 1967 & $\begin{array}{l}\text { VI 30-s, VI 60-s, } \\
\text { VI 120-s }\end{array}$ & FR 1 & $30 \mathrm{~V}-200 \mathrm{~V}$ & $100 \mathrm{~ms}$ & Monkeys & No & Yes \\
\hline $\begin{array}{l}\text { Camp, Raymond, \& } \\
\text { Church }\end{array}$ & 1967 & VI 60-s & FR & $\begin{array}{l}\text { Exp. } 1-0.1 \mathrm{~mA}, \\
0.2 \mathrm{~mA}, 0.3 \mathrm{~mA} \text {, } \\
0.5 \mathrm{~mA}, 2.0 \mathrm{~mA}\end{array}$ & $2000 \mathrm{~ms}$ & Rats & No & Yes \\
\hline Holz & 1968 & $\begin{array}{l}\text { concurrent } \\
\text { VI 114-s, } \\
\text { VI 450-s, }\end{array}$ & FR 1 & $\begin{array}{l}3.0 \mathrm{~mA}, 6.0 \mathrm{~mA}, \\
7.5 \mathrm{~mA}, 9.0 \mathrm{~mA}, \\
12.0 \mathrm{~mA}\end{array}$ & $90 \mathrm{~ms}$ & Pigeons & No & Yes \\
\hline Boe & 1971 & FR 33 & $\begin{array}{l}\text { FR 1, FR 11, FR 21, } \\
\text { VR } 11\end{array}$ & $50 \mathrm{~V}, 80 \mathrm{~V}, 100 \mathrm{~V}$ & $250 \mathrm{~ms}$ & Rats & No & Yes \\
\hline $\begin{array}{l}\text { Dworkin, Bimle, \& } \\
\text { Miyauchi }\end{array}$ & 1989 & RR, RI & $\mathrm{RR}$ & $0.4 \mathrm{~mA}, 0.8 \mathrm{~mA}$ & $100 \mathrm{~ms}$ & Rats & No & Yes \\
\hline $\begin{array}{l}\text { Miyauchi, Dworkin, } \\
\text { Co, \& Smith }\end{array}$ & 1989 & $\mathrm{RR}$ & $\mathrm{RR}$ & $0.4 \mathrm{~mA}$ & $100 \mathrm{~ms}$ & Rats & No & Yes \\
\hline $\begin{array}{l}\text { Pitts, Lewis, \& } \\
\text { Dworkin }\end{array}$ & 1993 & RR, yoked VI & $\mathrm{RR}$ & $0.3 \mathrm{~mA}-0.6 \mathrm{~mA}$ & $100 \mathrm{~ms}$ & Pigeons & No & Yes \\
\hline
\end{tabular}


Table 2. Experiment 1: Number of baseline sessions, shock intensity, and values of $t$ (in s) for the four phases. Each phase began with a baseline condition in which responding was reinforced on a variable-interval 40-s schedule. Thereafter, shock was contingent on interresponse times (IRTs) greater than the values of $t$ listed below.

\begin{tabular}{|c|c|c|c|c|c|c|c|c|}
\hline \multirow[b]{3}{*}{ Rat } & \multirow[b]{3}{*}{ Phase } & \multirow{3}{*}{$\begin{array}{l}\text { Baseline } \\
\text { Sessions } \\
\end{array}$} & \multicolumn{6}{|c|}{ Shock Conditions } \\
\hline & & & \multirow{2}{*}{$\begin{array}{c}\text { Shock } \\
\text { Intensity } \\
(\mathrm{mA}) \\
\end{array}$} & \multicolumn{5}{|c|}{$t(\mathrm{~s})$ at Each Percentile of Baseline IRT Distribution } \\
\hline & & & & 90 & 80 & 70 & 60 & 50 \\
\hline \multirow[t]{4}{*}{ JL5 } & 1 & 37 & 0.05 & 2.58 & 1.31 & 0.96 & 0.77 & 0.66 \\
\hline & 2 & 14 & 0.10 & 2.14 & 0.96 & 0.69 & 0.55 & 0.46 \\
\hline & 3 & 33 & 0.20 & 2.43 & 1.20 & 0.80 & 0.62 & 0.50 \\
\hline & 4 & 13 & 0.40 & 2.27 & 0.81 & 0.57 & 0.46 & 0.39 \\
\hline \multirow[t]{4}{*}{ JL8 } & 1 & 40 & 0.05 & 6.14 & 3.97 & 2.86 & 1.66 & 1.04 \\
\hline & 2 & 24 & 0.10 & 5.54 & 3.27 & 1.31 & 0.90 & 0.73 \\
\hline & 3 & 24 & 0.20 & 7.10 & 4.98 & 2.72 & 1.25 & 0.94 \\
\hline & 4 & 13 & 0.40 & 9.90 & 5.70 & 1.99 & 1.28 & 0.99 \\
\hline JL14 & 1 & 38 & 0.05 & 4.22 & 1.73 & 1.05 & 0.78 & 0.62 \\
\hline \multirow[t]{4}{*}{ JL16 } & 1 & 38 & 0.05 & 2.72 & 1.18 & 0.78 & 0.58 & 0.44 \\
\hline & 2 & 13 & 0.10 & 2.78 & 1.00 & 0.51 & 0.38 & 0.31 \\
\hline & 3 & 42 & 0.20 & 3.79 & 1.39 & 0.85 & 0.62 & 0.49 \\
\hline & 4 & 16 & 0.40 & 5.43 & 2.79 & 1.13 & 0.71 & 0.54 \\
\hline
\end{tabular}

Note: Results for Rat JL14 are limited to the first phase because this rat was injured during the second baseline condition and was eliminated from the study. 
Table 3. Experiment 1: Reinforcement and shock rates for all rats. Mean rates are listed with standard deviations in parentheses, based on the stable 6 sessions of baseline conditions and all 5 sessions of the shock conditions.

\begin{tabular}{|c|c|c|c|c|c|c|c|c|c|c|}
\hline \multirow{3}{*}{$\begin{array}{c}\text { Phase } \\
1\end{array}$} & \multirow{3}{*}{$\begin{array}{c}\text { Condition } \\
\text { Baseline }\end{array}$} & \multirow{3}{*}{$\begin{array}{c}\text { Percentile } \\
-\end{array}$} & \multicolumn{2}{|c|}{ Rat JL5 } & \multicolumn{2}{|c|}{ Rat JL8 } & \multicolumn{2}{|c|}{ Rat JL14 } & \multicolumn{2}{|c|}{ Rat JL16 } \\
\hline & & & \multirow{2}{*}{$\begin{array}{c}\text { Reinforcers } \\
\text { per min }\end{array}$} & $\begin{array}{l}\text { Shocks } \\
\text { per min }\end{array}$ & \multirow{2}{*}{$\begin{array}{c}\begin{array}{c}\text { Reinforcers } \\
\text { per min }\end{array} \\
1.38(0.02)\end{array}$} & $\begin{array}{l}\text { Shocks } \\
\text { per min }\end{array}$ & $\begin{array}{l}\text { Reinforcers } \\
\text { per min }\end{array}$ & $\begin{array}{l}\text { Shocks } \\
\text { per min }\end{array}$ & \multirow{2}{*}{$\begin{array}{c}\text { Reinforcers } \\
\text { per min }\end{array}$} & $\begin{array}{l}\text { Shocks } \\
\text { per min }\end{array}$ \\
\hline & & & & - & & - & $1.42(0.01)$ & - & & - \\
\hline \multirow[t]{5}{*}{ Shock $=0.05 \mathrm{~mA}$} & Shock 1 & 90th & $1.44(0.01)$ & $4.51(0.16)$ & $1.37(0.01)$ & $1.74(0.12)$ & $1.42(0.01)$ & $3.81(0.45)$ & $1.43(0.01)$ & $5.25(0.47)$ \\
\hline & Shock 2 & 80th & $1.45(0.01)$ & $9.11(0.53)$ & $1.38(0.03)$ & $3.84(0.15)$ & $1.41(0.01)$ & $8.36(0.42)$ & $1.44(0.01)$ & $11.16(0.24)$ \\
\hline & Shock 3 & 70th & $1.45(0.03)$ & $13.46(0.67)$ & $1.39(0.01)$ & $5.20(0.22)$ & $1.40(0.02)$ & $10.28(0.76)$ & $1.43(0.01)$ & $14.06(0.74)$ \\
\hline & Shock 4 & 60th & $1.43(0.01)$ & $15.84(1.08)$ & $1.37(0.01)$ & $6.26(0.33)$ & $1.41(0.01)$ & $12.27(0.87)$ & $1.43(0.01)$ & 16.79 (1.18) \\
\hline & Shock 5 & 50th & $1.44(0.01)$ & $20.83(0.78)$ & $1.37(0.01)$ & $9.20(0.30)$ & $1.38(0.02)$ & $12.86(0.82)$ & $1.42(0.01)$ & $21.21(0.83)$ \\
\hline 2 & Baseline & - & $1.44(0.02)$ & - & $1.41(0.01)$ & - & - & - & $1.44(0.01)$ & - \\
\hline \multirow[t]{5}{*}{ Shock $=0.1 \mathrm{~mA}$} & Shock 1 & 90th & $1.44(0.01)$ & $6.27(0.54)$ & $1.38(0.02)$ & $2.59(0.28)$ & - & - & $1.42(0.01)$ & $5.62(0.21)$ \\
\hline & Shock 2 & 80th & $1.45(0.00)$ & $11.73(0.51)$ & $1.38(0.02)$ & $4.96(0.41)$ & - & - & $1.42(0.01)$ & $11.03(0.16)$ \\
\hline & Shock 3 & 70th & $1.44(0.01)$ & $17.73(0.41)$ & $1.37(0.00)$ & $7.30(0.10)$ & - & - & $1.43(0.01)$ & $14.19(0.48)$ \\
\hline & Shock 4 & 60th & $1.45(0.01)$ & $25.11(1.23)$ & $1.33(0.01)$ & $9.84(0.65)$ & - & - & $1.42(0.01)$ & $20.70(2.56)$ \\
\hline & Shock 5 & 50th & $1.45(0.01)$ & 32.37 (1.11) & $1.34(0.01)$ & $12.70(1.07)$ & - & - & $1.42(0.01)$ & $27.01(2.11)$ \\
\hline 3 & Baseline & - & $1.46(0.01)$ & - & $1.38(0.01)$ & - & - & - & $1.43(0.01)$ & - \\
\hline \multirow[t]{5}{*}{ Shock $=0.2 \mathrm{~mA}$} & Shock 1 & 90th & $1.44(0.01)$ & $5.87(0.37)$ & $1.37(0.01)$ & $1.71(0.17)$ & - & - & $1.41(0.01)$ & $4.26(0.40)$ \\
\hline & Shock 2 & 80th & $1.44(0.01)$ & $10.42(0.61)$ & $1.37(0.01)$ & $2.85(0.19)$ & - & - & $1.40(0.03)$ & $9.06(0.24)$ \\
\hline & Shock 3 & 70th & $1.44(0.01)$ & 14.31 (1.29) & $1.34(0.00)$ & $4.21(0.30)$ & - & - & $1.40(0.02)$ & $12.06(0.78)$ \\
\hline & Shock 4 & 60th & $1.43(0.01)$ & $18.72(0.92)$ & $1.35(0.03)$ & $7.79(0.20)$ & - & - & $1.39(0.02)$ & $13.77(1.06)$ \\
\hline & Shock 5 & 50th & $1.44(0.01)$ & $21.86(0.78)$ & $1.29(0.05)$ & $9.75(0.49)$ & - & - & $1.38(0.01)$ & 14.49 (1.39) \\
\hline 4 & Baseline & - & $1.45(0.00)$ & - & $1.35(0.02)$ & - & - & - & $1.41(0.01)$ & - \\
\hline \multirow[t]{5}{*}{ Shock $=0.4 \mathrm{~mA}$} & Shock 1 & 90th & $1.44(0.01)$ & $6.67(0.21)$ & $1.34(0.02)$ & $1.18(0.19)$ & - & - & $1.40(0.01)$ & $3.19(0.30)$ \\
\hline & Shock 2 & 80th & $1.43(0.01)$ & $13.16(0.93)$ & $1.34(0.01)$ & $2.69(0.10)$ & - & - & $1.39(0.02)$ & $5.90(0.54)$ \\
\hline & Shock 3 & 70th & $1.43(0.01)$ & $17.84(0.52)$ & $1.32(0.01)$ & $4.65(0.14)$ & - & - & $1.36(0.01)$ & $7.24(0.27)$ \\
\hline & Shock 4 & 60th & $1.44(0.01)$ & $22.07(1.17)$ & $1.32(0.03)$ & $6.21(0.60)$ & - & - & $1.37(0.02)$ & $9.00(0.59)$ \\
\hline & Shock 5 & 50th & $1.42(0.00)$ & 26.05 (1.69) & $1.29(0.03)$ & $7.31(0.61)$ & - & - & $1.35(0.03)$ & $11.40(0.77)$ \\
\hline
\end{tabular}


Table 4. Experiment 2: Number of baseline sessions, percentiles, and values of $t$ (in s) for the four phases. Each phase began with a baseline condition in which responding was reinforced on a variable-interval 40-s schedule. Thereafter, shock was contingent on interresponse times (IRTs) greater than the values of $t$ listed below.

\begin{tabular}{|c|c|c|c|c|c|c|c|c|}
\hline \multirow[b]{3}{*}{ Rat } & \multirow[b]{3}{*}{ Phase } & \multirow{3}{*}{$\begin{array}{l}\text { Baseline } \\
\text { Sessions }\end{array}$} & \multicolumn{6}{|c|}{ Shock Conditions } \\
\hline & & & \multirow[b]{2}{*}{ Percentile } & \multicolumn{5}{|c|}{$t(\mathrm{~s})$ at Each Shock Intensity (mA) } \\
\hline & & & & 0.05 & 0.1 & 0.2 & 0.4 & 0.8 \\
\hline \multirow[t]{4}{*}{ JL2 } & 1 & 38 & 80 & 1.08 & 1.08 & 1.08 & 1.08 & $1.08^{\mathrm{a}}$ \\
\hline & 2 & 17 & 70 & 0.49 & 0.49 & 0.49 & $0.49^{\mathrm{a}}$ & -- \\
\hline & 3 & 13 & 60 & 0.40 & 0.40 & 0.40 & 0.40 & $0.40^{\mathrm{a}}$ \\
\hline & 4 & 14 & 50 & 0.38 & 0.38 & 0.38 & 0.38 & $0.38^{\mathrm{a}}$ \\
\hline \multirow[t]{4}{*}{ JL11 } & 1 & 40 & 80 & 2.26 & 2.26 & 2.26 & 2.26 & $2.26^{\mathrm{a}}$ \\
\hline & 2 & 27 & 70 & 0.87 & 0.87 & 0.87 & 0.87 & $0.87^{\mathrm{a}}$ \\
\hline & 3 & 41 & 60 & 0.50 & 0.50 & 0.50 & 0.50 & 0.50 \\
\hline & 4 & 16 & 50 & 0.32 & 0.32 & 0.32 & 0.32 & $0.32^{\mathrm{b}}$ \\
\hline \multirow[t]{4}{*}{ JL13 } & 1 & 39 & 80 & 1.81 & 1.81 & 1.81 & 1.81 & 1.81 \\
\hline & 2 & 26 & 70 & 0.74 & 0.74 & 0.74 & 0.74 & 0.74 \\
\hline & 3 & 23 & 60 & 0.58 & 0.58 & 0.58 & 0.58 & 0.58 \\
\hline & 4 & 13 & 50 & 0.47 & 0.47 & 0.47 & 0.47 & 0.47 \\
\hline \multirow[t]{4}{*}{ JL19 } & 1 & 37 & 80 & 5.56 & 5.56 & 5.56 & 5.56 & 5.56 \\
\hline & 2 & 19 & 70 & 3.11 & 3.11 & 3.11 & 3.11 & $3.11^{\mathrm{a}}$ \\
\hline & 3 & 42 & 60 & 1.08 & 1.08 & 1.08 & 1.08 & $1.08^{\mathrm{b}}$ \\
\hline & 4 & 15 & 50 & 0.33 & 0.33 & 0.33 & 0.33 & $0.33^{\mathrm{a}}$ \\
\hline
\end{tabular}

${ }^{\mathrm{a}}$ Only 2 sessions were conducted in this condition. ${ }^{\mathrm{b}}$ Only 3 sessions were conducted in this condition. 
Table 5. Experiment 2: Reinforcement and shock rates for all rats. Mean rates are listed with standard deviations in parentheses, based on the stable 6 sessions of the baseline conditions and all 5 sessions of the shock conditions.

\begin{tabular}{|c|c|c|c|c|c|c|c|c|c|c|}
\hline \multirow{3}{*}{$\begin{array}{c}\text { Phase } \\
1\end{array}$} & \multirow{3}{*}{$\begin{array}{c}\text { Condition } \\
\text { Baseline }\end{array}$} & \multirow{3}{*}{$\begin{array}{c}\begin{array}{c}\text { Intensity } \\
(\mathrm{mA})\end{array} \\
-\end{array}$} & \multicolumn{2}{|c|}{ Rat JL2 } & \multicolumn{2}{|c|}{ Rat JL11 } & \multicolumn{2}{|c|}{ Rat JL13 } & \multicolumn{2}{|c|}{ Rat JL19 } \\
\hline & & & \multirow{2}{*}{$\begin{array}{c}\begin{array}{c}\text { Reinforcers } \\
\text { per min }\end{array} \\
1.43(0.01)\end{array}$} & $\begin{array}{l}\text { Shocks } \\
\text { per min }\end{array}$ & \multirow{2}{*}{$\begin{array}{c}\begin{array}{c}\text { Reinforcers } \\
\text { per min }\end{array} \\
1.43(0.01)\end{array}$} & $\begin{array}{l}\text { Shocks } \\
\text { per min }\end{array}$ & \multirow{2}{*}{$\begin{array}{l}\text { Reinforcers } \\
\text { per min }\end{array}$} & $\begin{array}{l}\text { Shocks } \\
\text { per min }\end{array}$ & \multirow{2}{*}{$\begin{array}{c}\begin{array}{c}\text { Reinforcers } \\
\text { per min }\end{array} \\
1.39(0.01)\end{array}$} & $\begin{array}{l}\text { Shocks } \\
\text { per min } \\
\end{array}$ \\
\hline & & & & - & & - & & - & & - \\
\hline \multirow[t]{5}{*}{ 80th percentile } & Shock 1 & 0.05 & $1.44(0.01)$ & $8.52(0.63)$ & $1.43(0.01)$ & $6.75(0.71)$ & $1.44(0.01)$ & $8.74(0.60)$ & $1.37(0.01)$ & $3.73(0.01)$ \\
\hline & Shock 2 & 0.1 & $1.43(0.01)$ & $7.74(0.27)$ & $1.42(0.01)$ & $5.83(0.52)$ & $1.43(0.01)$ & $7.83(0.40)$ & $1.37(0.01)$ & $3.92(0.01)$ \\
\hline & Shock 3 & 0.2 & $1.42(0.02)$ & $7.14(0.26)$ & $1.44(0.01)$ & $5.21(0.68)$ & $1.42(0.01)$ & $8.04(0.58)$ & $1.38(0.01)$ & $4.04(0.01)$ \\
\hline & Shock 4 & 0.4 & $1.40(0.02)$ & $6.40(0.62)$ & $1.43(0.04)$ & $5.12(0.28)$ & $1.42(0.01)$ & $8.42(0.40)$ & $1.36(0.04)$ & $3.69(0.04)$ \\
\hline & Shock 5 & 0.8 & $0.04(0.04)^{b}$ & $0.25(0.22)$ & $0.03(0.01)^{\mathrm{b}}$ & $0.14(0.10)$ & $0.86(0.42)$ & 4.37 (2.11) & $0.36(0.50)$ & $0.73(0.50)$ \\
\hline 2 & Baseline & - & $1.43(0.02)$ & - & $1.38(0.03)$ & - & $1.43(0.02)$ & - & $1.38(0.01)$ & - \\
\hline \multirow[t]{5}{*}{ 70th percentile } & Shock 1 & 0.05 & $1.40(0.01)$ & $17.94(0.94)$ & $1.36(0.05)$ & $11.44(0.73)$ & $1.40(0.01)$ & $12.76(0.64)$ & $1.34(0.03)$ & $5.29(0.03)$ \\
\hline & Shock 2 & 0.1 & $1.42(0.01)$ & $15.42(0.31)$ & $1.40(0.02)$ & 10.19 & $1.41(0.01)$ & $12.76(0.47)$ & $1.34(0.05)$ & $5.28(0.05)$ \\
\hline & Shock 3 & 0.2 & $1.36(0.13)$ & 12.05 (1.39) & $1.42(0.01)$ & $10.36(0.57)$ & $1.41(0.01)$ & $12.63(0.33)$ & $1.34(0.02)$ & $5.02(0.02)$ \\
\hline & Shock 4 & 0.4 & $0.01(0.01)^{\mathrm{b}}$ & $0.19(0.02)$ & $1.21(0.30)$ & $7.82(2.02)$ & $1.40(0.02)$ & $12.45(0.91)$ & $1.35(0.02)$ & $5.27(0.02)$ \\
\hline & Shock 5 & 0.8 & - & - & $0.03(0.00)^{\mathrm{b}}$ & $0.25(0.05)$ & $1.38(0.01)$ & $10.65(0.40)$ & $0.03(0.00)^{\mathrm{b}}$ & $0.13(0.05)$ \\
\hline 3 & Baseline & - & $1.44(0.02)$ & - & $1.40(0.03)$ & - & $1.42(0.02)$ & - & $1.28(0.04)$ & - \\
\hline \multirow[t]{5}{*}{ 60th percentile } & Shock 1 & 0.05 & $1.41(0.01)$ & $24.48(2.45)$ & $1.39(0.03)$ & 19.15 & $1.42(0.01)$ & $15.88(0.55)$ & $1.29(0.02)$ & $5.10(0.02)$ \\
\hline & Shock 2 & 0.1 & $1.41(0.01)$ & $24.88(3.41)$ & $1.41(0.02)$ & $16.90(1.17)$ & $1.39(0.00)$ & $15.97(1.49)$ & $1.26(0.05)$ & $4.64(0.05)$ \\
\hline & Shock 3 & 0.2 & $1.42(0.01)$ & $23.50(1.18)$ & $1.40(0.03)$ & $16.11(0.86)$ & $1.38(0.03)$ & 16.59 (1.45) & $1.28(0.05)$ & $5.02(0.05)$ \\
\hline & Shock 4 & 0.4 & $0.90(0.65)$ & $14.22(10.20)$ & $1.41(0.02)$ & $15.15(0.59)$ & $1.40(0.01)$ & $15.93(1.21)$ & $1.24(0.03)$ & $4.52(0.03)$ \\
\hline & Shock 5 & 0.8 & $0.00(0.00)^{\mathrm{b}}$ & $0.09(0.01)$ & $1.04(0.24)$ & $8.06(2.83)$ & $1.38(0.01)$ & $14.50(0.56)$ & $0.41(0.58)^{\mathrm{a}}$ & $1.55(2.06)$ \\
\hline 4 & Baseline & - & $1.45(0.01)$ & - & $1.42(0.01)$ & - & $1.42(0.02)$ & - & $1.22(0.03)$ & - \\
\hline \multirow[t]{5}{*}{ 50th percentile } & Shock 1 & 0.05 & $1.41(0.01)$ & $27.52(2.93)$ & $1.39(0.00)$ & $30.86(5.09)$ & $1.41(0.01)$ & $22.52(0.62)$ & $1.27(0.02)$ & $13.60(0.02)$ \\
\hline & Shock 2 & 0.1 & $1.42(0.02)$ & $26.51(1.08)$ & $1.38(0.02)$ & $23.09(2.20)$ & $1.40(0.00)$ & $22.59(0.37)$ & $1.24(0.03)$ & $12.81(0.03)$ \\
\hline & Shock 3 & 0.2 & $1.38(0.07)$ & $21.26(1.31)$ & $1.38(0.02)$ & $22.05(2.90)$ & $1.40(0.01)$ & $20.59(1.22)$ & $1.27(0.04)$ & $12.53(0.04)$ \\
\hline & Shock 4 & 0.4 & $1.15(0.40)$ & $15.83(5.88)$ & $1.35(0.05)$ & $21.83(4.04)$ & $1.40(0.02)$ & $19.58(0.69)$ & $1.28(0.02)$ & $12.65(0.02)$ \\
\hline & Shock 5 & 0.8 & $0.00(0.00)^{\mathrm{b}}$ & $0.15(0.08)$ & $0.50(0.62)^{\mathrm{a}}$ & $6.65(8.55)$ & $1.38(0.02)$ & $18.96(0.72)$ & $0.00(0.00)^{b}$ & $0.03(0.01)$ \\
\hline
\end{tabular}

${ }^{\mathrm{a}}$ Only 3 sessions were conducted in this condition. ${ }^{\mathrm{b}}$ Only 2 sessions were conducted in this condition. 
Table 6. Experiment 3: Number of baseline sessions, shock intensities, and values of $t$ (in s) for the four phases. Each phase began with a baseline condition in which responding was reinforced on a variable-interval 40-s schedule. Thereafter, shock was contingent on interresponse times (IRTs) less than the values of $t$ listed below.

\begin{tabular}{|c|c|c|c|c|c|c|c|c|}
\hline \multirow[b]{3}{*}{ Rat } & \multirow[b]{3}{*}{ Phase } & \multirow{3}{*}{$\begin{array}{l}\text { Baseline } \\
\text { Sessions } \\
\end{array}$} & \multicolumn{6}{|c|}{ Shock Conditions } \\
\hline & & & \multirow{2}{*}{$\begin{array}{c}\text { Shock } \\
\text { Intensity } \\
(\mathrm{mA}) \\
\end{array}$} & \multicolumn{5}{|c|}{$t(\mathrm{~s})$ at Each Percentile of Baseline IRT Distribution } \\
\hline & & & & 10 & 20 & 30 & 40 & 50 \\
\hline \multirow[t]{4}{*}{ JL1 } & 1 & 36 & 0.05 & 0.26 & 0.31 & 0.38 & 0.45 & 0.54 \\
\hline & 2 & 32 & 0.10 & 0.32 & 0.40 & 0.47 & 0.54 & 0.64 \\
\hline & 3 & 25 & 0.20 & 0.27 & 0.33 & 0.38 & 0.44 & 0.52 \\
\hline & 4 & 13 & 0.40 & 0.30 & 0.34 & 0.38 & 0.43 & 0.49 \\
\hline \multirow[t]{4}{*}{ JL3 } & 1 & 38 & 0.05 & 0.27 & 0.33 & 0.38 & 0.43 & 0.52 \\
\hline & 2 & 13 & 0.10 & 0.30 & 0.36 & 0.41 & 0.47 & 0.53 \\
\hline & 3 & 30 & 0.20 & 0.27 & 0.34 & 0.40 & 0.46 & 0.53 \\
\hline & 4 & 13 & 0.40 & 0.26 & 0.35 & 0.41 & 0.48 & 0.57 \\
\hline \multirow[t]{4}{*}{ JL15 } & 1 & 40 & 0.05 & 0.18 & 0.25 & 0.34 & 0.52 & 0.83 \\
\hline & 2 & 18 & 0.10 & 0.35 & 0.68 & 1.13 & 1.74 & 2.42 \\
\hline & 3 & 30 & 0.20 & 0.27 & 0.53 & 1.02 & 1.80 & 2.59 \\
\hline & 4 & 14 & 0.40 & 0.28 & 0.64 & 1.29 & 1.95 & 2.67 \\
\hline \multirow[t]{4}{*}{ JL17 } & 1 & 34 & 0.05 & 0.27 & 0.37 & 0.48 & 0.62 & 0.80 \\
\hline & 2 & 13 & 0.10 & 0.40 & 0.50 & 0.60 & 0.72 & 0.88 \\
\hline & 3 & 44 & 0.20 & 0.40 & 0.53 & 0.67 & 0.83 & 1.04 \\
\hline & 4 & 14 & 0.40 & 0.52 & 0.69 & 0.83 & 1.00 & 1.29 \\
\hline
\end{tabular}


Table 7. Experiment 3: Reinforcement and shock rates for all rats. Mean rates are listed with standard deviations in parentheses, based on the stable 6 sessions of the baseline conditions and all 5 sessions of the shock conditions.

\begin{tabular}{|c|c|c|c|c|c|c|c|c|c|c|}
\hline \multirow[b]{2}{*}{ Phase } & \multirow[b]{2}{*}{ Condition } & \multirow[b]{2}{*}{ Percentile } & \multicolumn{2}{|c|}{ Rat JL1 } & \multicolumn{2}{|c|}{ Rat JL3 } & \multicolumn{2}{|c|}{ Rat JL15 } & \multicolumn{2}{|c|}{ Rat JL17 } \\
\hline & & & $\begin{array}{c}\text { Reinforcers } \\
\text { per min }\end{array}$ & $\begin{array}{l}\text { Shocks } \\
\text { per min }\end{array}$ & $\begin{array}{c}\text { Reinforcers } \\
\text { per min }\end{array}$ & $\begin{array}{l}\text { Shocks } \\
\text { per min }\end{array}$ & $\begin{array}{c}\text { Reinforcers } \\
\text { per min }\end{array}$ & $\begin{array}{l}\text { Shocks } \\
\text { per min }\end{array}$ & $\begin{array}{c}\text { Reinforcers } \\
\text { per min }\end{array}$ & $\begin{array}{l}\text { Shocks } \\
\text { per min }\end{array}$ \\
\hline 1 & Baseline & - & $1.42(0.02)$ & - & $1.41(0.02)$ & - & $1.44(0.01)$ & - & $1.36(0.04)$ & - \\
\hline \multirow[t]{5}{*}{ Shock $=0.05 \mathrm{~mA}$} & Shock 1 & 10th & $1.42(0.01)$ & $5.17(1.81)$ & $1.42(0.01)$ & $4.66(0.79)$ & $1.42(0.01)$ & $2.75(0.32)$ & $1.36(0.01)$ & $1.24(0.42)$ \\
\hline & Shock 2 & 20th & $1.42(0.01)$ & $19.25(4.84)$ & $1.42(0.01)$ & $9.09(0.99)$ & $1.42(0.02)$ & $2.43(1.22)$ & $1.37(0.01)$ & $3.11(0.87)$ \\
\hline & Shock 3 & 30th & $1.42(0.02)$ & $21.40(7.82)$ & $1.42(0.01)$ & $13.13(2.99)$ & $1.41(0.01)$ & $3.75(1.00)$ & $1.34(0.02)$ & $4.88(0.80)$ \\
\hline & Shock 4 & 40th & $1.41(0.02)$ & $16.13(4.88)$ & $1.42(0.01)$ & 16.45 (2.79) & $1.42(0.02)$ & 5.54 (1.03) & $1.34(0.01)$ & $6.24(1.50)$ \\
\hline & Shock 5 & 50th & $1.35(0.02)$ & 7.35 (3.25) & $1.40(0.01)$ & $17.26(1.55)$ & $1.40(0.01)$ & $9.56(2.27)$ & $1.34(0.02)$ & $5.79(2.04)$ \\
\hline 2 & Baseline & - & $1.35(0.02)$ & - & $1.42(0.00)$ & - & $1.36(0.02)$ & - & $1.35(0.02)$ & - \\
\hline \multirow[t]{5}{*}{ Shock $=0.1 \mathrm{~mA}$} & Shock 1 & 10th & $1.36(0.00)$ & $1.42(0.46)$ & $1.41(0.01)$ & $4.90(1.31)$ & $1.39(0.02)$ & $3.09(0.53)$ & $1.33(0.05)$ & $1.22(0.77)$ \\
\hline & Shock 2 & 20th & $1.37(0.02)$ & $6.58(1.55)$ & $1.42(0.01)$ & $9.12(1.96)$ & $1.38(0.01)$ & $3.98(0.84)$ & $1.32(0.02)$ & $1.93(0.68)$ \\
\hline & Shock 3 & 30th & $1.37(0.03)$ & 9.99 (3.87) & $1.43(0.01)$ & $12.24(1.60)$ & $1.38(0.02)$ & $7.23(1.44)$ & $1.31(0.04)$ & $2.61(1.17)$ \\
\hline & Shock 4 & 40th & $1.35(0.02)$ & $6.70(2.68)$ & $1.42(0.01)$ & $14.13(1.10)$ & $1.39(0.01)$ & $9.76(1.30)$ & $1.33(0.03)$ & 5.33 (1.69) \\
\hline & Shock 5 & 50th & $1.35(0.03)$ & 10.70 (3.99) & $1.40(0.01)$ & $12.70(2.06)$ & $1.34(0.01)$ & 4.85 (1.96) & $1.35(0.03)$ & $6.02(1.65)$ \\
\hline 3 & Baseline & - & $1.39(0.01)$ & - & $1.43(0.02)$ & & $1.40(0.01)$ & - & $1.28(0.06)$ & - \\
\hline \multirow[t]{5}{*}{ Shock $=0.2 \mathrm{~mA}$} & Shock 1 & 10th & $1.38(0.04)$ & 2.01 (1.09) & $1.42(0.01)$ & $3.75(1.10)$ & $1.38(0.01)$ & $1.36(0.34)$ & $1.25(0.03)$ & $0.49(0.42)$ \\
\hline & Shock 2 & 20th & $1.36(0.02)$ & 3.83 (1.45) & $1.41(0.02)$ & $6.89(2.72)$ & $1.39(0.01)$ & 2.89 (0.99) & $1.26(0.04)$ & $1.61(1.44)$ \\
\hline & Shock 3 & 30th & $1.38(0.01)$ & $10.03(2.60)$ & $1.41(0.01)$ & $8.02(2.38)$ & $1.38(0.02)$ & $2.92(1.10)$ & $1.24(0.03)$ & $0.98(0.44)$ \\
\hline & Shock 4 & 40th & $1.37(0.02)$ & $10.02(1.65)$ & $1.39(0.01)$ & $10.71(2.68)$ & $1.38(0.03)$ & $5.81(1.01)$ & $1.28(0.06)$ & 3.41 (1.63) \\
\hline & Shock 5 & 50th & $1.39(0.01)$ & $14.43(5.03)$ & $1.41(0.01)$ & $16.98(4.80)$ & $1.34(0.02)$ & $4.32(1.92)$ & $1.29(0.01)$ & $3.25(0.80)$ \\
\hline 4 & Baseline & - & $1.37(0.02)$ & - & $1.42(0.01)$ & & $1.37(0.04)$ & & $1.28(0.02)$ & - \\
\hline \multirow[t]{5}{*}{ Shock $=0.4 \mathrm{~mA}$} & Shock 1 & 10th & $1.39(0.01)$ & $2.10(0.82)$ & $1.41(0.01)$ & 3.59 (1.18) & $1.37(0.02)$ & $1.48(0.65)$ & $1.04(0.40)$ & $0.53(0.17)$ \\
\hline & Shock 2 & 20th & $1.39(0.03)$ & $5.59(1.54)$ & $1.40(0.01)$ & $5.79(1.45)$ & $1.37(0.02)$ & $2.47(0.47)$ & $1.22(0.04)$ & $1.61(0.96)$ \\
\hline & Shock 3 & 30th & $1.38(0.02)$ & $7.76(2.75)$ & $1.39(0.03)$ & 8.25 (1.96) & $1.38(0.00)$ & $4.43(0.70)$ & $1.25(0.04)$ & $2.58(0.77)$ \\
\hline & Shock 4 & 40th & $1.38(0.01)$ & 11.37 (1.39) & $1.40(0.02)$ & $12.19(4.04)$ & $1.38(0.01)$ & $8.30(1.66)$ & $1.24(4.04)$ & $2.76(1.46)$ \\
\hline & Shock 5 & 50th & $1.34(0.02)$ & $13.08(4.83)$ & $1.38(0.01)$ & $10.42(3.41)$ & $1.36(0.02)$ & $4.26(1.28)$ & $1.18(0.10)$ & 2.22 \\
\hline
\end{tabular}


Table 8. Experiment 4: Number of baseline sessions, percentiles, and values of $t$ (in s) for the four phases. Each phase began with a baseline condition in which responding was reinforced on a variable-interval 40-s schedule. Thereafter, shock was contingent on interresponse times (IRTs) less than the values of $t$ listed below.

\begin{tabular}{|c|c|c|c|c|c|c|c|c|}
\hline \multirow[b]{3}{*}{ Rat } & \multirow[b]{3}{*}{ Phase } & \multirow[b]{3}{*}{$\begin{array}{l}\text { Baseline } \\
\text { Sessions } \\
\end{array}$} & \multicolumn{6}{|c|}{ Shock Conditions } \\
\hline & & & \multirow[b]{2}{*}{ Percentile } & \multicolumn{5}{|c|}{$t(\mathrm{~s})$ at Each Shock Intensity $(\mathrm{mA})$} \\
\hline & & & & 0.05 & 0.1 & 0.2 & 0.4 & 0.8 \\
\hline \multirow[t]{4}{*}{ JL7 } & 1 & 41 & 20 & 0.32 & 0.32 & 0.32 & 0.32 & 0.32 \\
\hline & 2 & $56^{\mathrm{a}}$ & 30 & 0.41 & 0.41 & 0.41 & 0.41 & 0.41 \\
\hline & 3 & 14 & 40 & 0.77 & 0.77 & 0.77 & 0.77 & 0.77 \\
\hline & 4 & 15 & 50 & 1.59 & 1.59 & 1.59 & 1.59 & 1.59 \\
\hline \multirow[t]{4}{*}{ JL10 } & 1 & 40 & 20 & 0.37 & 0.37 & 0.37 & 0.37 & 0.37 \\
\hline & 2 & 13 & 30 & 0.63 & 0.63 & 0.63 & 0.63 & 0.63 \\
\hline & 3 & 42 & 40 & 0.34 & 0.34 & 0.34 & 0.34 & 0.34 \\
\hline & 4 & 15 & 50 & 0.47 & 0.47 & 0.47 & 0.47 & 0.47 \\
\hline \multirow[t]{4}{*}{ JL12 } & 1 & 39 & 20 & 0.23 & 0.23 & 0.23 & 0.23 & 0.23 \\
\hline & 2 & 13 & 30 & 0.33 & 0.33 & 0.33 & 0.33 & 0.33 \\
\hline & 3 & 41 & 40 & 0.49 & 0.49 & 0.49 & 0.49 & 0.49 \\
\hline & 4 & 14 & 50 & 0.74 & 0.74 & 0.74 & 0.74 & $0.74^{\mathrm{b}}$ \\
\hline \multirow[t]{4}{*}{ JL18 } & 1 & 33 & 20 & 0.25 & 0.25 & 0.25 & 0.25 & 0.25 \\
\hline & 2 & 21 & 30 & 0.40 & 0.40 & 0.40 & 0.40 & 0.40 \\
\hline & 3 & 31 & 40 & 0.36 & 0.36 & 0.36 & 0.36 & 0.36 \\
\hline & 4 & 15 & 50 & 0.44 & 0.44 & 0.44 & 0.44 & 0.44 \\
\hline
\end{tabular}

${ }^{a}$ Total includes sessions in which JL7 was trained on a VI 40-s schedule of pellet delivery and excludes the 31 sessions of remedial training described in the text. ${ }^{b}$ There were only 3 sessions in this condition. 
Table 9. Experiment 4: Reinforcement and shock rates for all rats. Mean rates are listed with standard deviations in parentheses, based on the stable 6 sessions of baseline conditions and all 5 sessions of the shock conditions.

\begin{tabular}{|c|c|c|c|c|c|c|c|c|c|c|}
\hline \multirow{3}{*}{$\begin{array}{c}\text { Phase } \\
1\end{array}$} & \multirow{3}{*}{$\begin{array}{c}\text { Condition } \\
\text { Baseline }\end{array}$} & \multirow{3}{*}{$\begin{array}{c}\begin{array}{c}\text { Intensity } \\
(\mathrm{mA})\end{array} \\
-\end{array}$} & \multicolumn{2}{|c|}{ Rat JL7 } & \multicolumn{2}{|c|}{ Rat JL10 } & \multicolumn{2}{|c|}{ Rat JL12 } & \multicolumn{2}{|c|}{ Rat JL18 } \\
\hline & & & \multirow{2}{*}{$\begin{array}{c}\begin{array}{c}\text { Reinforcers } \\
\text { per min }\end{array} \\
1.32(0.02)\end{array}$} & $\begin{array}{l}\text { Shocks } \\
\text { per min } \\
\end{array}$ & \multirow{2}{*}{$\begin{array}{c}\begin{array}{c}\text { Reinforcers } \\
\text { per min }\end{array} \\
1.45(0.01)\end{array}$} & $\begin{array}{l}\text { Shocks } \\
\text { per min }\end{array}$ & $\begin{array}{c}\text { Reinforcers } \\
\text { per min }\end{array}$ & $\begin{array}{l}\text { Shocks } \\
\text { per min } \\
\end{array}$ & \multirow{2}{*}{$\begin{array}{l}\text { Reinforcers } \\
\text { per min }\end{array}$} & $\begin{array}{l}\text { Shocks } \\
\text { per min }\end{array}$ \\
\hline & & & & - & & - & $1.47(0.00)$ & - & & - \\
\hline \multirow{5}{*}{ 20th percentile } & Shock 1 & 0.05 & $1.32(0.03)$ & $2.14(0.71)$ & $1.43(0.01)$ & $9.24(0.70)$ & $1.46(0.00)$ & $16.57(1.84)$ & $1.46(0.01)$ & $10.38(0.01)$ \\
\hline & Shock 2 & 0.1 & $1.28(0.03)$ & $2.38(0.39)$ & $1.43(0.01)$ & $8.91(1.88)$ & $1.46(0.01)$ & 15.16 & $1.45(0.01)$ & $13.45(0.01)$ \\
\hline & Shock 3 & 0.2 & $1.29(0.04)$ & $2.94(1.23)$ & $1.42(0.01)$ & $5.94(2.25)$ & $1.47(0.01)$ & $17.22(1.31)$ & $1.45(0.00)$ & $8.15(0.00)$ \\
\hline & Shock 4 & 0.4 & $1.27(0.04)$ & $1.11(0.98)$ & $1.40(0.06)$ & $2.97(1.55)$ & $1.45(0.00)$ & $12.17(3.06)$ & $1.45(0.01)$ & $6.74(0.01)$ \\
\hline & Shock 5 & 0.8 & $1.18(0.07)$ & $0.13(0.12)$ & $1.25(0.14)$ & $0.18(0.14)$ & $1.43(0.01)$ & 2.15 (1.17) & $1.35(0.13)$ & $0.23(0.13)$ \\
\hline 2 & Baseline & - & $1.32(0.03)$ & - & $1.38(0.01)$ & - & $1.45 \quad(0.00)$ & - & $1.44(0.02)$ & - \\
\hline \multirow[t]{5}{*}{ 30th percentile } & Shock 1 & 0.05 & $1.29(0.02)$ & $2.28(0.93)$ & $1.38(0.01)$ & $6.26(1.64)$ & $1.46 \quad(0.00)$ & $19.92(1.88)$ & $1.43(0.02)$ & $11.07(0.02)$ \\
\hline & Shock 2 & 0.1 & $1.29(0.02)$ & $2.63(1.04)$ & $1.37(0.03)$ & $4.63(1.13)$ & $1.46 \quad(0.00)$ & $19.04(0.92)$ & $1.40(0.01)$ & $7.17(0.01)$ \\
\hline & Shock 3 & 0.2 & $1.29(0.01)$ & $1.67(0.28)$ & $1.38(0.01)$ & $5.22(1.35)$ & $1.46 \quad(0.01)$ & $16.86(2.64)$ & $1.42(0.01)$ & $5.75(0.01)$ \\
\hline & Shock 4 & 0.4 & $1.30(0.01)$ & $2.01(0.51)$ & $1.38(0.02)$ & $1.17(1.30)$ & $1.46 \quad(0.00)$ & $15.69(3.27)$ & $1.41(0.01)$ & $1.48(0.01)$ \\
\hline & Shock 5 & 0.8 & $1.29(0.01)$ & $0.46(0.19)$ & $1.36(0.01)$ & $0.31(0.16)$ & $1.45 \quad(0.01)$ & $11.41(4.27)$ & $1.39(0.01)$ & $0.13(0.01)$ \\
\hline 3 & Baseline & - & $1.30(0.01)$ & - & $1.40(0.01)$ & - & $1.45 \quad(0.01)$ & - & $1.44(0.01)$ & - \\
\hline \multirow[t]{5}{*}{ 40th percentile } & Shock 1 & 0.05 & $1.31(0.01)$ & 3.18 (1.64) & $1.38(0.02)$ & 11.56 (3.69) & $1.44 \quad(0.01)$ & $23.72(2.67)$ & $1.44(0.01)$ & $17.07(0.01)$ \\
\hline & Shock 2 & 0.1 & $1.32(0.02)$ & $2.74(1.43)$ & $1.39(0.01)$ & $11.00(2.49)$ & $1.43 \quad(0.01)$ & $20.71(3.40)$ & $1.42(0.01)$ & $12.14(0.01)$ \\
\hline & Shock 3 & 0.2 & $1.32(0.01)$ & $1.98(0.67)$ & $1.39(0.01)$ & $5.87(1.58)$ & $1.44 \quad(0.00)$ & $21.03(4.81)$ & $1.42(0.02)$ & $6.90(0.02)$ \\
\hline & Shock 4 & 0.4 & $1.31(0.02)$ & $0.93(0.49)$ & $1.40(0.00)$ & $9.79(2.84)$ & $1.44 \quad(0.01)$ & $14.22(3.65)$ & $1.42(0.02)$ & $4.47(0.02)$ \\
\hline & Shock 5 & 0.8 & $1.29(0.01)$ & $0.46(0.52)$ & $1.34(0.06)$ & $0.54(0.42)$ & $1.43 \quad(0.01)$ & $6.33(2.58)$ & $1.42(0.01)$ & $1.09(0.01)$ \\
\hline 4 & Baseline & - & $1.34(0.01)$ & - & $1.38(0.01)$ & - & $1.45 \quad(0.01)$ & - & $1.44(0.01)$ & - \\
\hline \multirow[t]{5}{*}{ 50th percentile } & Shock 1 & 0.05 & $1.33(0.02)$ & $3.14(0.72)$ & $1.38(0.01)$ & $14.17(4.19)$ & $1.44 \quad(0.01)$ & $22.67(2.21)$ & $1.42(0.00)$ & $16.61(0.00)$ \\
\hline & Shock 2 & 0.1 & $1.33(0.01)$ & $2.61(0.93)$ & $1.37(0.01)$ & $9.41(2.71)$ & $1.44 \quad(0.00)$ & $24.70(4.19)$ & $1.42(0.00)$ & $14.30(0.00)$ \\
\hline & Shock 3 & 0.2 & $1.33(0.01)$ & $2.20(0.62)$ & $1.37(0.01)$ & $8.15(1.86)$ & $1.44 \quad(0.01)$ & $18.40(4.20)$ & $1.42(0.01)$ & $14.49(0.01)$ \\
\hline & Shock 4 & 0.4 & $1.32(0.02)$ & $1.91(0.71)$ & $1.36(0.03)$ & $7.92(3.35)$ & $1.44 \quad(0.01)$ & $15.00(2.67)$ & $1.40(0.01)$ & $4.83(0.01)$ \\
\hline & Shock 5 & 0.8 & $1.31(0.01)$ & $0.21(0.07)$ & $1.32(0.03)$ & $0.41(0.20)$ & $1.42(0.02)^{\mathrm{a}}$ & $1.30(0.92)$ & $1.39(0.03)$ & $0.59(0.03)$ \\
\hline
\end{tabular}




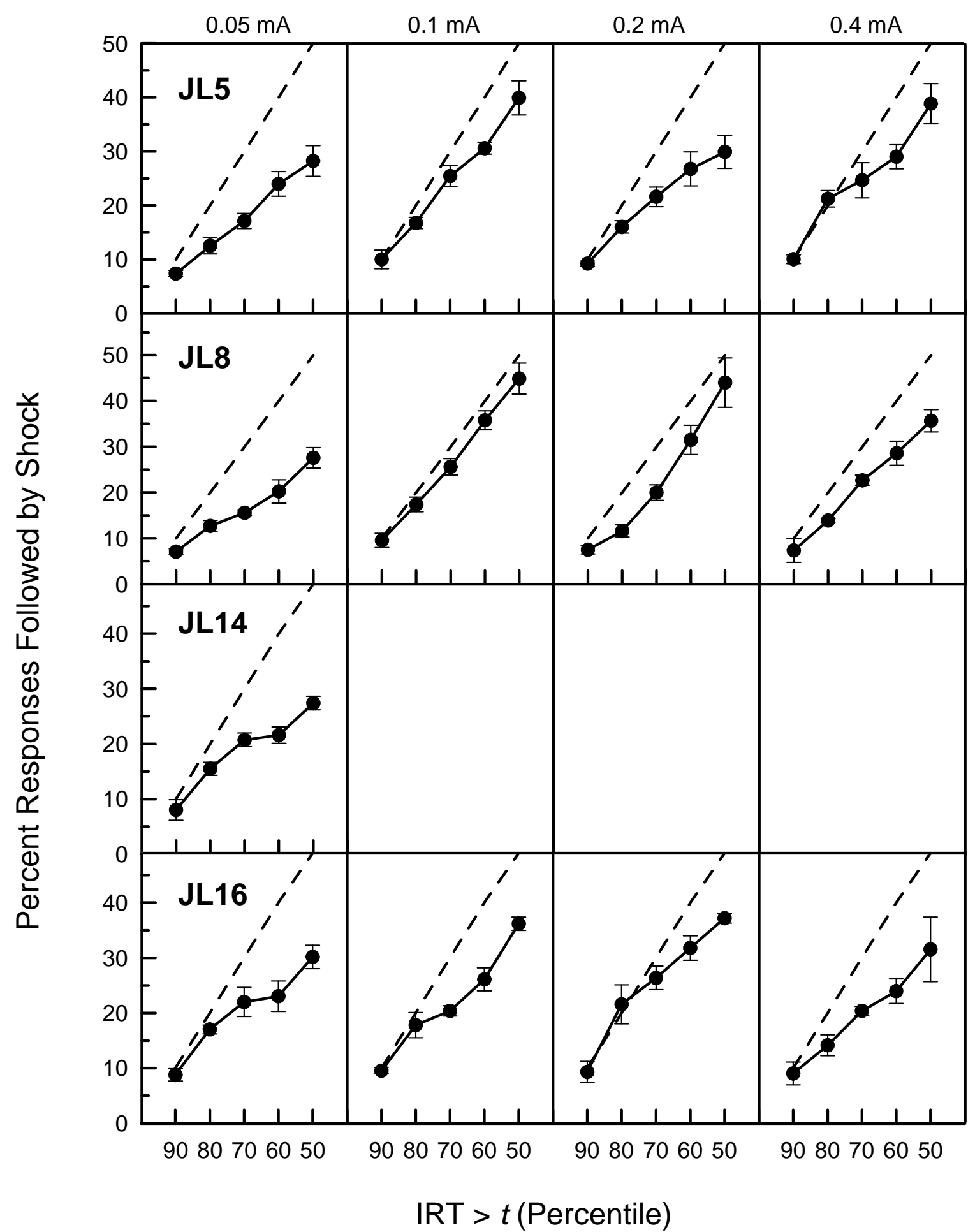

Figure 1. Experiment 1: Percent of responses followed by shock. Error bars extend one standard deviation above and one standard deviation below the mean of each shock condition. The reference line indicates the percent of baseline responses that satisfied the shock contingency. Percentiles are listed in descending order because this order reflects the increase in the portion of the IRT distribution susceptible to the shock contingency. Note that the scale of the ordinate is different for Rat JL8. 


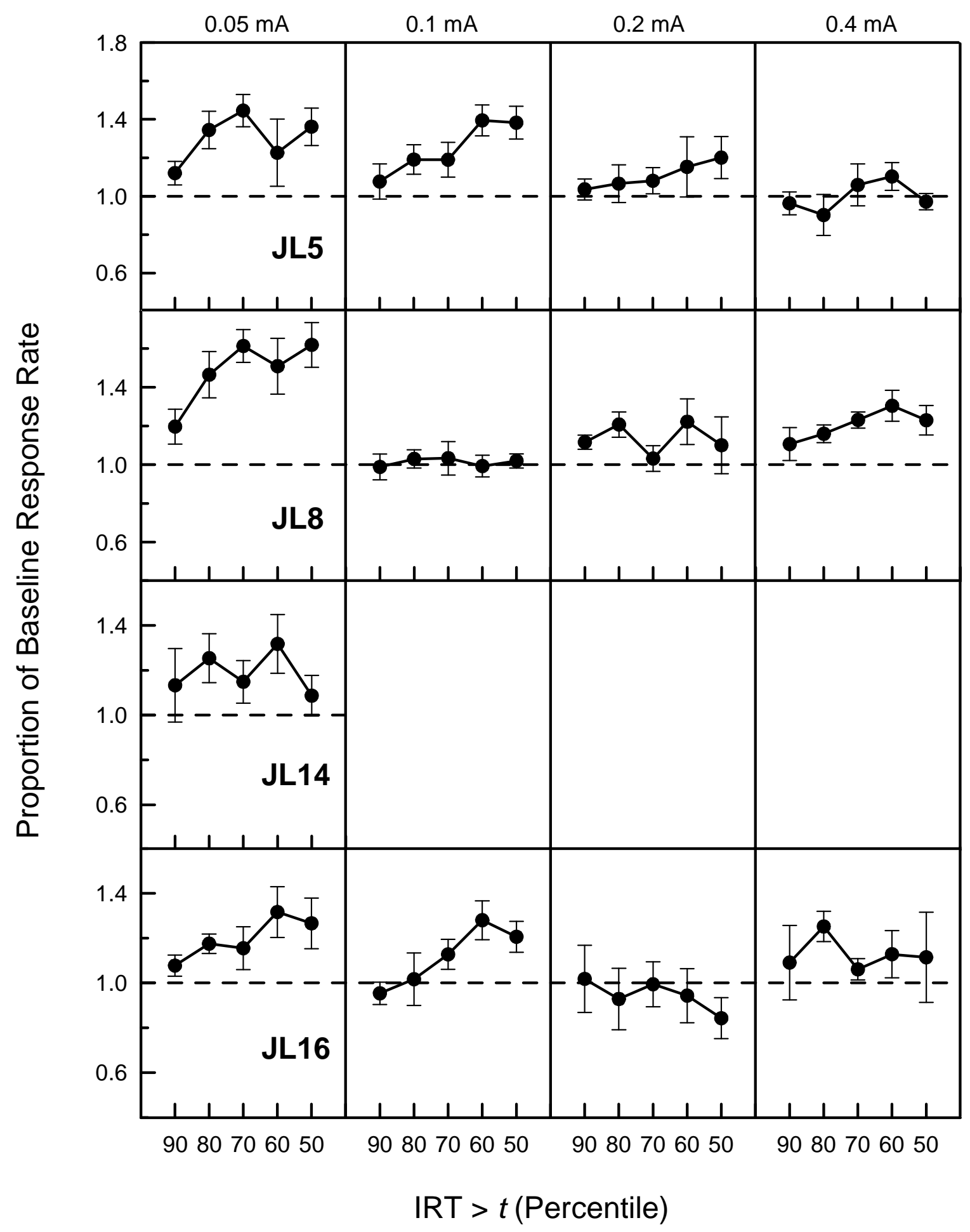

Figure 2. Experiment 1: Proportion of baseline response rates across all shock conditions. Error bars extend one standard deviation above and one standard deviation below the mean. Percentiles are listed in descending order because this order reflects the increase in the portion of the IRT distribution susceptible to the shock contingency. Note that the ordinate is scaled from 0.4 to 1.8 . 


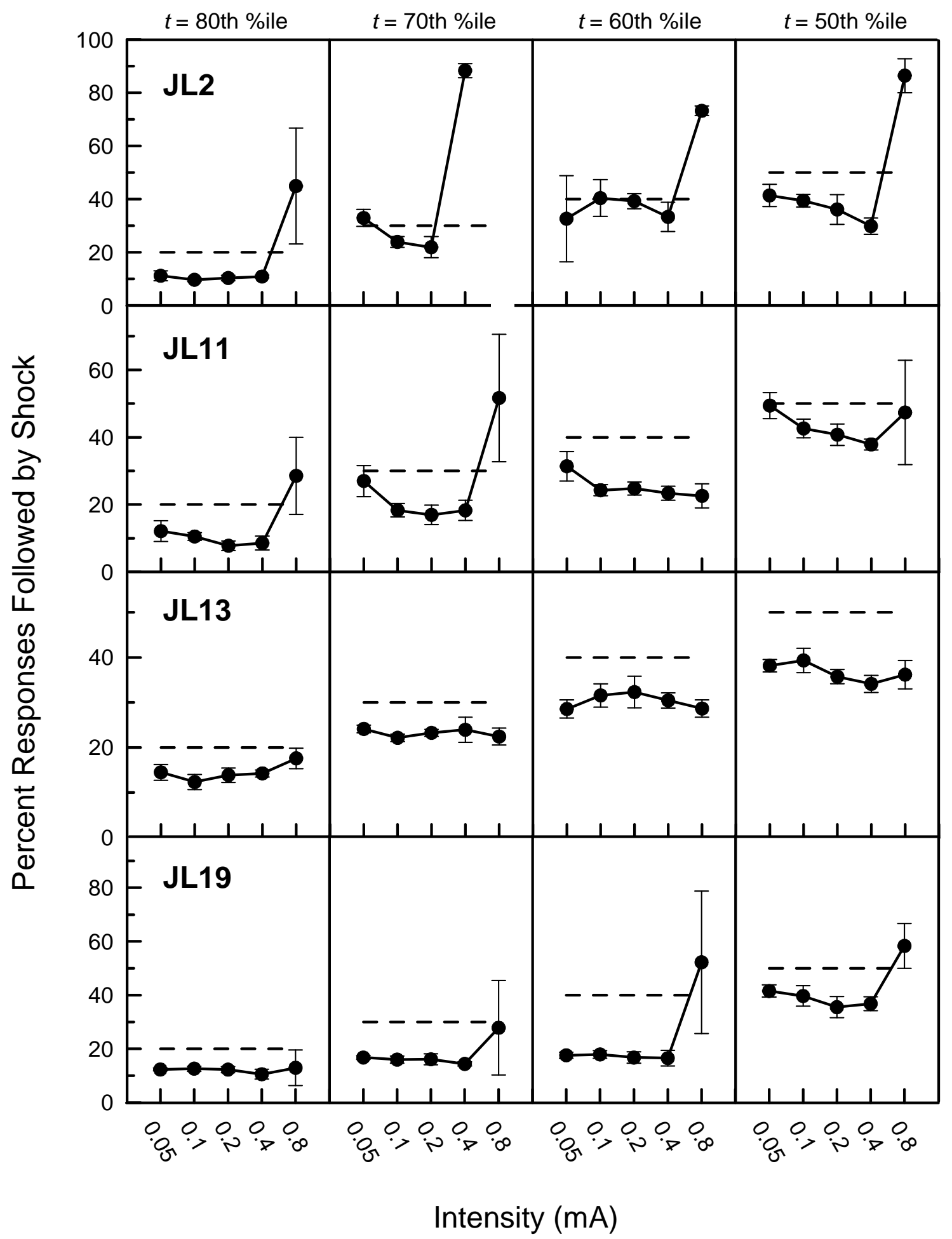

Figure 3. Experiment 2: Percent of responses followed by shock. Error bars extend one standard deviation above and one standard deviation below the mean. Note the change in the scaling of the ordinate for Rat JL19. 


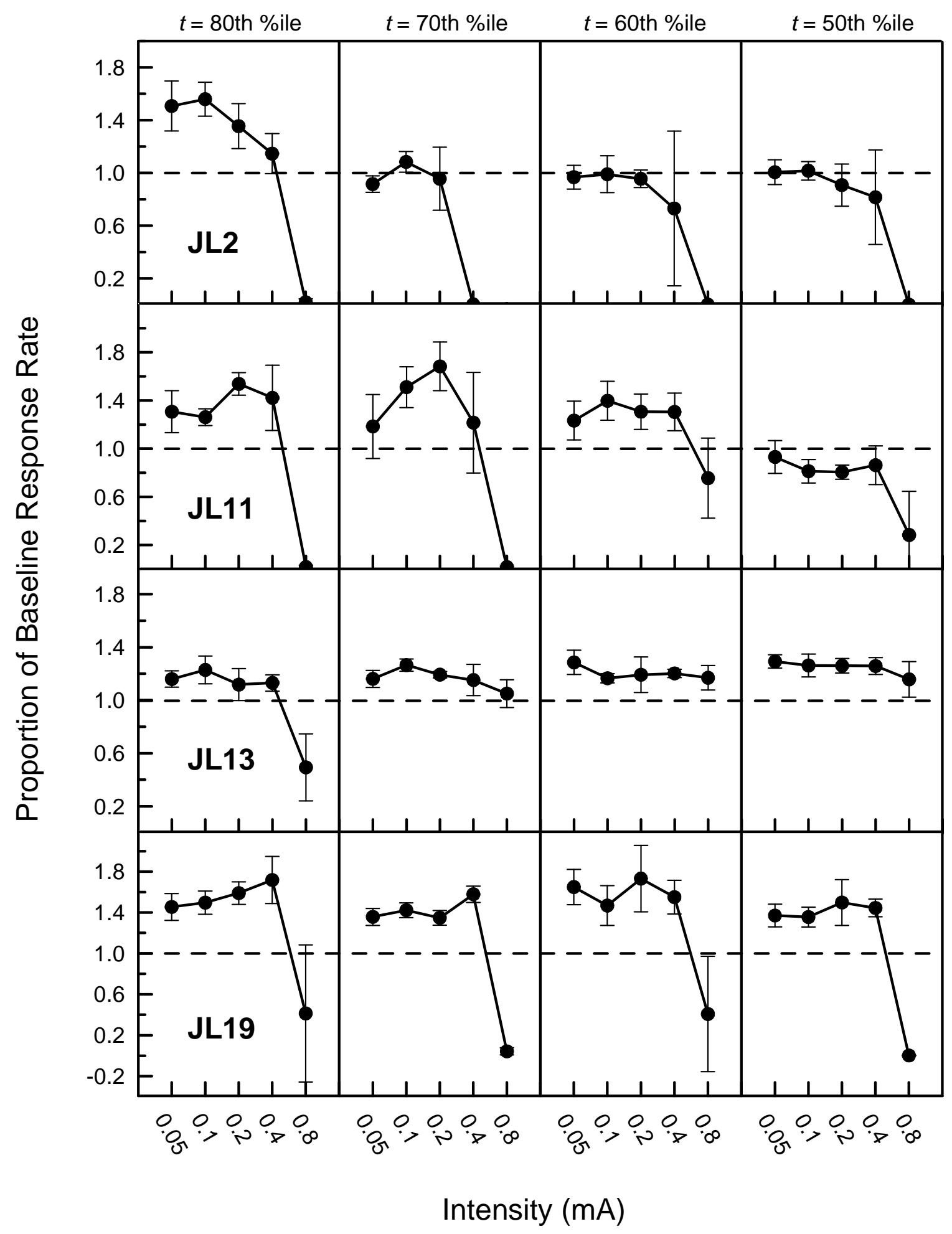

Figure 4. Experiment 2: Proportion of baseline response rates across all shock conditions. Error bars extend one standard deviation above and one standard deviation below the mean. Note the changes in the scaling of the ordinate for Rat JL11 and JL19. 


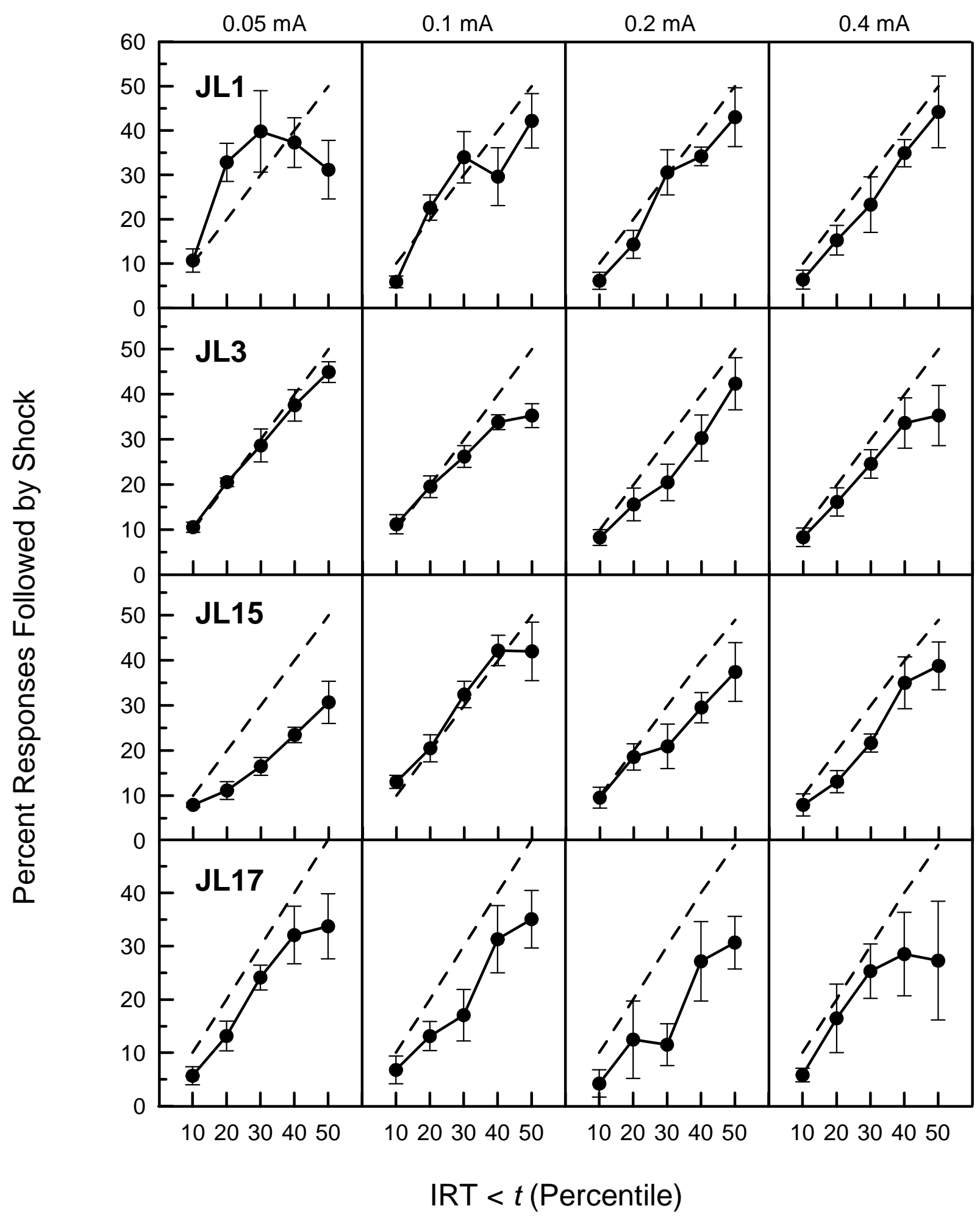

Figure 5. Experiment 3: Percent of responses followed by shock. Error bars extend one standard deviation above and one standard deviation below the mean. Note that the scale of the ordinate varies across rats. 


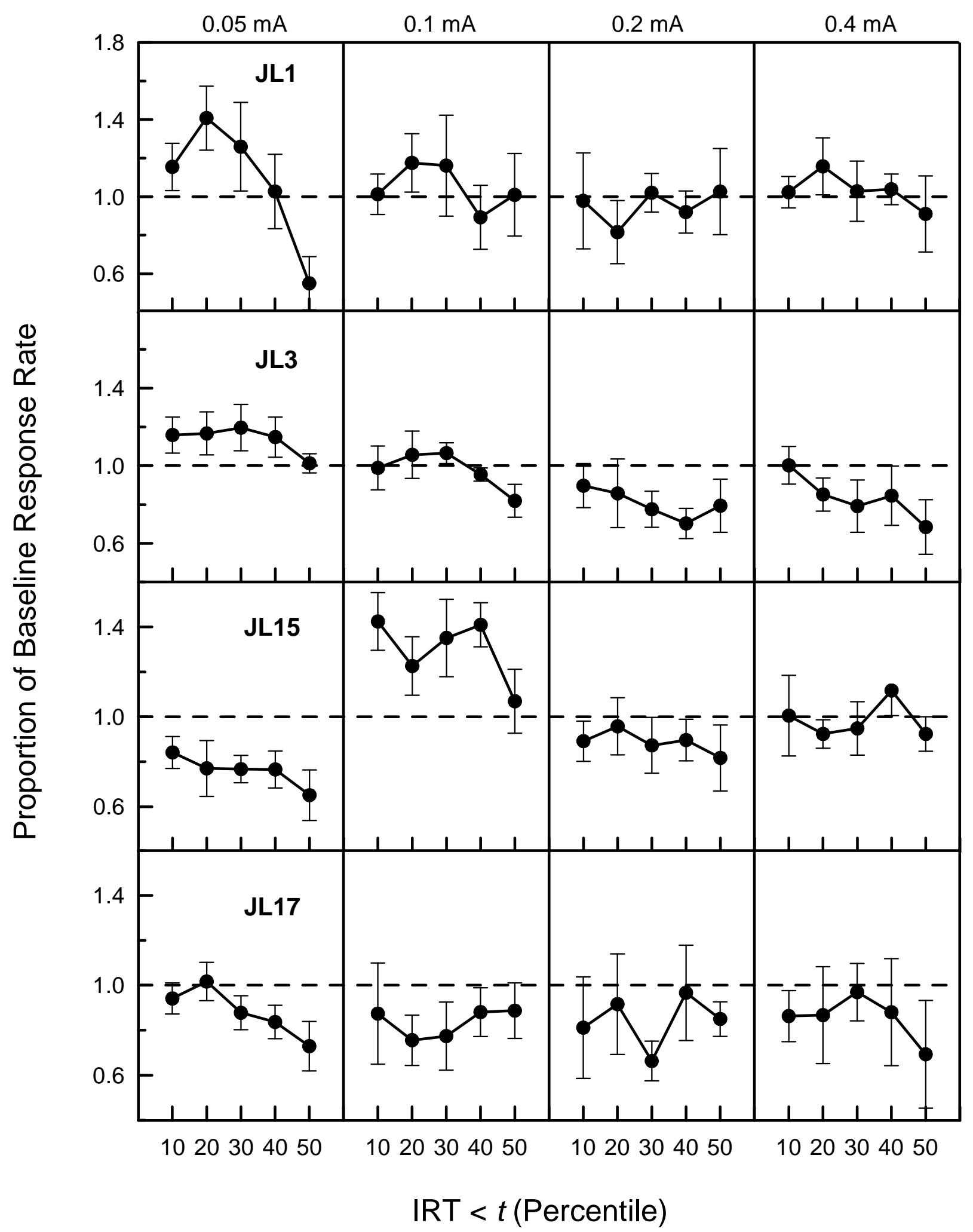

Figure 6. Experiment 3: Proportion of baseline response rates across all shock conditions. Error bars extend one standard deviation above and one standard deviation below the mean. Note the changes in the scaling of the ordinate for Rat JL15 and JL17. 


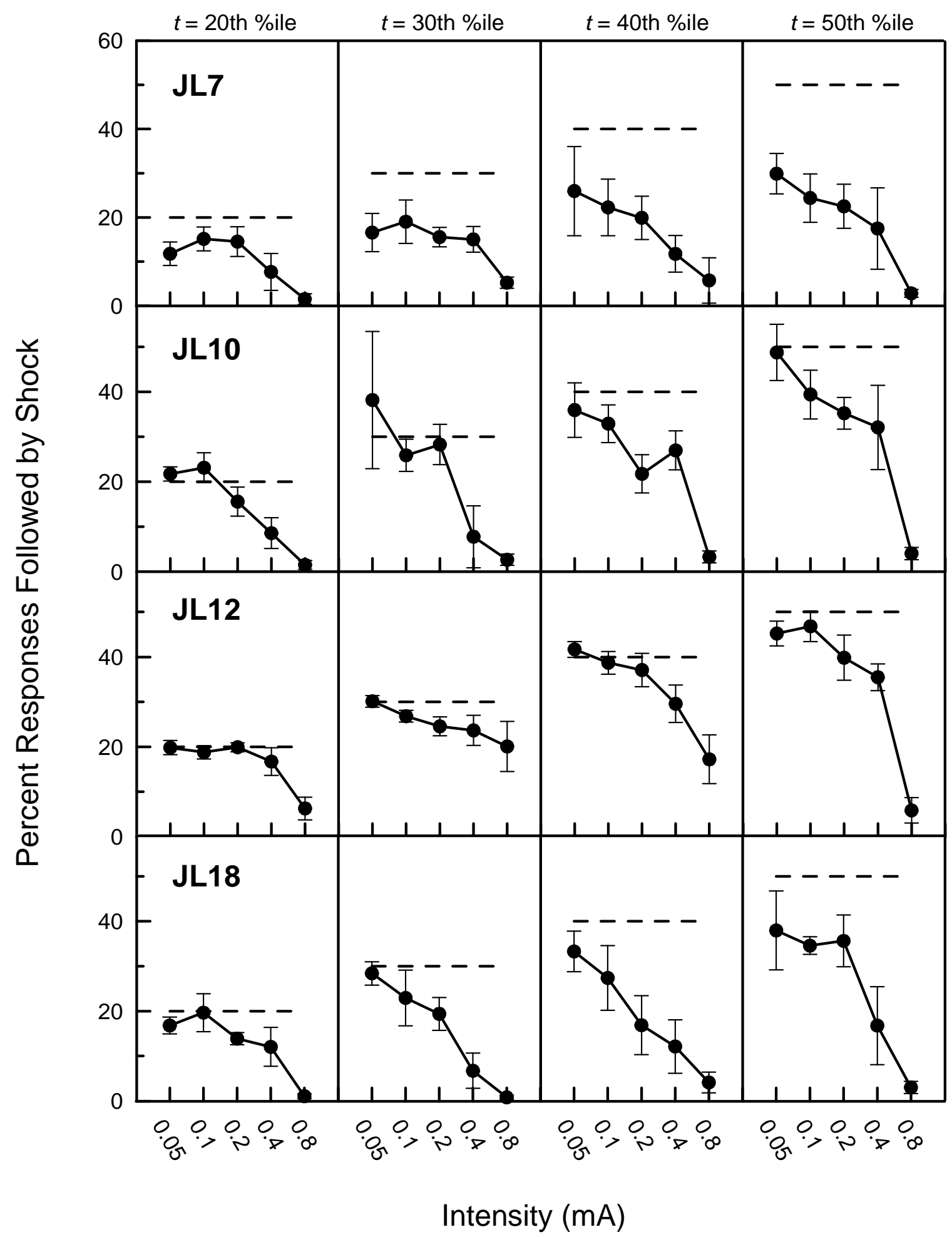

Figure 7. Experiment 4: Percent of responses followed by shock. Error bars extend one standard deviation above and one standard deviation below the mean. 


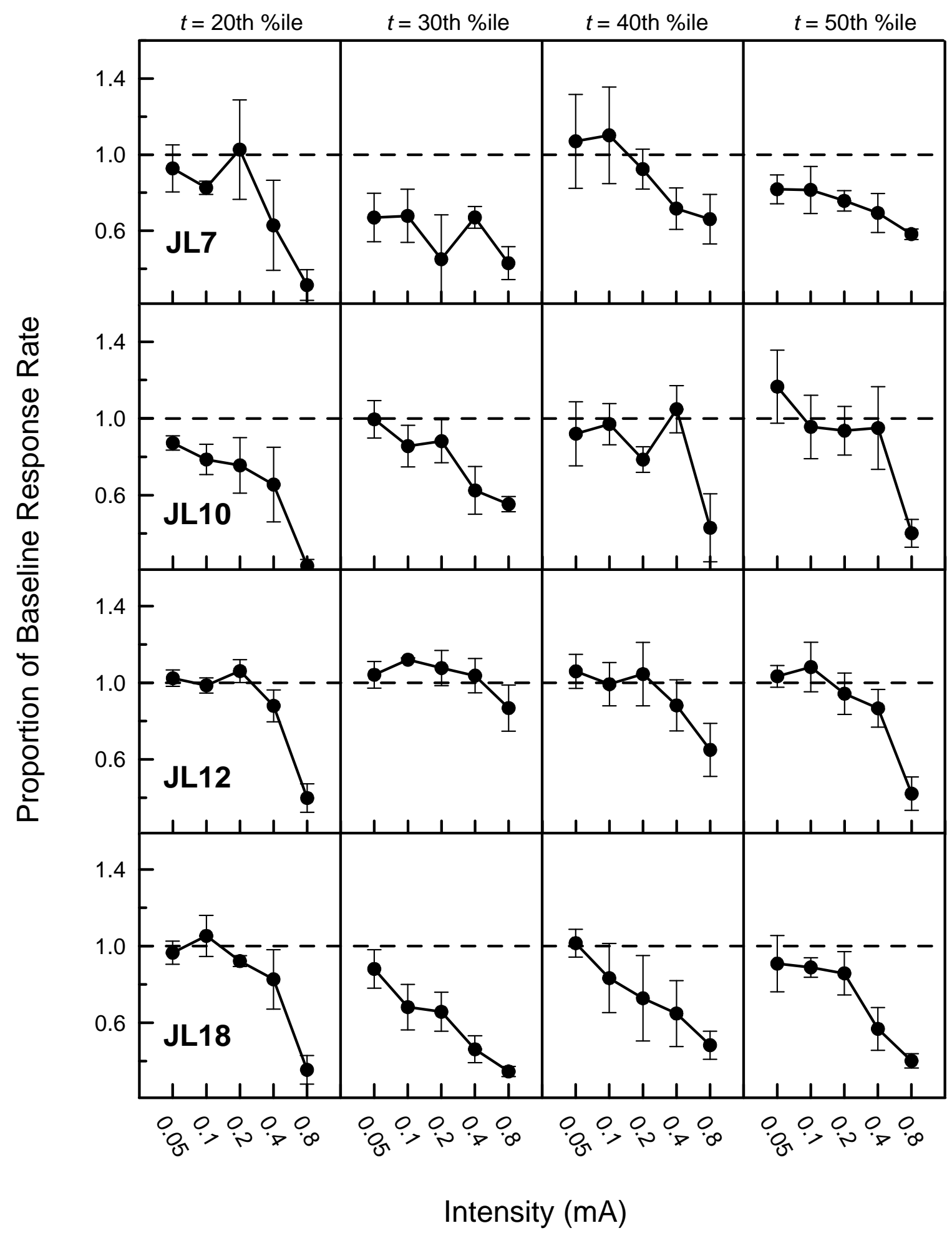

Figure 8. Experiment 4: Proportion of baseline response rates across all shock conditions. Error bars extend one standard deviation above and one standard deviation below the mean. 


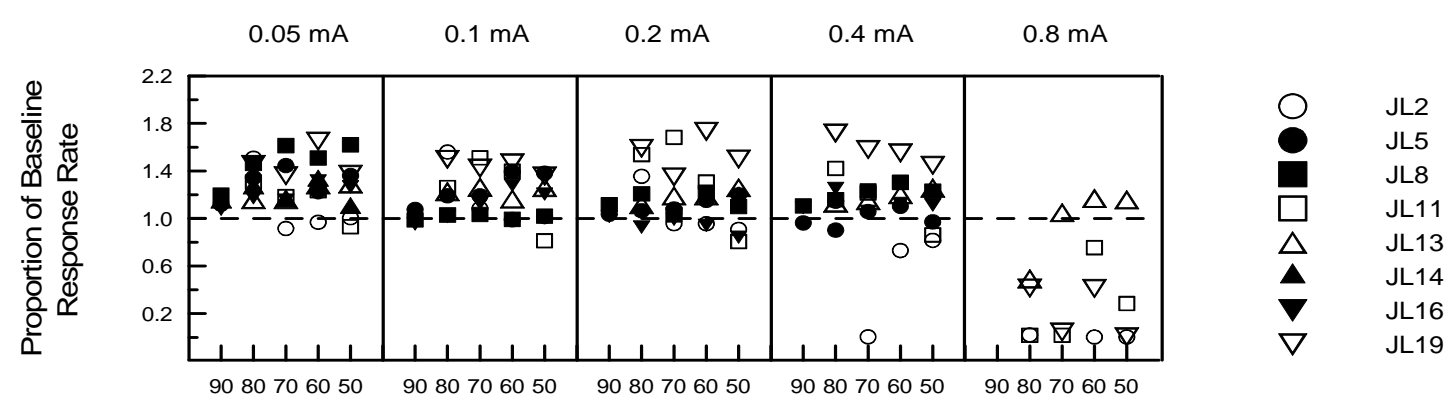

IRT $>t$ (Percentile)
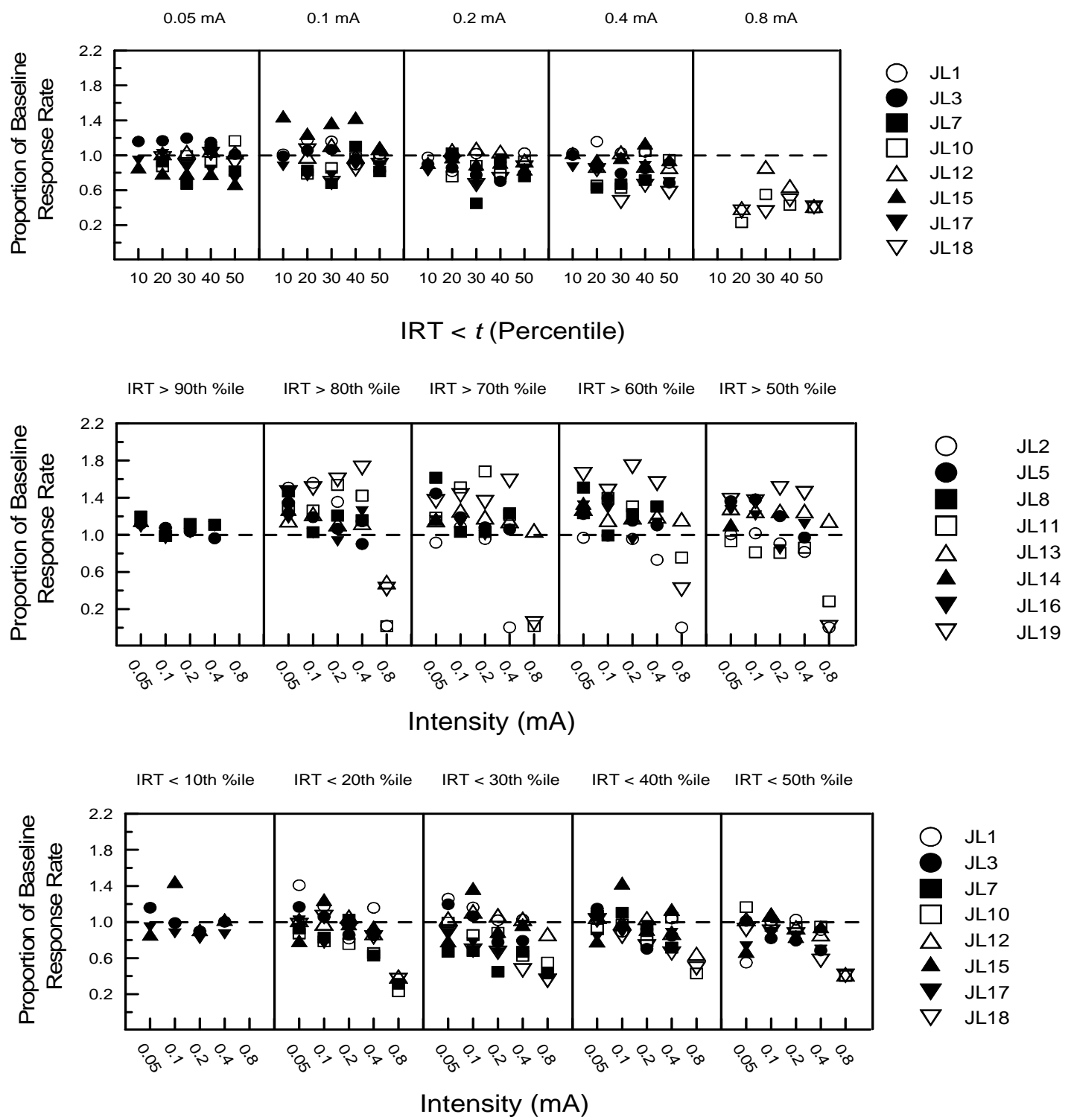

Figure 9. Experiments 1,2,3, and 4: Proportion of baseline response rates for all rats in the four experiments. The first and third sets of panels present data from Experiment 1 (closed symbols) and Experiment 2 (open symbols). The second and fourth sets of panels present data from Experiment 3 (closed symbols) and Experiment 4 (open symbols). 
Appendix A

Additional Analyses for Experiment 1 


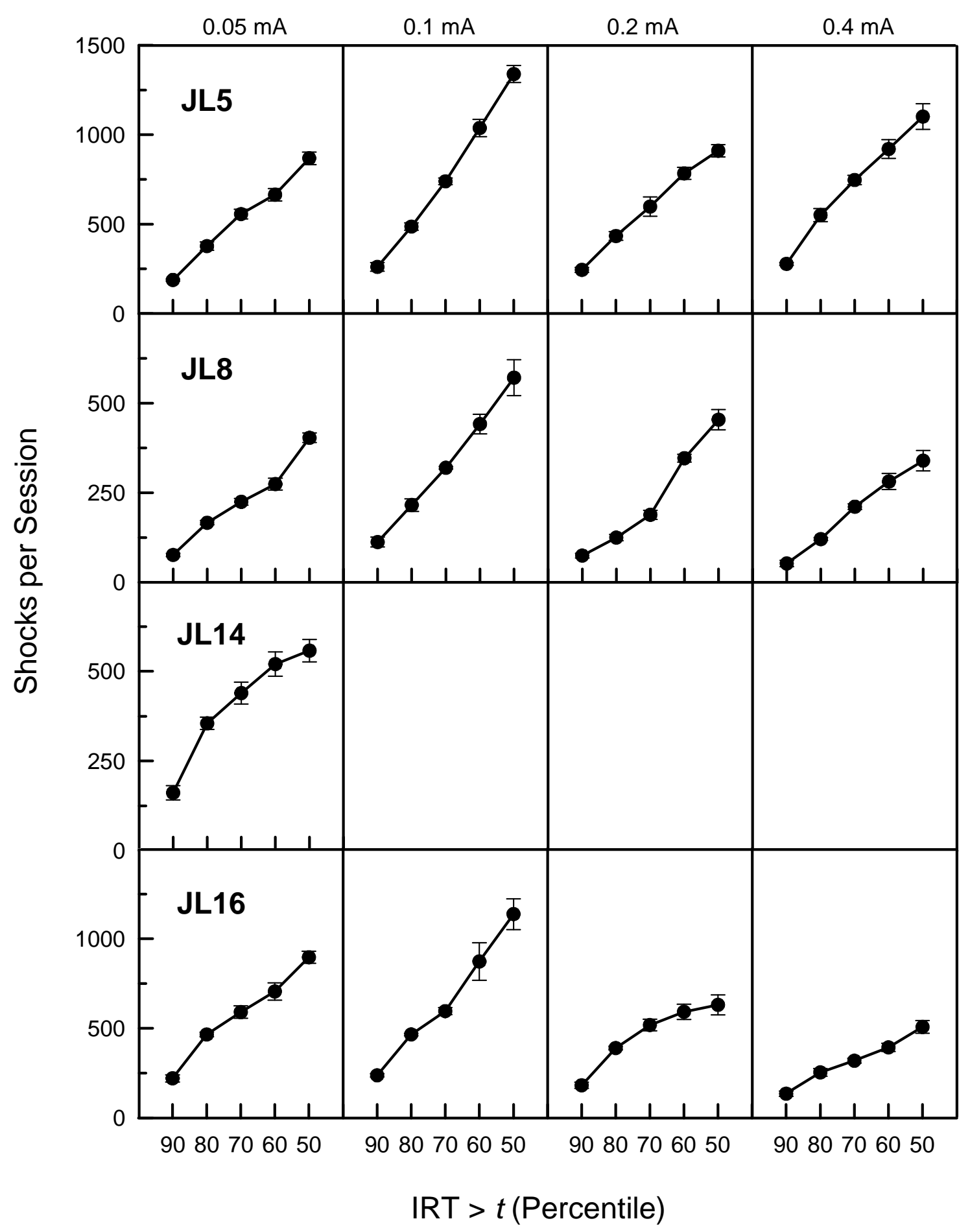

Figure A1. Experiment 1: Mean shocks per session across shock conditions. Error bars extend one standard deviation above and below the mean. Percentiles are listed in descending order because this order reflects the increase in the portion of the IRT distribution susceptible to the shock contingency. Note that the scale of the ordinate varies across rats. 


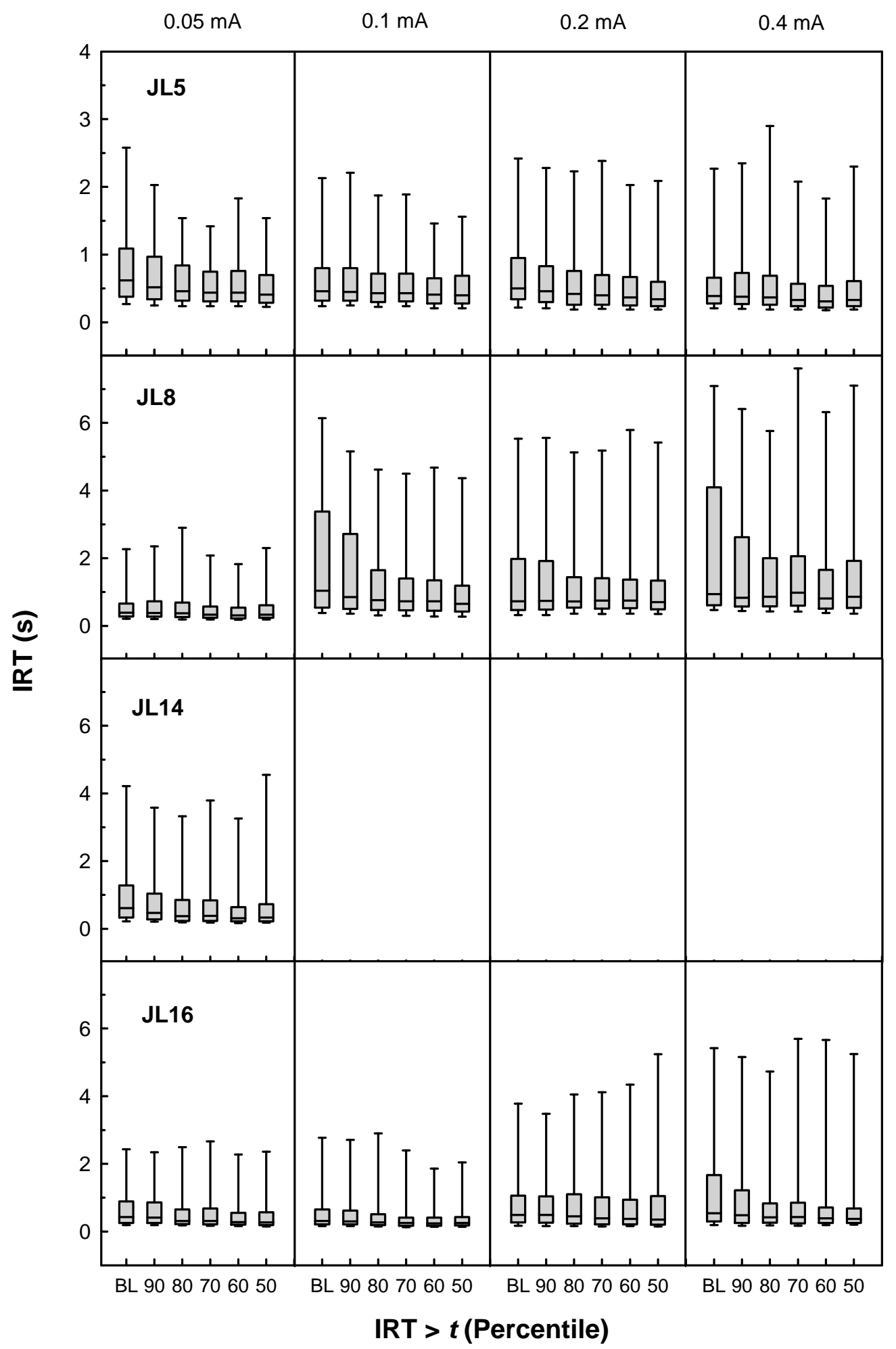

Figure A2. Experiment 1: Summaries of the IRT distributions from the stable baseline sessions and all shock sessions displayed in the form of box and whisker plots. The boxes extend from the $25^{\text {th }}$ to the $75^{\text {th }}$ percentile with the $50^{\text {th }}$ percentile depicted as a horizontal line within the box. Whiskers extend from the $10^{\text {th }}$ to the $90^{\text {th }}$ percentile. Note the ordinate scale varies across rats. 


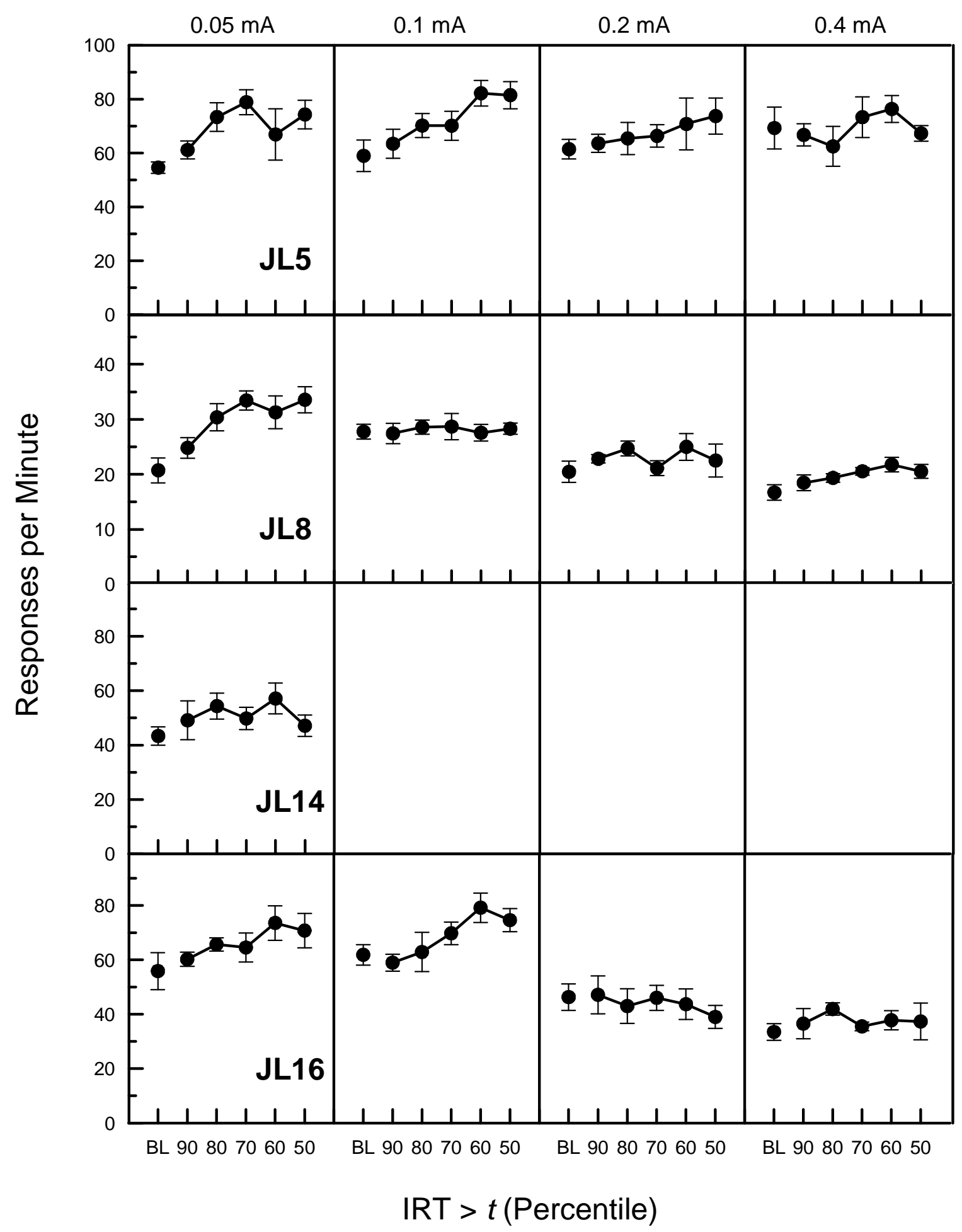

Figure A3. Experiment 1: Mean response rates across the baseline and shock conditions for each phase. Error bars extend one standard deviation above and one standard deviation below the mean. Percentiles are listed in descending order because this order reflects the increase in the portion of the IRT distribution susceptible to the shock contingency. Note the change in the scale of the ordinate for Rat JL8. 
Experiment 1: Tests of Within-Subjects Effects

Measure: Differences Between Percent of Responses Followed by Shock and Those Indicated by Reference Line

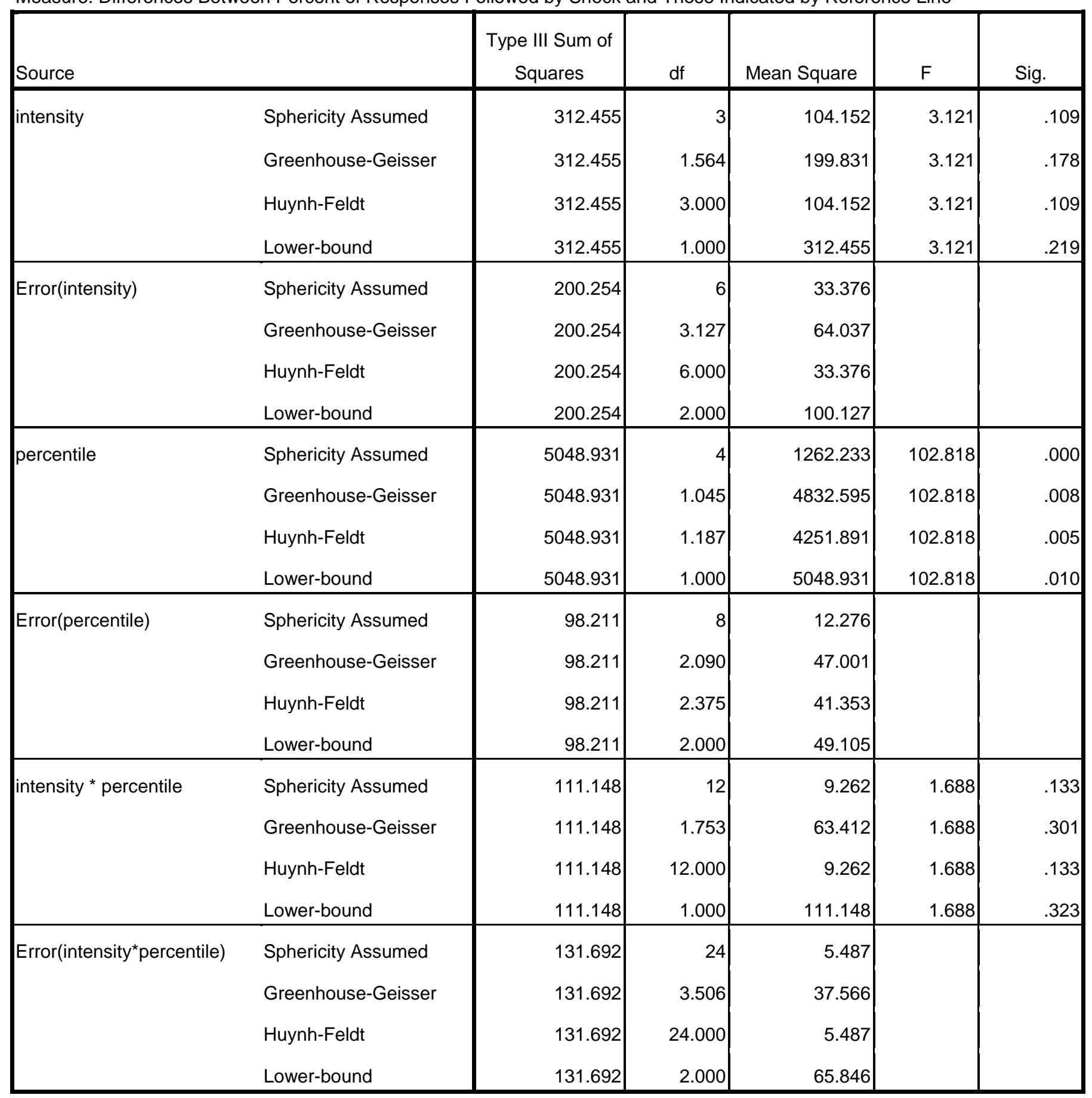


Experiment 1: Pairwise Comparisons for Percentile

Measure: Differences Between Percent of Responses Followed by Shock and Reference Line Values

\begin{tabular}{|c|c|c|c|c|c|c|}
\hline \multirow[b]{2}{*}{ (I) percentile } & \multirow[b]{2}{*}{ (J) percentile } & \multirow{2}{*}{$\begin{array}{c}\text { Mean } \\
\text { Difference } \\
(\mathrm{I}-\mathrm{J})\end{array}$} & \multirow[b]{2}{*}{ Std. Error } & \multirow[b]{2}{*}{ Sig. ${ }^{a}$} & \multicolumn{2}{|c|}{ 95\% Confidence Interval for Difference ${ }^{a}$} \\
\hline & & & & & Lower Bound & Upper Bound \\
\hline \multirow[t]{4}{*}{ 90th } & 80th & $-7.321^{\star}$ & .706 & .009 & -10.359 & -4.283 \\
\hline & 70th & $-13.085^{\star}$ & .028 & .000 & -13.205 & -12.965 \\
\hline & 60 th & $-18.874^{\star}$ & 1.208 & .004 & -24.073 & -13.675 \\
\hline & 50th & $-26.607^{\star}$ & 1.786 & .004 & -34.292 & -18.922 \\
\hline \multirow[t]{4}{*}{ 80th } & 90th & $7.321^{*}$ & .706 & .009 & 4.283 & 10.359 \\
\hline & 70th & $-5.764^{*}$ & .703 & .015 & -8.787 & -2.740 \\
\hline & 60th & $-11.553^{*}$ & 1.912 & .026 & -19.780 & -3.325 \\
\hline & 50th & $-19.286^{*}$ & 2.460 & .016 & -29.870 & -8.702 \\
\hline \multirow[t]{4}{*}{ 70th } & 90th & $13.085^{\star}$ & .028 & .000 & 12.965 & 13.205 \\
\hline & 80th & $5.764^{\star}$ & .703 & .015 & 2.740 & 8.787 \\
\hline & 60th & $-5.789^{*}$ & 1.210 & .041 & -10.994 & -.584 \\
\hline & 50th & $-13.522^{\star}$ & 1.780 & .017 & -21.182 & -5.862 \\
\hline \multirow[t]{4}{*}{ 60th } & 90th & $18.874^{\star}$ & 1.208 & .004 & 13.675 & 24.073 \\
\hline & 80th & $11.553^{\star}$ & 1.912 & .026 & 3.325 & 19.780 \\
\hline & 70th & $5.789^{\star}$ & 1.210 & .041 & .584 & 10.994 \\
\hline & 50th & $-7.733^{*}$ & .690 & .008 & -10.704 & -4.763 \\
\hline \multirow[t]{4}{*}{ 50th } & 90th & $26.607^{\star}$ & 1.786 & .004 & 18.922 & 34.292 \\
\hline & 80th & $19.286^{\star}$ & 2.460 & .016 & 8.702 & 29.870 \\
\hline & 70th & $13.522^{\star}$ & 1.780 & .017 & 5.862 & 21.182 \\
\hline & 60th & $7.733^{\star}$ & .690 & .008 & 4.763 & 10.704 \\
\hline
\end{tabular}

Based on estimated marginal means

*. The mean difference is significant at the .05 level.

a. Adjustment for multiple comparisons: Least Significant Difference (equivalent to no adjustments). 
Experiment 1: Tests of Within-Subjects Effects

Measure: Proportional Response Rates

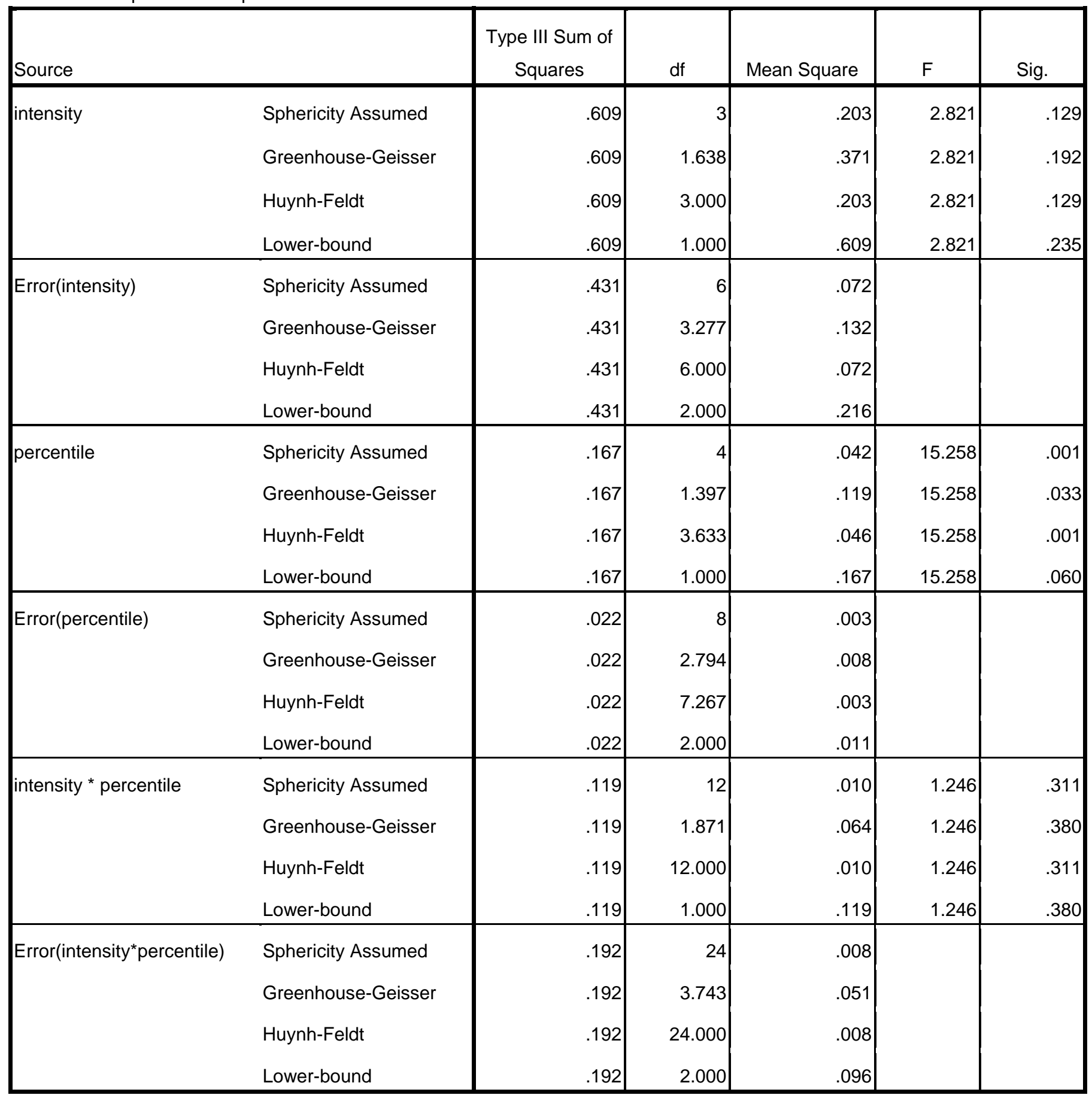


Experiment 1: Pairwise Comparisons for Percentile

Measure: Proportional Response Rate

\begin{tabular}{|c|c|c|c|c|c|c|}
\hline \multirow[b]{2}{*}{ (I) percentile } & \multirow[b]{2}{*}{ (J) percentile } & \multirow{2}{*}{$\begin{array}{c}\text { Mean } \\
\text { Difference } \\
(\mathrm{I}-\mathrm{J})\end{array}$} & \multirow{2}{*}{$\begin{array}{l}\text { Std. } \\
\text { Error }\end{array}$} & \multirow[b]{2}{*}{ Sig. ${ }^{a}$} & \multicolumn{2}{|c|}{$\begin{array}{l}\text { 95\% Confidence Interval for } \\
\text { Difference }^{a}\end{array}$} \\
\hline & & & & & Lower Bound & Upper Bound \\
\hline \multirow[t]{4}{*}{ 90th } & 80th & $-.083^{\star}$ & .016 & .036 & -.153 & -.013 \\
\hline & 70th & -.107 & .029 & .067 & -.232 & .019 \\
\hline & 60th & $-.152^{\star}$ & .011 & .005 & -.200 & -.105 \\
\hline & 50th & -.131 & .032 & .053 & -.267 & .005 \\
\hline \multirow[t]{4}{*}{ 80th } & 90th & $.083^{\star}$ & .016 & .036 & .013 & .153 \\
\hline & 70th & -.024 & .023 & .408 & -.122 & .075 \\
\hline & 60th & $-.070^{*}$ & .015 & .044 & -.135 & -.005 \\
\hline & 50th & -.048 & .028 & .226 & -.168 & .072 \\
\hline \multirow[t]{4}{*}{ 70th } & 90th & .107 & .029 & .067 & -.019 & .232 \\
\hline & 80th & .024 & .023 & .408 & -.075 & .122 \\
\hline & 60th & -.046 & .018 & .131 & -.125 & .033 \\
\hline & 50th & -.024 & .006 & .056 & -.050 & .002 \\
\hline \multirow[t]{4}{*}{ 60th } & 90th & $.152^{\star}$ & .011 & .005 & .105 & .200 \\
\hline & 80th & $.070^{*}$ & .015 & .044 & .005 & .135 \\
\hline & 70th & .046 & .018 & .131 & -.033 & .125 \\
\hline & 50th & .021 & .020 & .404 & -.066 & .109 \\
\hline \multirow[t]{4}{*}{ 50th } & 90th & .131 & .032 & .053 & -.005 & .267 \\
\hline & 80th & .048 & .028 & .226 & -.072 & .168 \\
\hline & 70th & .024 & .006 & .056 & -.002 & .050 \\
\hline & 60th & -.021 & .020 & .404 & -.109 & .066 \\
\hline
\end{tabular}

Based on estimated marginal means

*. The mean difference is significant at the .05 level.

a. Adjustment for multiple comparisons: Least Significant Difference (equivalent to no adjustments). 
Appendix B

Additional Analyses for Experiment 2 


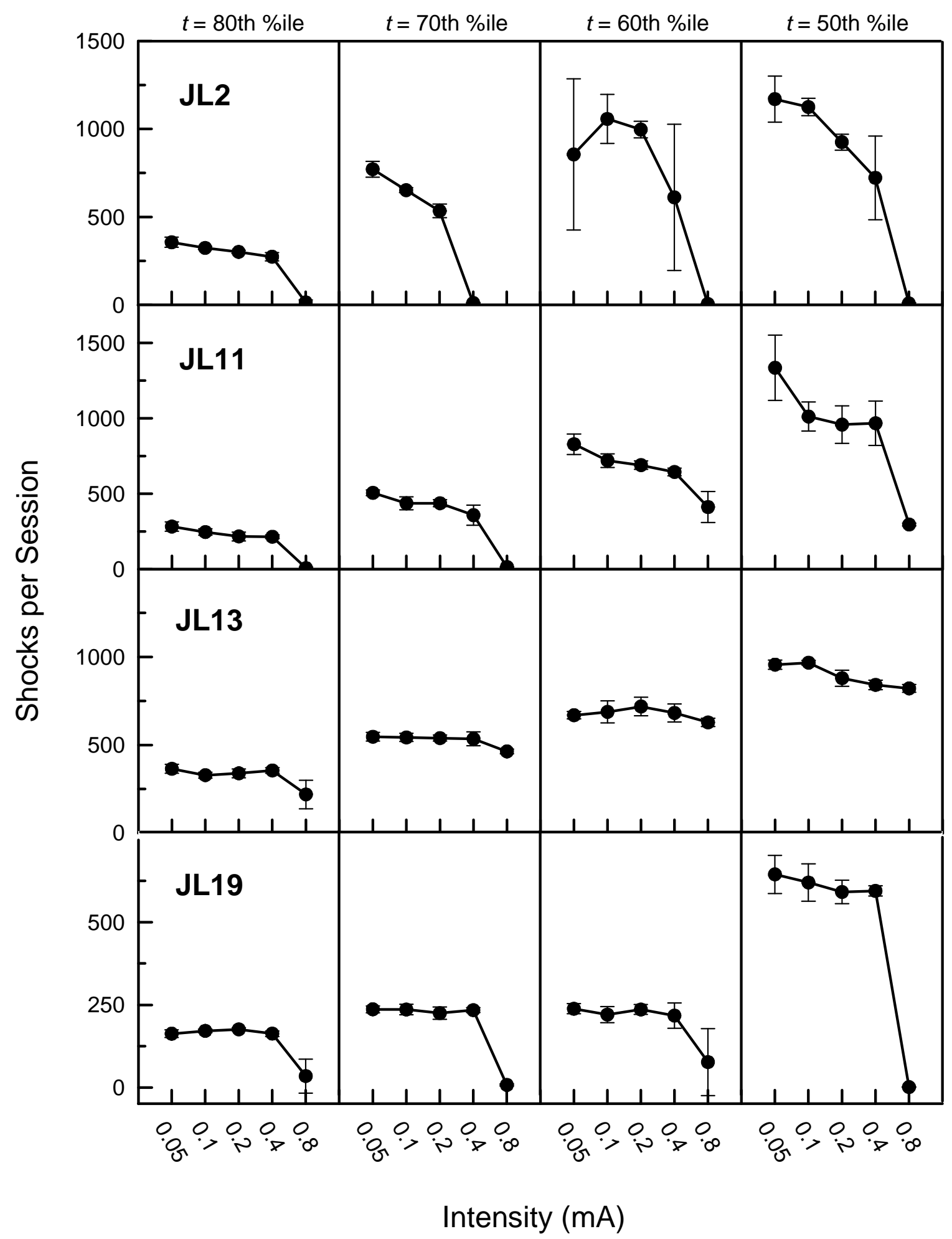

Figure B1. Experiment 2: Mean shocks per session across each shock conditions. Error bars extend one standard deviation above and one standard deviation below the mean. Rat JL2 was not exposed to the fifth shock condition. Note the scaling of the ordinate varies across rats. 


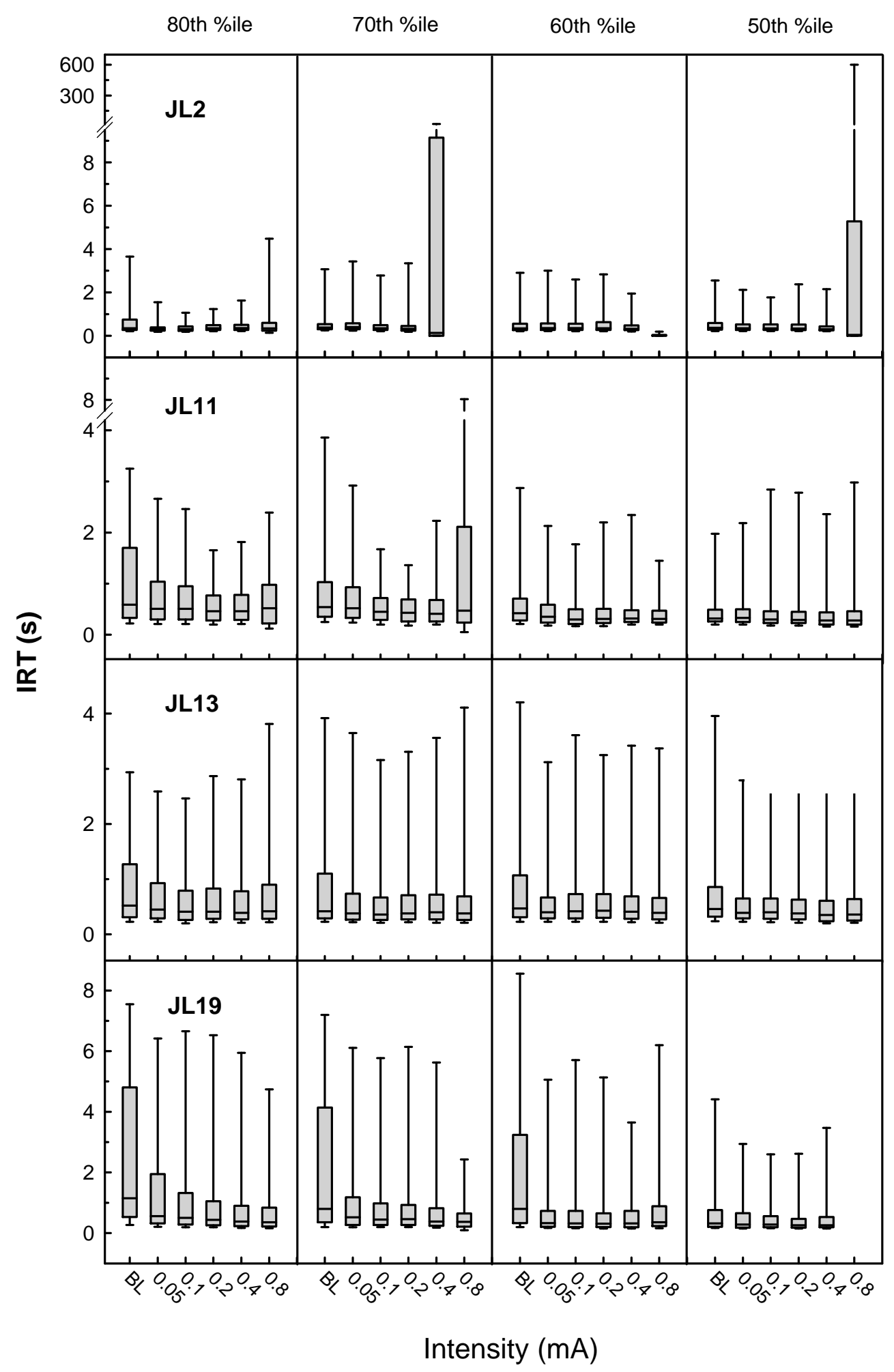

Figure B2. Experiment 2: Summaries of the IRT distributions from the stable baseline sessions and all shock sessions displayed in the form of box and whisker plots. All other details are the same as those in Figure A2. 


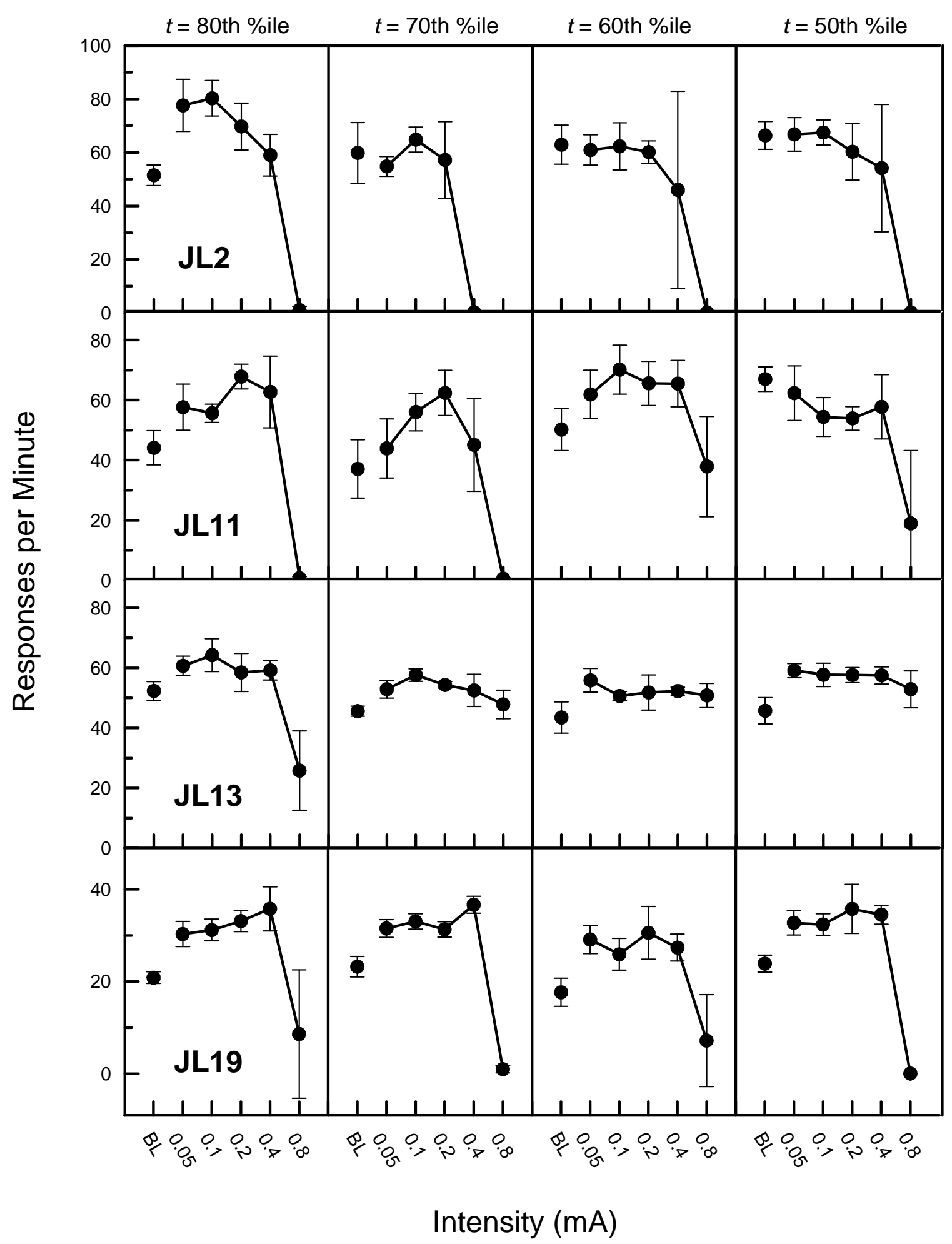

Figure B3. Experiment 2: Mean response rates across the baseline and shock conditions for each phase. Error bars extend one standard deviation above and one standard deviation below the mean. Note the change in the scale of the ordinate for Rat JL2 and Rat JL19. 


\section{Experiment 2: Tests of Within-Subjects Effects}

Measure: Differences Between Percent of Responses Followed by Shock and Those Indicated by Reference Line

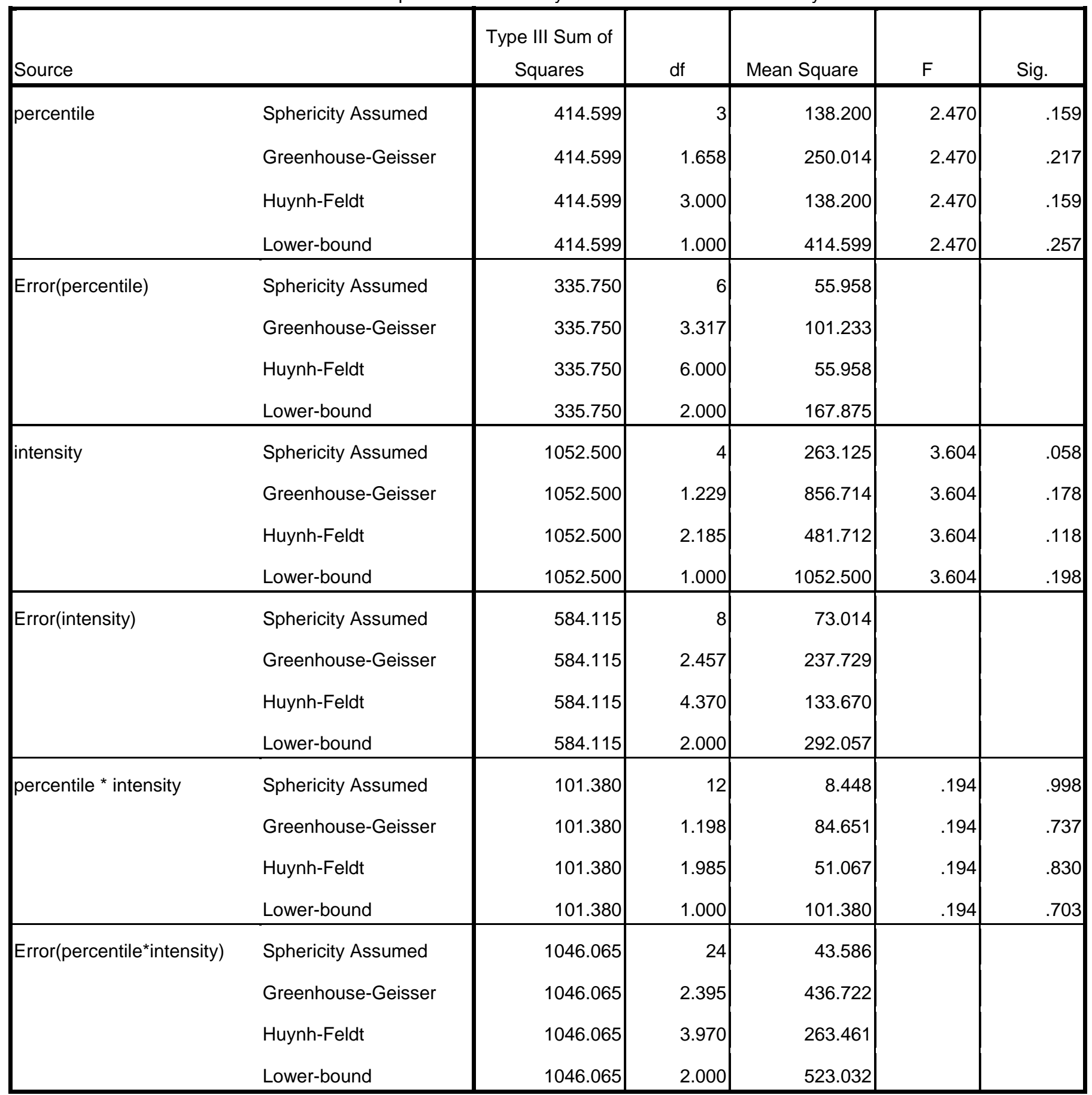


Experiment 2: Tests of Within-Subjects Effects

Measure: Proportional Response Rates

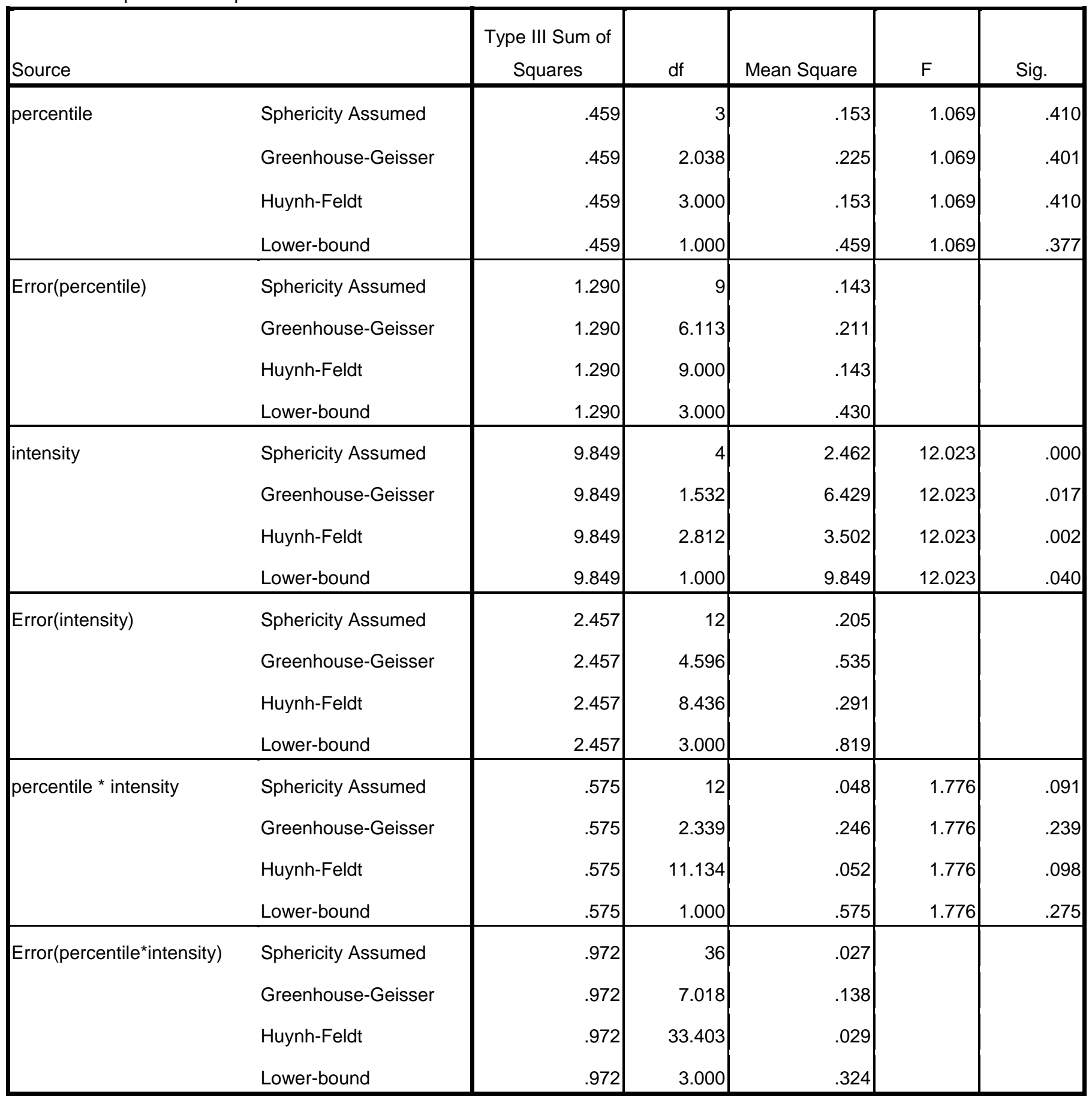


Experiment 2: Pairwise Comparisons for Intensity

Measure: Proportional Response Rates

\begin{tabular}{|c|c|c|c|c|c|c|}
\hline \multirow{2}{*}{\multicolumn{2}{|c|}{$\begin{array}{l}\text { (I) }(\mathrm{J}) \\
\text { intensity intensity }\end{array}$}} & \multirow{2}{*}{$\begin{array}{c}\text { Mean Difference } \\
\text { (I-J) }\end{array}$} & \multirow[b]{2}{*}{ Std. Error } & \multirow[b]{2}{*}{ Sig. ${ }^{a}$} & \multicolumn{2}{|c|}{$\begin{array}{l}\text { 95\% Confidence Interval for } \\
\text { Difference }^{a}\end{array}$} \\
\hline & & & & & Lower Bound & Upper Bound \\
\hline \multirow[t]{4}{*}{0.05} & 0.1 & -.032 & .024 & .275 & -.108 & .044 \\
\hline & 0.2 & -.041 & .053 & .495 & -.208 & .127 \\
\hline & 0.4 & .078 & .120 & .562 & -.304 & .461 \\
\hline & 0.8 & $.872^{\star}$ & .217 & .028 & .182 & 1.562 \\
\hline \multirow[t]{4}{*}{0.1} & 0.05 & .032 & .024 & .275 & -.044 & .108 \\
\hline & 0.2 & -.009 & .053 & .878 & -.179 & .161 \\
\hline & 0.4 & .110 & .133 & .470 & -.314 & .534 \\
\hline & 0.8 & $.904^{\star}$ & .220 & .026 & .204 & 1.604 \\
\hline \multirow[t]{4}{*}{0.2} & 0.05 & .041 & .053 & .495 & -.127 & .208 \\
\hline & 0.1 & .009 & .053 & .878 & -.161 & .179 \\
\hline & 0.4 & .119 & .091 & .281 & -.170 & .407 \\
\hline & 0.8 & $.913^{\star}$ & .239 & .032 & .153 & 1.673 \\
\hline \multirow[t]{4}{*}{0.4} & 0.05 & -.078 & .120 & .562 & -.461 & .304 \\
\hline & 0.1 & -.110 & .133 & .470 & -.534 & .314 \\
\hline & 0.2 & -.119 & .091 & .281 & -.407 & .170 \\
\hline & 0.8 & $.794^{\star}$ & .239 & .045 & .035 & 1.554 \\
\hline \multirow[t]{4}{*}{0.8} & 0.05 & $-.872^{*}$ & .217 & .028 & -1.562 & -.182 \\
\hline & 0.1 & $-.904^{*}$ & .220 & .026 & -1.604 & -.204 \\
\hline & 0.2 & $-.913^{*}$ & .239 & .032 & -1.673 & -.153 \\
\hline & 0.4 & $-.794^{\star}$ & .239 & .045 & -1.554 & -.035 \\
\hline
\end{tabular}

Based on estimated marginal means

a. Adjustment for multiple comparisons: Least Significant Difference (equivalent to no adjustments).

*. The mean difference is significant at the .05 level. 
Appendix C

Additional Analyses for Experiment 3 


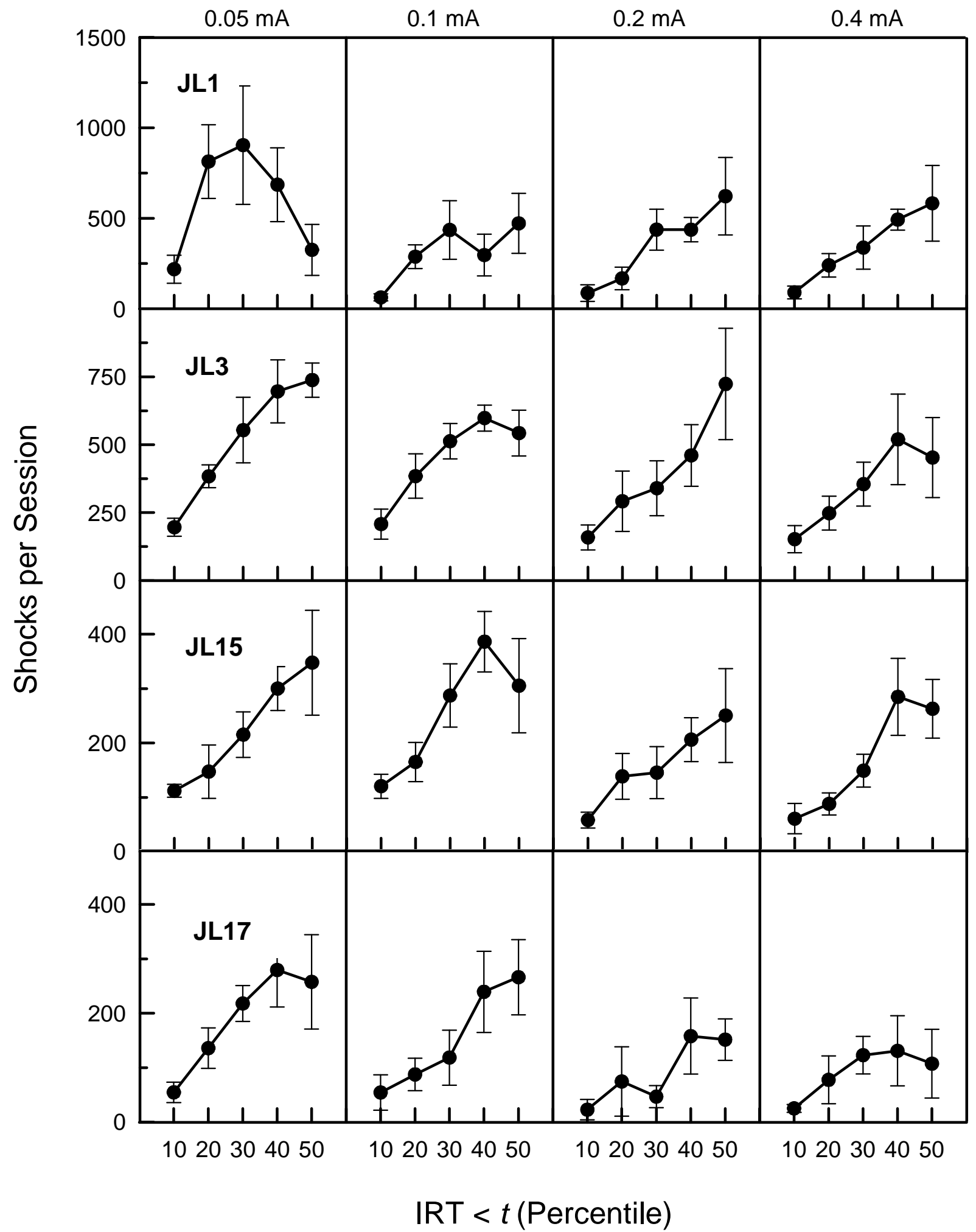

Figure C1. Experiment 3: Mean shocks per session across shock conditions. Error bars extend one standard deviation above and one standard deviation below the mean. Note the scaling of the ordinate varies across rats. 


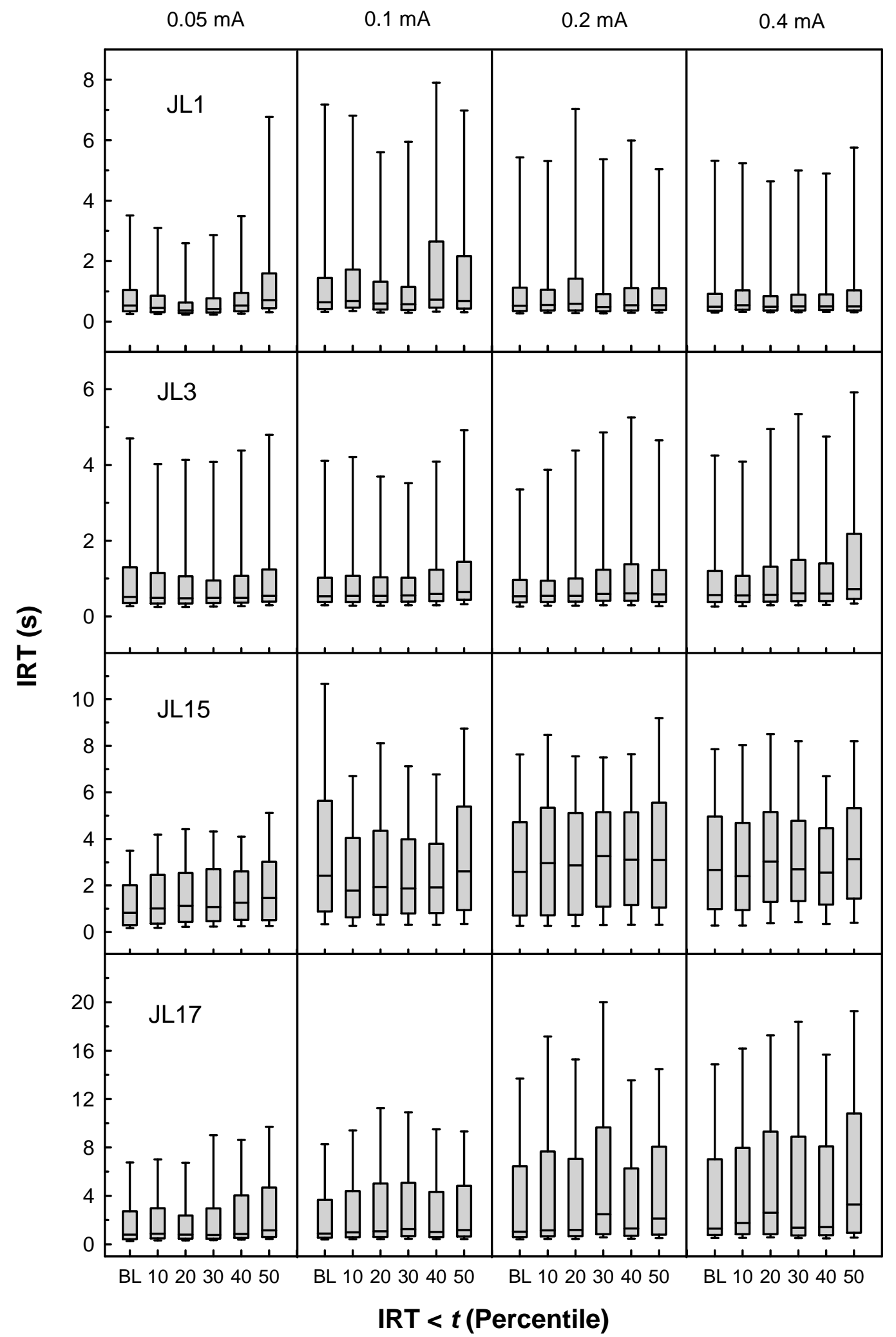

Figure C2. Experiment 3: Summaries of the IRT distributions from the stable baseline sessions and all shock sessions displayed in the form of box and whisker plots. All other details are the same as those in Figure A2. Note that the scale of the ordinate varies across rats. 


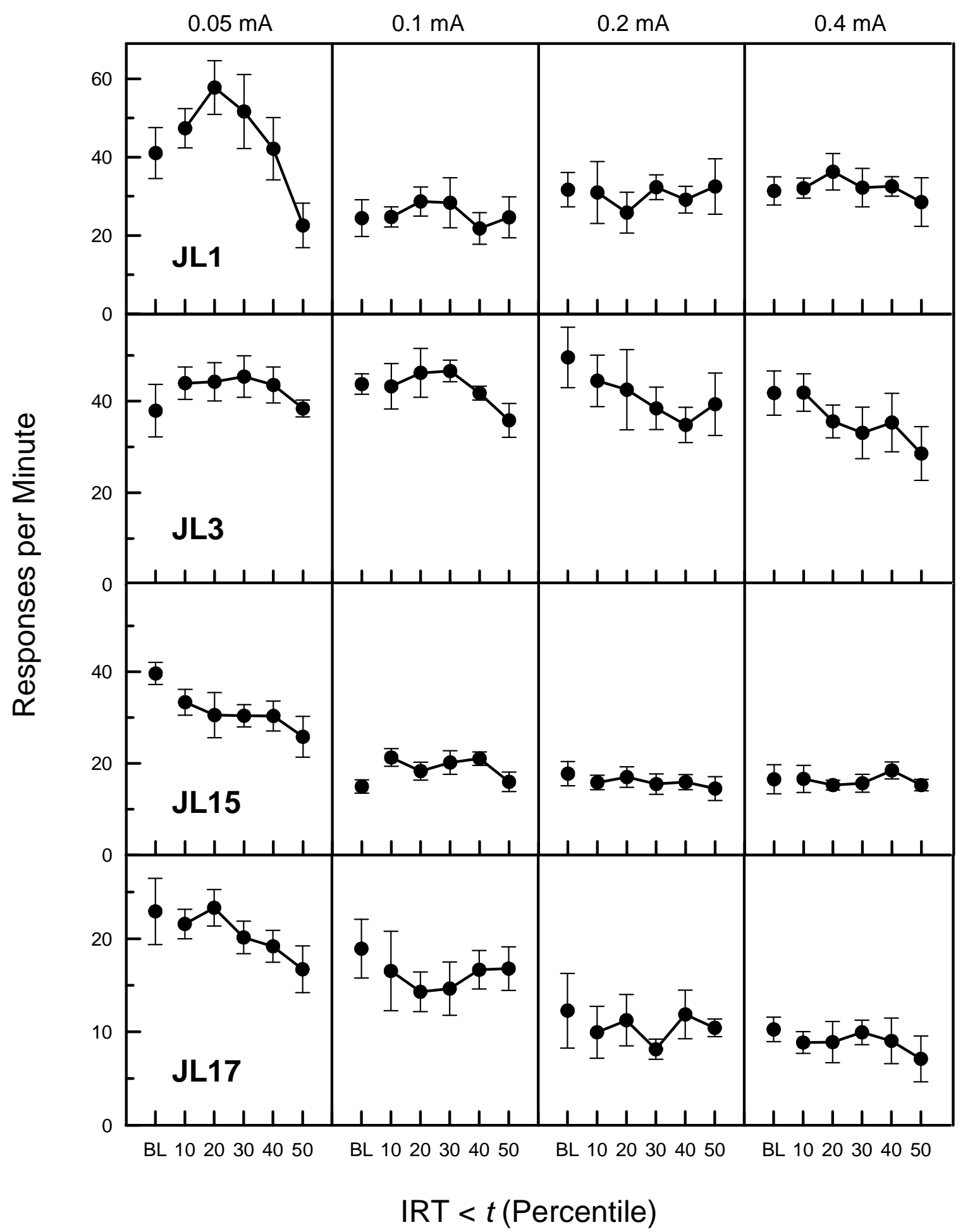

Figure C3. Experiment 3: Mean response rates across the baseline and shock conditions for each phase. Error bars extend one standard deviation above and one standard deviation below the mean. Note the change in the scale of the ordinate for Rat JL1 and Rat JL17. 
Experiment 3: Tests of Within-Subjects Effects

Measure: Differences Between Percent of Responses Followed by Shock and Those Indicated by Reference Line

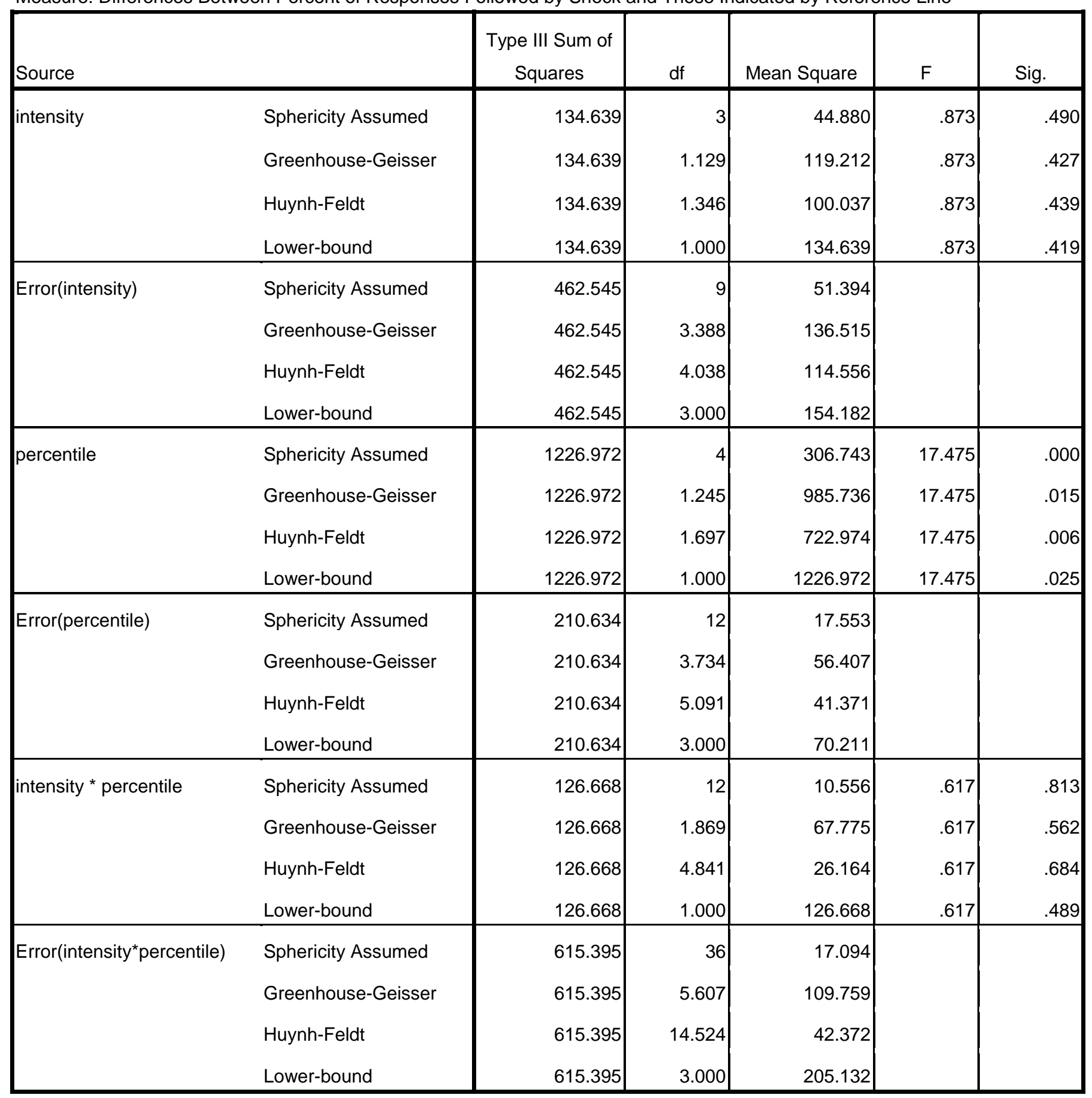




\section{Experiment 3: Pairwise Comparisons for Percentile}

Measure: Differences Between Percent Responses Followed by Shock and Reference Line

\begin{tabular}{|c|c|c|c|c|c|c|}
\hline \multirow{2}{*}{ (I) percentile } & \multirow{2}{*}{$\begin{array}{l}(\mathrm{J}) \\
\text { percentile }\end{array}$} & \multirow{2}{*}{$\begin{array}{c}\text { Mean } \\
\text { Difference } \\
(\mathrm{I}-\mathrm{J})\end{array}$} & \multirow[b]{2}{*}{ Std. Error } & \multirow[b]{2}{*}{ Sig. ${ }^{a}$} & \multicolumn{2}{|c|}{$\begin{array}{c}\text { 95\% Confidence Interval for } \\
\text { Difference }^{a}\end{array}$} \\
\hline & & & & & Lower Bound & Upper Bound \\
\hline \multirow[t]{4}{*}{10} & 20 & -.824 & 1.670 & .656 & -6.137 & 4.490 \\
\hline & 30 & -3.221 & 2.649 & .311 & -11.650 & 5.208 \\
\hline & 40 & $-5.501^{*}$ & .795 & .006 & -8.032 & -2.970 \\
\hline & 50 & $-10.912^{*}$ & 1.470 & .005 & -15.591 & -6.234 \\
\hline \multirow[t]{4}{*}{20} & 10 & .824 & 1.670 & .656 & -4.490 & 6.137 \\
\hline & 30 & -2.398 & 1.062 & .109 & -5.778 & .983 \\
\hline & 40 & $-4.677^{\star}$ & .881 & .013 & -7.482 & -1.873 \\
\hline & 50 & $-10.089^{*}$ & .908 & .002 & -12.977 & -7.200 \\
\hline \multirow[t]{4}{*}{30} & 10 & 3.221 & 2.649 & .311 & -5.208 & 11.650 \\
\hline & 20 & 2.398 & 1.062 & .109 & -.983 & 5.778 \\
\hline & 40 & -2.280 & 1.898 & .316 & -8.320 & 3.761 \\
\hline & 50 & $-7.691^{*}$ & 1.462 & .013 & -12.343 & -3.039 \\
\hline \multirow[t]{4}{*}{40} & 10 & $5.501^{*}$ & .795 & .006 & 2.970 & 8.032 \\
\hline & 20 & $4.677^{\star}$ & .881 & .013 & 1.873 & 7.482 \\
\hline & 30 & 2.280 & 1.898 & .316 & -3.761 & 8.320 \\
\hline & 50 & $-5.411^{*}$ & .936 & .010 & -8.391 & -2.431 \\
\hline \multirow[t]{4}{*}{50} & 10 & $10.912^{*}$ & 1.470 & .005 & 6.234 & 15.591 \\
\hline & 20 & $10.089^{\star}$ & .908 & .002 & 7.200 & 12.977 \\
\hline & 30 & $7.691^{*}$ & 1.462 & .013 & 3.039 & 12.343 \\
\hline & 40 & $5.411^{*}$ & .936 & .010 & 2.431 & 8.391 \\
\hline
\end{tabular}

Based on estimated marginal means

a. Adjustment for multiple comparisons: Least Significant Difference (equivalent to no adjustments).

*. The mean difference is significant at the .05 level. 
Experiment 3: Tests of Within-Subjects Effects

Measure: Proportional Response Rates

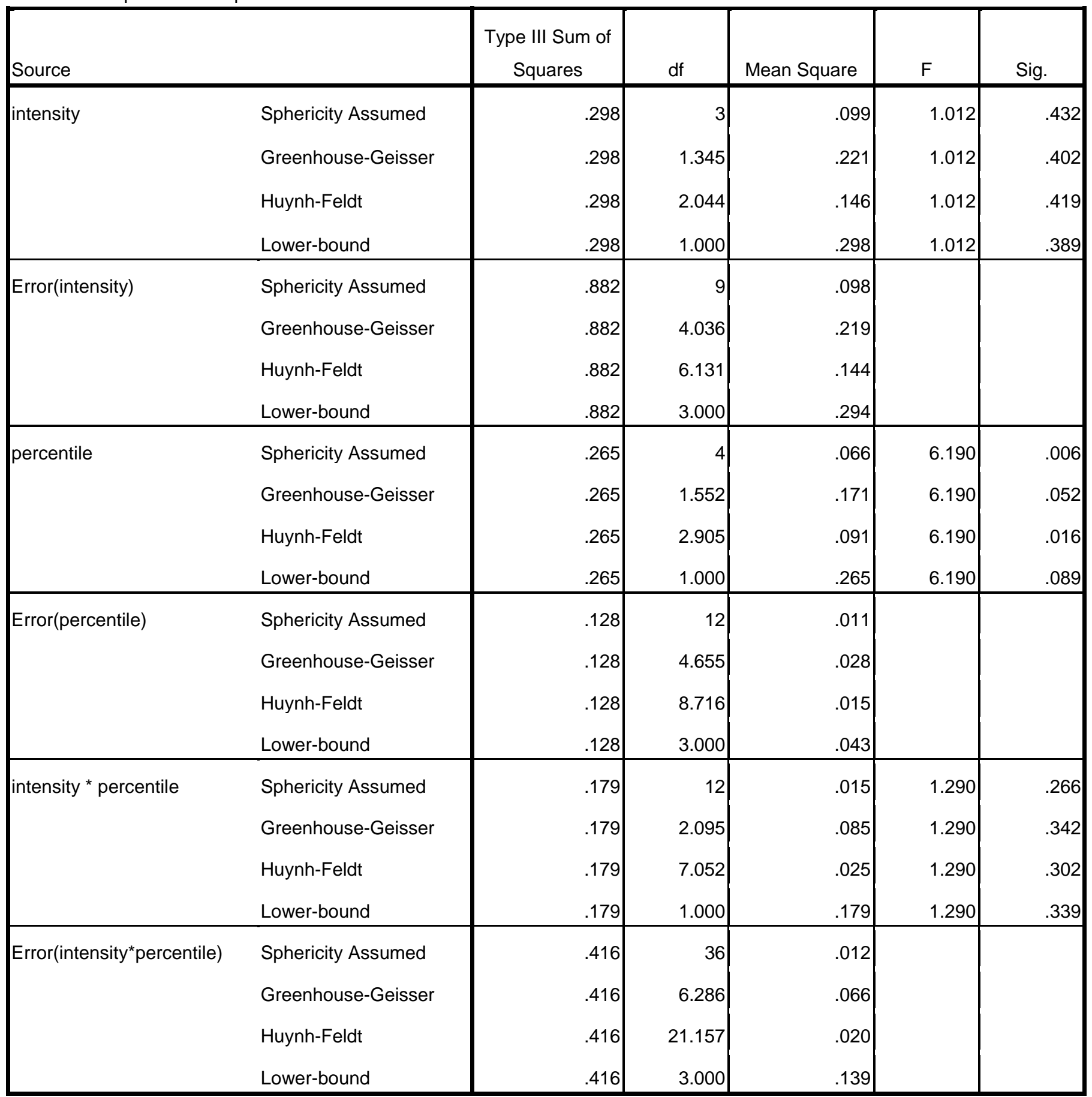


Experiment 3: Pairwise Comparisons for Percentile

Measure: Proportional Response Rate

\begin{tabular}{|c|c|c|c|c|c|c|}
\hline \multirow{2}{*}{$\begin{array}{l}\text { (I) } \\
\text { percentile }\end{array}$} & \multirow{2}{*}{$\begin{array}{l}(\mathrm{J}) \\
\text { percentile }\end{array}$} & \multirow{2}{*}{$\begin{array}{c}\text { Mean } \\
\text { Difference } \\
(\mathrm{I}-\mathrm{J})\end{array}$} & \multirow[b]{2}{*}{ Std. Error } & \multirow[b]{2}{*}{ Sig. ${ }^{a}$} & \multicolumn{2}{|c|}{$\begin{array}{l}\text { 95\% Confidence Interval for } \\
\text { Difference }^{a}\end{array}$} \\
\hline & & & & & Lower Bound & Upper Bound \\
\hline \multirow[t]{4}{*}{10} & 20 & -.003 & .036 & .941 & -.118 & .112 \\
\hline & 30 & .022 & .032 & .543 & -.081 & .125 \\
\hline & 40 & .037 & .029 & .296 & -.056 & .131 \\
\hline & 50 & $.153^{*}$ & .024 & .008 & .077 & .229 \\
\hline \multirow[t]{4}{*}{20} & 10 & .003 & .036 & .941 & -.112 & .118 \\
\hline & 30 & .025 & .017 & .236 & -.029 & .079 \\
\hline & 40 & .040 & .053 & .502 & -.128 & .208 \\
\hline & 50 & $.156^{\star}$ & .039 & .027 & .033 & .279 \\
\hline \multirow[t]{4}{*}{30} & 10 & -.022 & .032 & .543 & -.125 & .081 \\
\hline & 20 & -.025 & .017 & .236 & -.079 & .029 \\
\hline & 40 & .015 & .051 & .790 & -.149 & .178 \\
\hline & 50 & .131 & .043 & .057 & -.007 & .269 \\
\hline \multirow[t]{4}{*}{40} & 10 & -.037 & .029 & .296 & -.131 & .056 \\
\hline & 20 & -.040 & .053 & .502 & -.208 & .128 \\
\hline & 30 & -.015 & .051 & .790 & -.178 & .149 \\
\hline & 50 & $.116^{*}$ & .022 & .014 & .045 & .187 \\
\hline \multirow[t]{4}{*}{50} & 10 & $-.153^{*}$ & .024 & .008 & -.229 & -.077 \\
\hline & 20 & $-.156^{\star}$ & .039 & .027 & -.279 & -.033 \\
\hline & 30 & -.131 & .043 & .057 & -.269 & .007 \\
\hline & 40 & $-.116^{\star}$ & .022 & .014 & -.187 & -.045 \\
\hline
\end{tabular}

Based on estimated marginal means

a. Adjustment for multiple comparisons: Least Significant Difference (equivalent to no adjustments).

*. The mean difference is significant at the .05 level. 
Appendix D

Additional Analyses for Experiment 4 


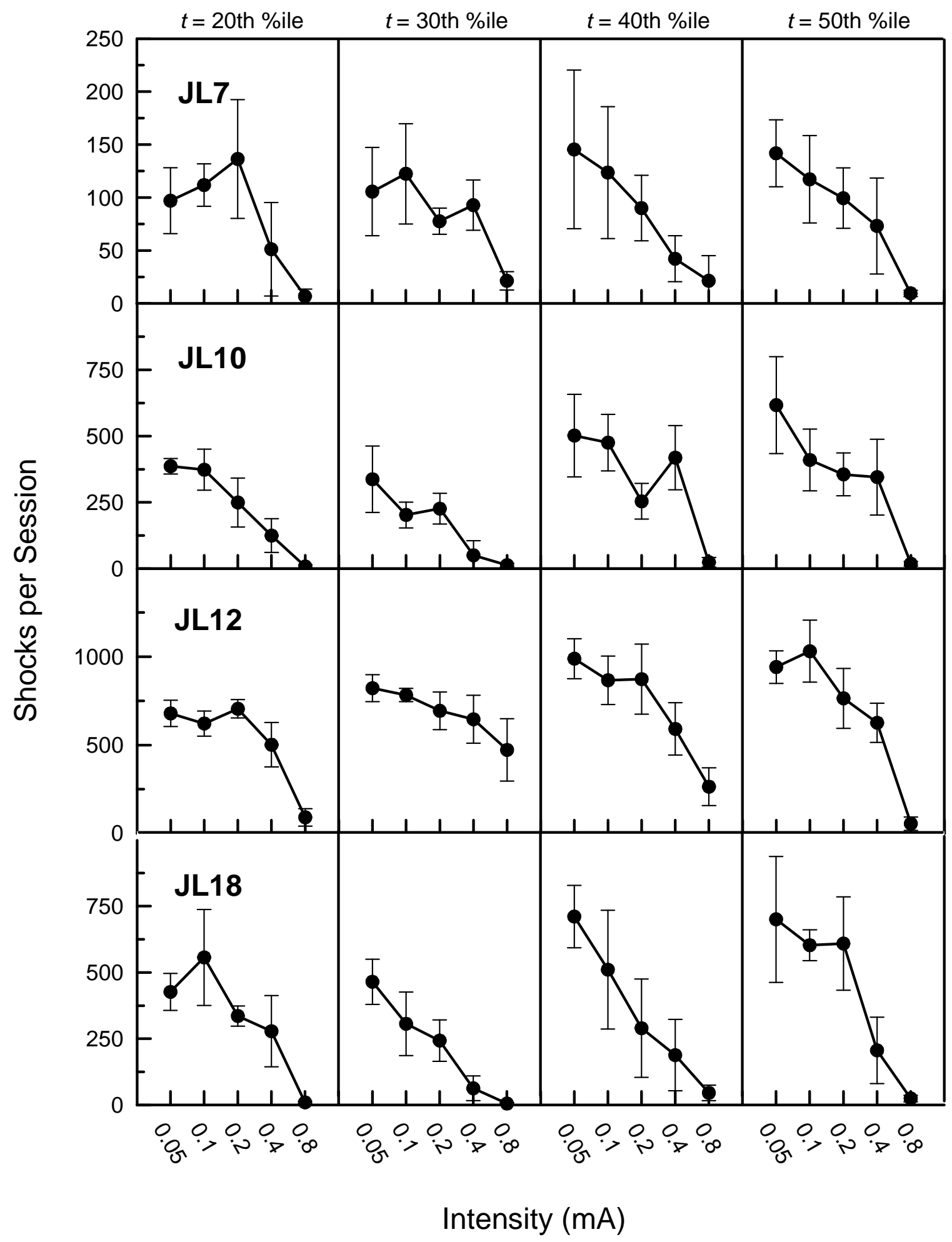

Figure D1. Experiment 4: Mean shocks per session across shock conditions. Error bars extend one standard deviation above and one standard deviation below the mean. Note the scaling of the ordinate varies across rats. 


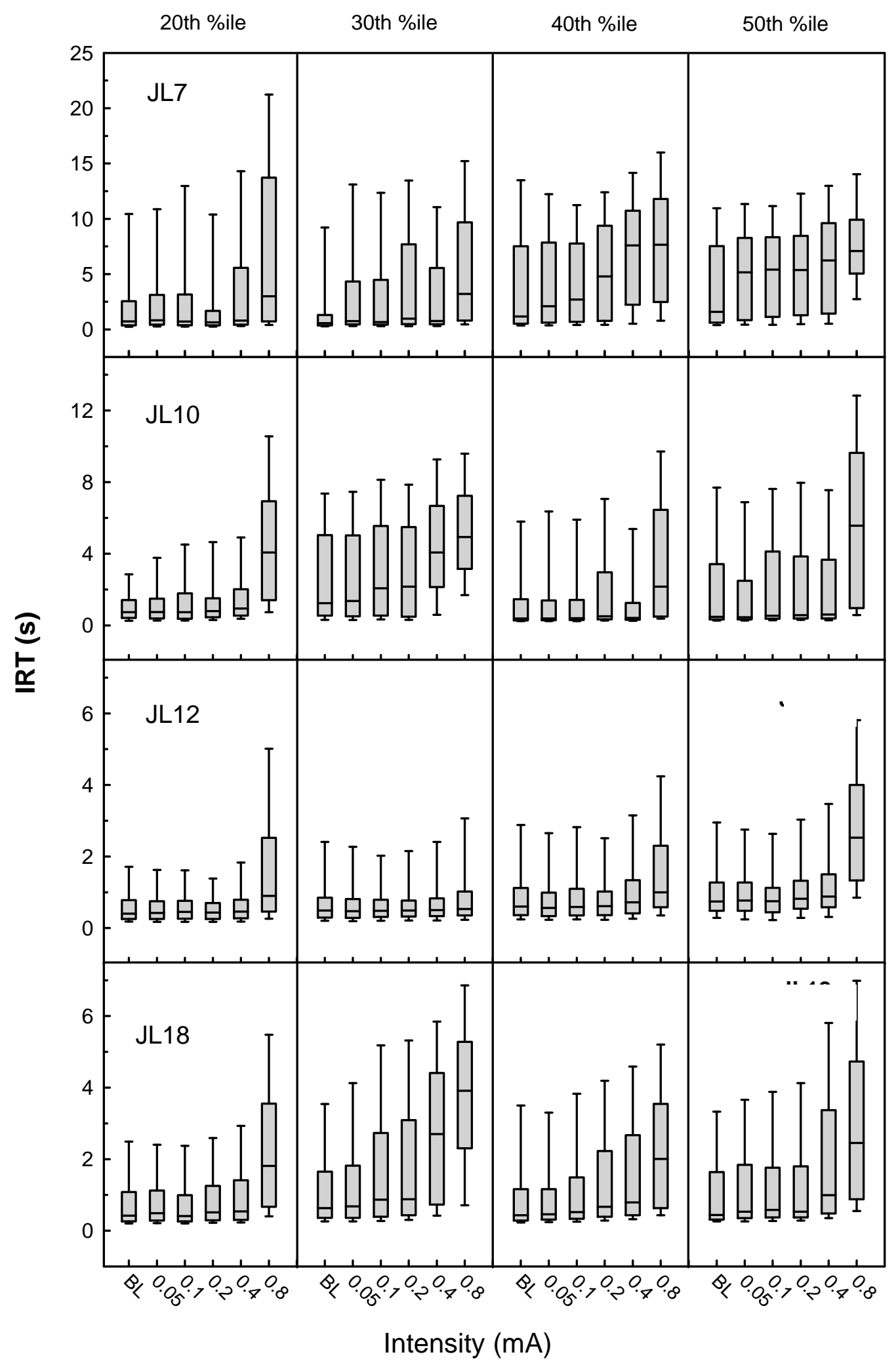

Figure D2. Experiment 4: Summaries of the IRT distributions from the stable baseline sessions and all shock sessions displayed in the form of box and whisker plots. All other details are the same as those in Figure A2. Note that the scale of the ordinate varies across rats. 


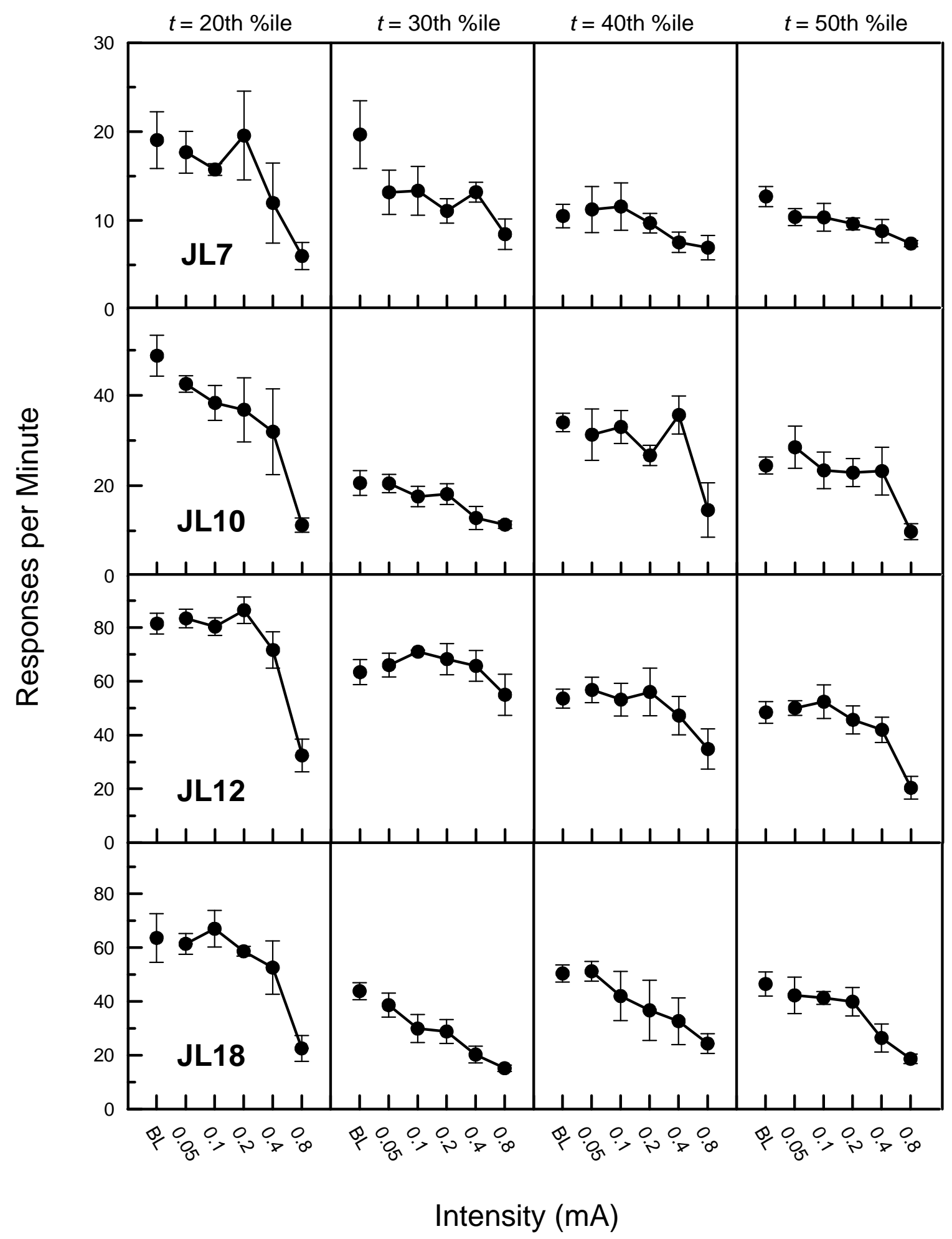

Figure D3. Experiment 4: Mean response rates across the baseline and shock conditions for each phase. Error bars extend one standard deviation above and one standard deviation below the mean. Note the change in the scale of the ordinate for Rat JL7 and Rat JL10. 


\section{Experiment 4: Tests of Within-Subjects Effects}

Measure: Differences Between Percent Responses Followed by Shock and Those Followed by Reference Line

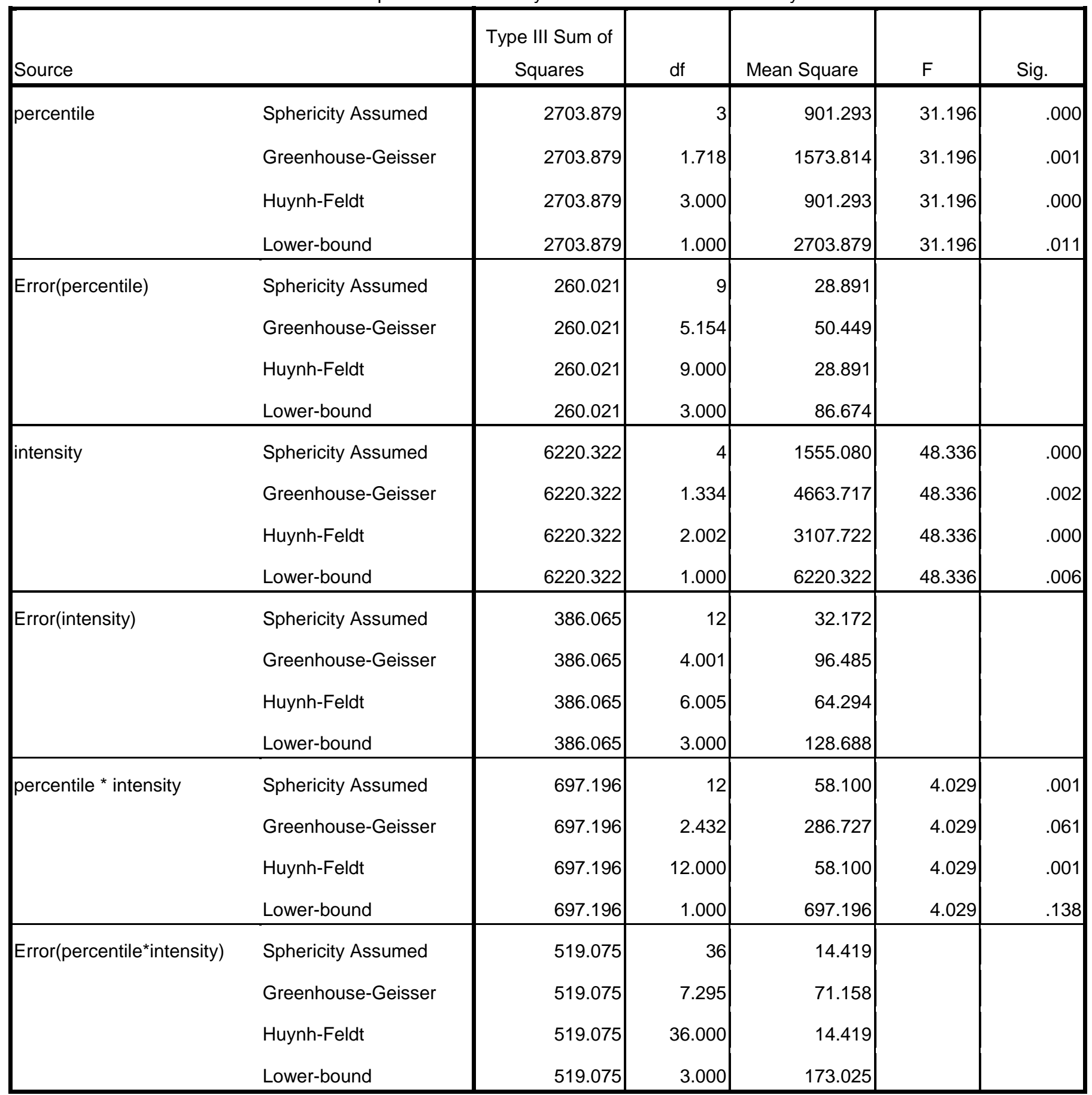




\section{Experiment 4: Pairwise Comparisons for Percentile}

Measure: Differences Between Percent Responses Followed by Shock and Reference Line

\begin{tabular}{|c|c|c|c|c|c|c|}
\hline \multirow{2}{*}{$\begin{array}{l}\text { (I) } \\
\text { percentile }\end{array}$} & \multirow{2}{*}{$\begin{array}{l}(\mathrm{J}) \\
\text { percentile }\end{array}$} & \multirow{2}{*}{$\begin{array}{c}\text { Mean } \\
\text { Difference } \\
(\mathrm{I}-\mathrm{J})\end{array}$} & \multirow[b]{2}{*}{ Std. Error } & \multirow[b]{2}{*}{ Sig. ${ }^{a}$} & \multicolumn{2}{|c|}{$\begin{array}{l}\text { 95\% Confidence Interval for } \\
\text { Difference }^{a} \\
\end{array}$} \\
\hline & & & & & Lower Bound & Upper Bound \\
\hline \multirow[t]{3}{*}{20} & 30 & $-4.426^{*}$ & 1.277 & .040 & -8.492 & -.361 \\
\hline & 40 & $-10.085^{\star}$ & 2.366 & .024 & -17.614 & -2.555 \\
\hline & 50 & $-15.426^{\star}$ & 2.147 & .006 & -22.258 & -8.594 \\
\hline \multirow[t]{3}{*}{30} & 20 & $4.426^{*}$ & 1.277 & .040 & .361 & 8.492 \\
\hline & 40 & $-5.658^{*}$ & 1.164 & .017 & -9.362 & -1.955 \\
\hline & 50 & $-10.999^{*}$ & 1.345 & .004 & -15.279 & -6.720 \\
\hline \multirow[t]{3}{*}{40} & 20 & $10.085^{*}$ & 2.366 & .024 & 2.555 & 17.614 \\
\hline & 30 & $5.658^{*}$ & 1.164 & .017 & 1.955 & 9.362 \\
\hline & 50 & $-5.341^{*}$ & 1.528 & .040 & -10.204 & -.479 \\
\hline \multirow[t]{3}{*}{50} & 20 & $15.426^{\star}$ & 2.147 & .006 & 8.594 & 22.258 \\
\hline & 30 & $10.999^{*}$ & 1.345 & .004 & 6.720 & 15.279 \\
\hline & 40 & $5.341^{*}$ & 1.528 & .040 & .479 & 10.204 \\
\hline
\end{tabular}

Based on estimated marginal means

*. The mean difference is significant at the .05 level.

a. Adjustment for multiple comparisons: Least Significant Difference (equivalent to no adjustments). 


\section{Experiment 4: Pairwise Comparisons of Intensity}

Measure: Differences Between Percent Responses Followed by Shock and Reference Line

\begin{tabular}{|c|c|c|c|c|c|c|}
\hline \multirow{2}{*}{$\begin{array}{l}\text { ( } 1) \\
\text { inten }\end{array}$} & \multirow{2}{*}{$\begin{array}{l}(\mathrm{J}) \\
\text { intensity }\end{array}$} & \multirow{2}{*}{$\begin{array}{c}\text { Mean Difference } \\
(\mathrm{I}-\mathrm{J})\end{array}$} & \multirow[b]{2}{*}{ Std. Error } & \multirow[b]{2}{*}{ Sig. ${ }^{a}$} & \multicolumn{2}{|c|}{$\begin{array}{l}\text { 95\% Confidence Interval for } \\
\text { Difference }^{a}\end{array}$} \\
\hline & & & & & Lower Bound & Upper Bound \\
\hline \multirow[t]{4}{*}{0.05} & 0.1 & -2.767 & 1.112 & .089 & -6.306 & .772 \\
\hline & 0.2 & $-6.349^{*}$ & 1.842 & .041 & -12.210 & -.489 \\
\hline & 0.4 & $-12.598^{\star}$ & 2.682 & .018 & -21.134 & -4.063 \\
\hline & 0.8 & $-24.792^{\star}$ & 3.443 & .006 & -35.750 & -13.835 \\
\hline \multirow[t]{4}{*}{0.1} & 0.05 & 2.767 & 1.112 & .089 & -.772 & 6.306 \\
\hline & 0.2 & $-3.582^{*}$ & .772 & .019 & -6.040 & -1.125 \\
\hline & 0.4 & $-9.832^{*}$ & 1.834 & .013 & -15.667 & -3.996 \\
\hline & 0.8 & $-22.025^{\star}$ & 2.371 & .003 & -29.571 & -14.480 \\
\hline \multirow[t]{4}{*}{0.2} & 0.05 & $6.349^{*}$ & 1.842 & .041 & .489 & 12.210 \\
\hline & 0.1 & $3.582^{*}$ & .772 & .019 & 1.125 & 6.040 \\
\hline & 0.4 & $-6.249^{\star}$ & 1.193 & .014 & -10.046 & -2.452 \\
\hline & 0.8 & $-18.443^{*}$ & 1.662 & .002 & -23.733 & -13.153 \\
\hline \multirow[t]{4}{*}{0.4} & 0.05 & $12.598^{*}$ & 2.682 & .018 & 4.063 & 21.134 \\
\hline & 0.1 & $9.832^{*}$ & 1.834 & .013 & 3.996 & 15.667 \\
\hline & 0.2 & $6.249^{*}$ & 1.193 & .014 & 2.452 & 10.046 \\
\hline & 0.8 & $-12.194^{\star}$ & 1.665 & .005 & -17.492 & -6.896 \\
\hline \multirow[t]{4}{*}{0.8} & 0.05 & $24.792^{\star}$ & 3.443 & .006 & 13.835 & 35.750 \\
\hline & 0.1 & $22.025^{\star}$ & 2.371 & .003 & 14.480 & 29.571 \\
\hline & 0.2 & $18.443^{*}$ & 1.662 & .002 & 13.153 & 23.733 \\
\hline & 0.4 & $12.194^{\star}$ & 1.665 & .005 & 6.896 & 17.492 \\
\hline
\end{tabular}

Based on estimated marginal means

a. Adjustment for multiple comparisons: Least Significant Difference (equivalent to no adjustments).

*. The mean difference is significant at the .05 level. 
Experiment 4: Tests of Within-Subjects Effects

Measure: Proportional Response Rate

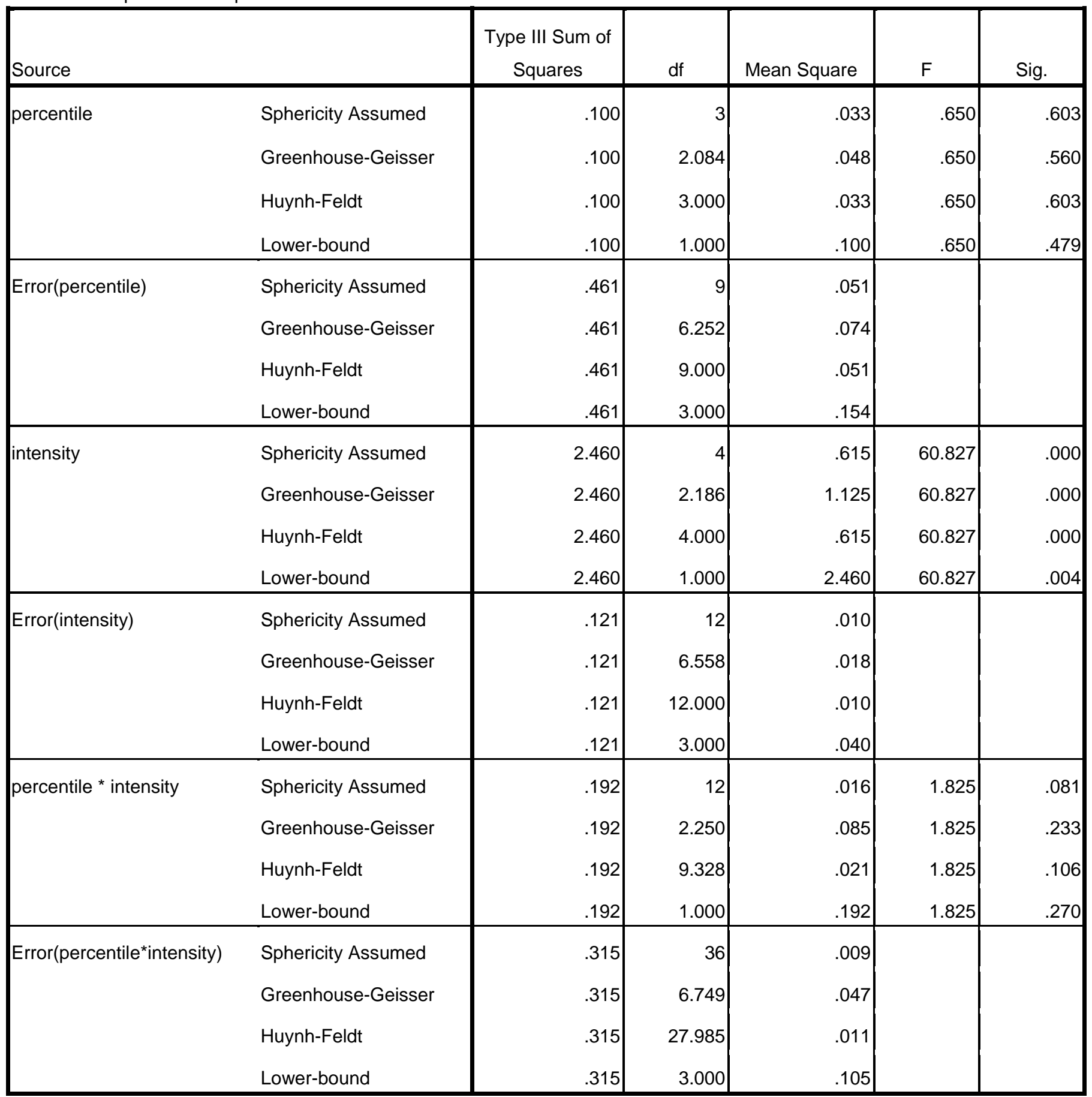


Experiment 4: Pairwise Comparisons for Intensity

Measure: Proportional Response Rates

\begin{tabular}{|c|c|c|c|c|c|c|}
\hline \multirow{2}{*}{$\begin{array}{l}\text { ( } 1) \\
\text { inten }\end{array}$} & \multirow{2}{*}{$\begin{array}{l}(\mathrm{J}) \\
\text { intensity }\end{array}$} & \multirow{2}{*}{$\begin{array}{c}\text { Mean Difference } \\
(\mathrm{I}-\mathrm{J})\end{array}$} & \multirow[b]{2}{*}{ Std. Error } & \multirow[b]{2}{*}{ Sig. ${ }^{a}$} & \multicolumn{2}{|c|}{$\begin{array}{l}\text { 95\% Confidence Interval for } \\
\text { Difference }^{a}\end{array}$} \\
\hline & & & & & Lower Bound & Upper Bound \\
\hline \multirow[t]{4}{*}{0.05} & 0.1 & .046 & .024 & .154 & -.031 & .124 \\
\hline & 0.2 & .091 & .035 & .081 & -.021 & .204 \\
\hline & 0.4 & $.201^{*}$ & .041 & .017 & .070 & .332 \\
\hline & 0.8 & $.490^{\star}$ & .047 & .002 & .340 & .640 \\
\hline \multirow[t]{4}{*}{0.1} & 0.05 & -.046 & .024 & .154 & -.124 & .031 \\
\hline & 0.2 & $.045^{\star}$ & .012 & .035 & .006 & .085 \\
\hline & 0.4 & $.154^{*}$ & .035 & .022 & .042 & .267 \\
\hline & 0.8 & $.444^{*}$ & .029 & .001 & .351 & .537 \\
\hline \multirow[t]{4}{*}{0.2} & 0.05 & -.091 & .035 & .081 & -.204 & .021 \\
\hline & 0.1 & $-.045^{\star}$ & .012 & .035 & -.085 & -.006 \\
\hline & 0.4 & $.109^{\star}$ & .031 & .040 & .009 & .209 \\
\hline & 0.8 & $.399^{*}$ & .029 & .001 & .305 & .493 \\
\hline \multirow[t]{4}{*}{0.4} & 0.05 & $-.201^{*}$ & .041 & .017 & -.332 & -.070 \\
\hline & 0.1 & $-.154^{\star}$ & .035 & .022 & -.267 & -.042 \\
\hline & 0.2 & $-.109^{*}$ & .031 & .040 & -.209 & -.009 \\
\hline & 0.8 & $.289^{*}$ & .053 & .012 & .122 & .457 \\
\hline \multirow[t]{4}{*}{0.8} & 0.05 & $-.490^{*}$ & .047 & .002 & -.640 & -.340 \\
\hline & 0.1 & $-.444^{\star}$ & .029 & .001 & -.537 & -.351 \\
\hline & 0.2 & $-.399^{*}$ & .029 & .001 & -.493 & -.305 \\
\hline & 0.4 & $-.289^{*}$ & .053 & .012 & -.457 & -.122 \\
\hline
\end{tabular}

Based on estimated marginal means

a. Adjustment for multiple comparisons: Least Significant Difference (equivalent to no adjustments).

*. The mean difference is significant at the .05 level. 